Doctorate in Professional Educational, Child and Adolescent Psychology

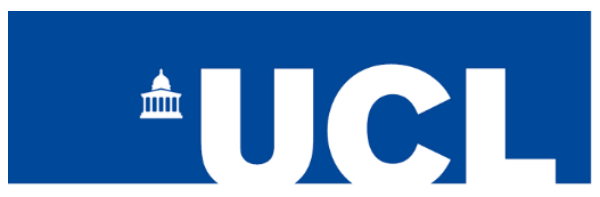

Institute of Education

Programme Director: Vivian Hill

Institute of Education, University of London

Doctorate in Professional Educational Child and Adolescent Psychology

\title{
What Are The Effective Features Of Consultation? A Mixed Methods Analysis
}

Patrick Langford

$28 / 05 / 2021$ 


\section{Thesis declaration}

I, Patrick Langford, confirm that the work presented in this thesis is my own.

Where information has been derived from other sources, I confirm that this has been indicated in the thesis.

Name: Patrick Langford

Date: 28/05/2021

Word count: 34,377 


\section{Acknowledgements}

This was all possible because of the kindness and generosity of a huge number of people. Whilst I cannot name everyone, please know that I am extremely grateful for the help in every form.

I would like to thank my supervisors Andy Tolmie and Tom Connor for helping me create the best piece of work I have ever done.

I would like to thank all the participants who gave so much time and effort.

I would like to thank my mum and dad for their unwavering support and Max for being disgusting.

I would like to thank Jess for being the best.

I would like to thank my friends for keeping me sane.

I would like to thank the $\mathrm{R}$ stats and the Twitter psychology communities, from whom I have learned so much. 


\begin{abstract}
Consultation is an integral part of many Educational Psychologist's (EPs) work. Yet there is a large heterogeneity in understanding and use of this tool. Such diversity makes evaluating its efficacy difficult. This research therefore sought to identify what the effective features of consultation are by linking observed features to changes in agreed outcomes for children and young people (CYP). Mixed methods were employed to explore what EPs believe are the key features of consultation, what the barriers to effective consultation are, what happens in a consultation for a child or young person, and what combination of features can be identified in consultations which lead to positive changes for CYP.
\end{abstract}

To explore EP views towards the effective features of consultation, 30 EPs were interviewed. Observable features of consultation were tallied for six consultations. For those consultations, goals were identified by participants and a baseline rating was given for each goal using Target Monitoring Evaluation (TME) forms. There were 10 goals identified. Change for these goals was recorded through completing the same form 6-8 weeks later, to allow analysis of which combination of features were present for children with differing progress towards outcomes. This was assessed using Qualitative Comparative Analysis (QCA).

The most effective features of consultation, as identified by EPs, included the expert knowledge EPs have, the collaborative nature of consultation, and creating a shared understanding of the CYP and context for all participants. Consultations which were most likely to see positive change for CYP were ones in which the consultation was not dominated by gaining an understanding of the presenting problem. These results give clarity as to what the features of an effective 
consultation are through a mixed methods analysis. The findings have implications for EPs who use consultation, as well as consultees and those whom consultations are for. 


\section{Impact statement}

Consultation is a fundamental but understudied pillar of educational psychologists (EPs) practice in the UK This research sought to qualitatively and quantitatively identify the core features of a consultation which helps produce change for the CYP with whom we work. By taking a mixed methods approach, this complex question could be analysed in a multitude of ways and through a range of methodologies. By doing so, the scope and depth of the issue is more likely to be understood. This can have a positive impact on both future research and practicing EPs across the country by helping them identify what they need to include in a consultation for it to be effective.

The data from this piece of research will be made publicly available, so that other researchers can download and analyse the results. Whilst thematic analysis (TA) was used, there are a wealth of methodologies which could be used to analyse the interview transcripts. There is also a range of research questions which can be explored using this data, thus allowing the research to have greater academic impact beyond this thesis.

As this is the first example of QCA within educational psychology research, this thesis serves as an introduction to this methodology. It will hopefully encourage other researchers to use this tool in the exploration of the causal relationship between combinations of causes and outcomes. QCA is a valuable tool to not only explore the relationship between features of consultation and change for CYP, but also for any desire to identify causal patterns for complex phenomena. 
This research will form part of the picture guiding EPs use of consultation in the future, such that better outcomes for CYP can be achieved through engaging in evidence-based practice. The findings of this thesis will be shared via open access platforms, allowing the widest readership and thus the greatest impact. By providing EPs with evidence-based recommendations, their practice will improve and the positive impact they will have in the communities they work will be increased.

This work can also be used to help Trainee Educational Psychologists (TEPs) gain an understanding of what consultation is and how they can be effective practitioners. Learning how to use consultation effectively is a foundational aspect of being an EP (Hatzichristou et al., 2017). This research can help elucidate the core features of consultation and what leads to change for CYP. It can therefore help ensure TEPs employ evidence-based practices in their work and support their development of proficiency in effective consultation, which is essential for all training (Newell \& Newman, 2014). 
Thesis declaration

Table of content

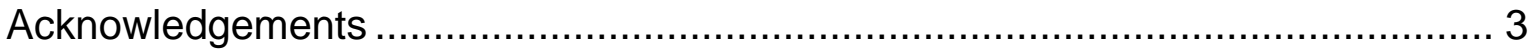

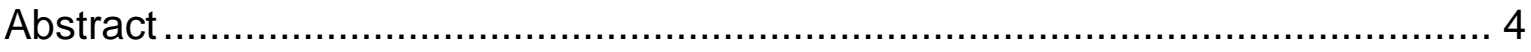

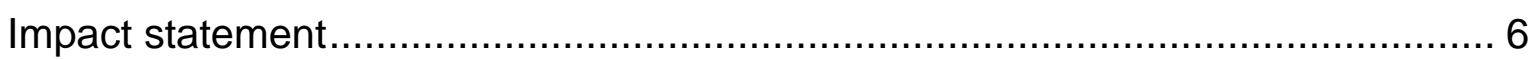

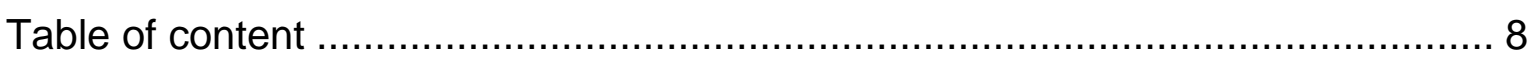

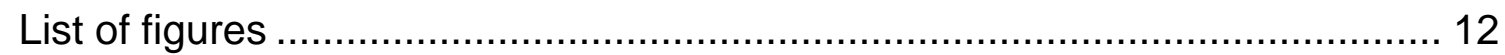

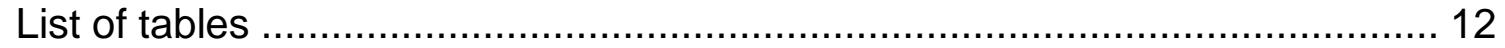

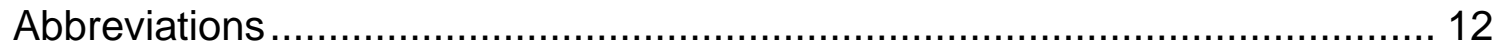

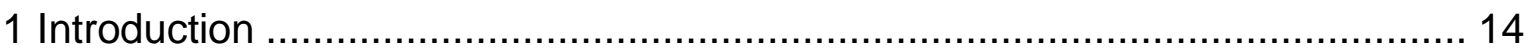

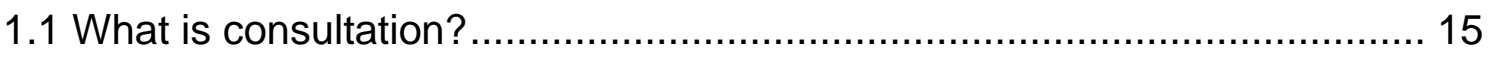

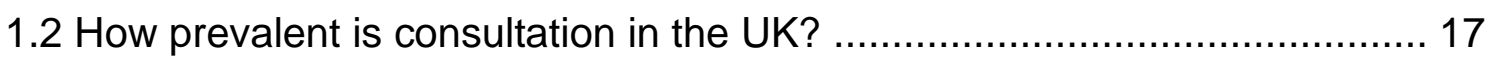

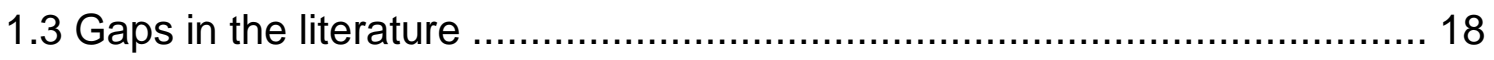

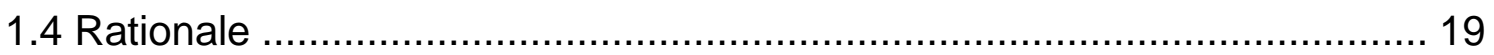

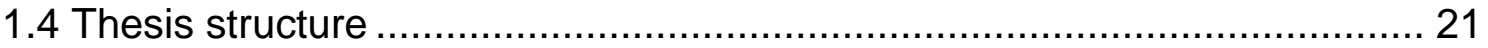

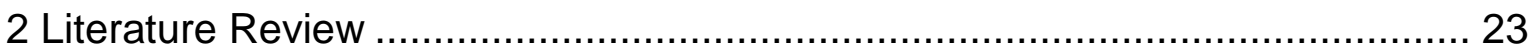

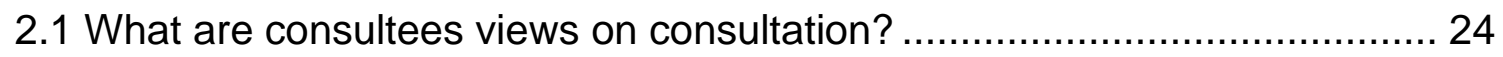

2.2 What are consultants' views on consultation? ....................................... 26

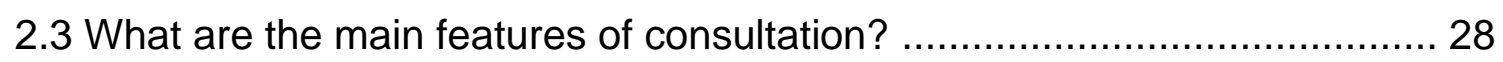

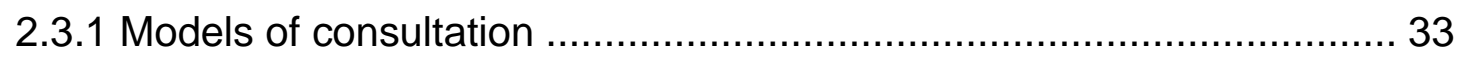

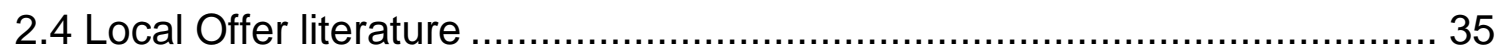

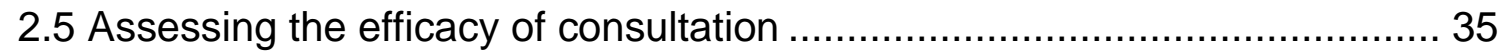

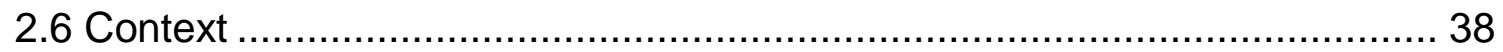

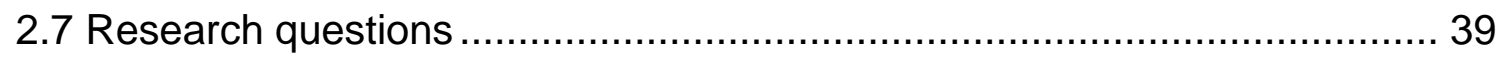

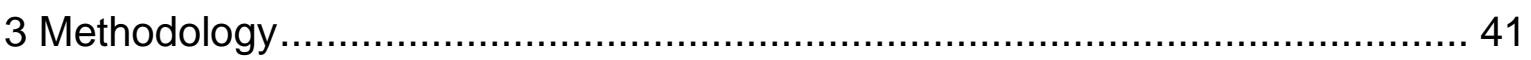

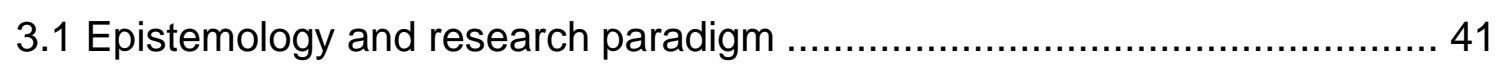

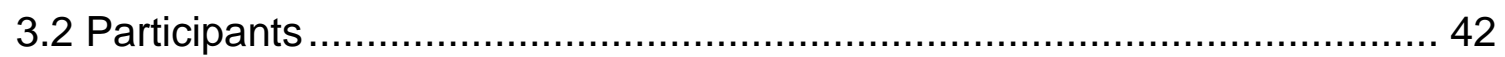

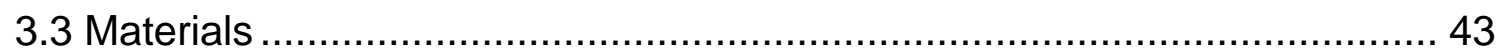

3.3.1 Interviews

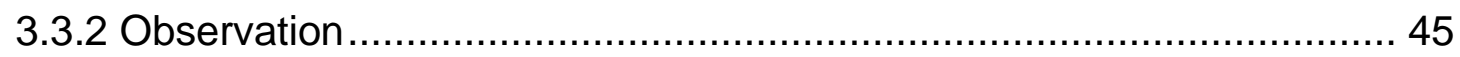

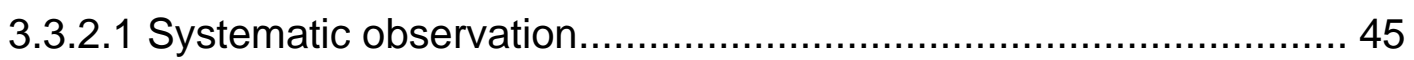

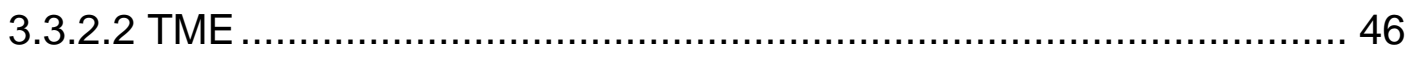

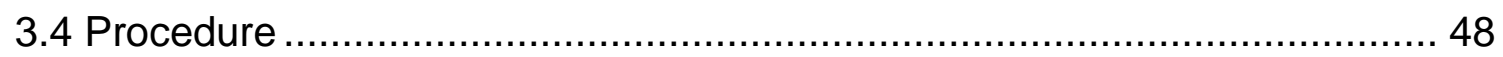

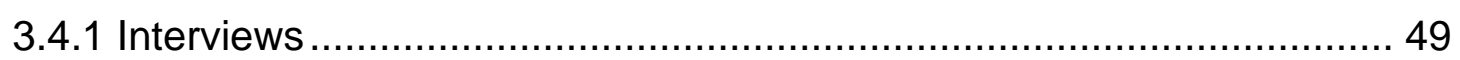

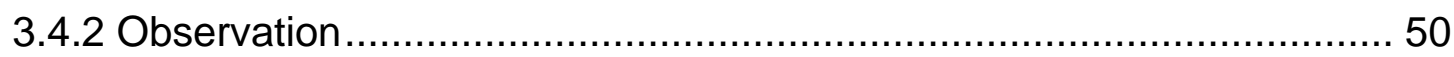




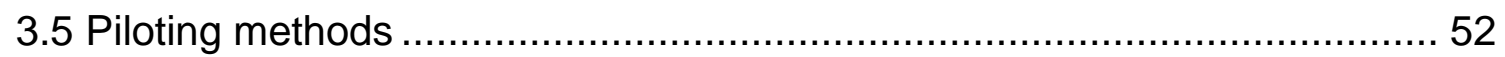

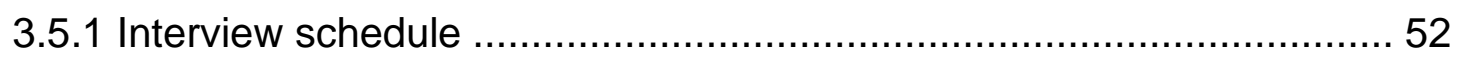

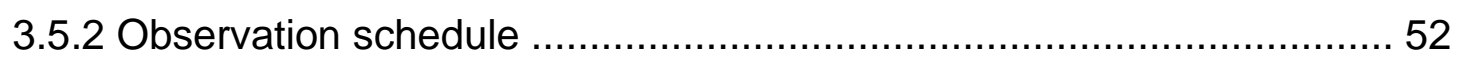

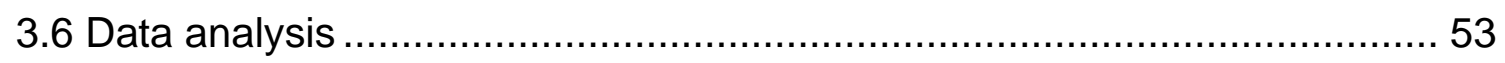

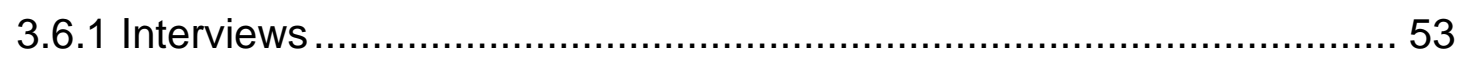

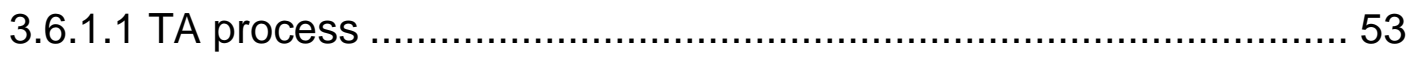

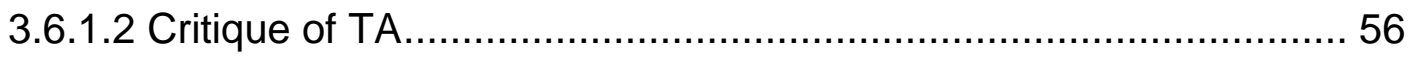

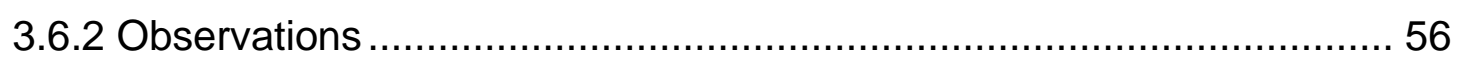

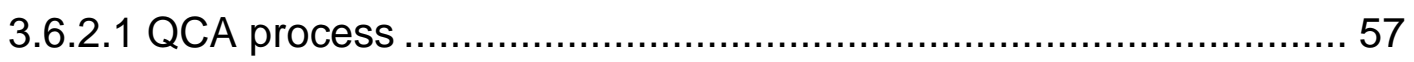

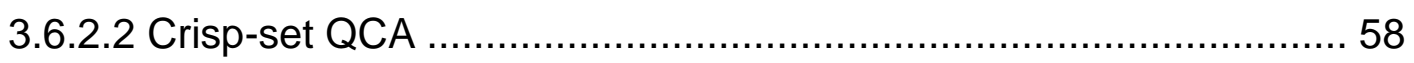

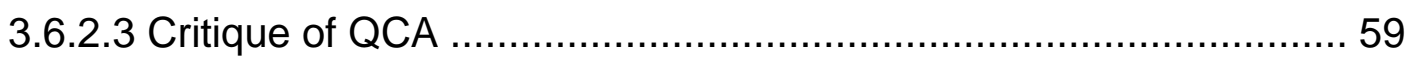

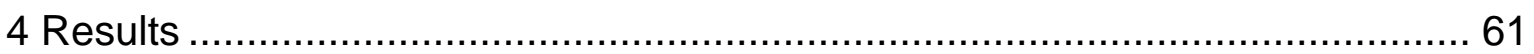

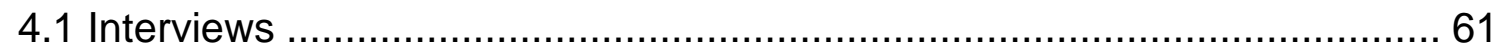

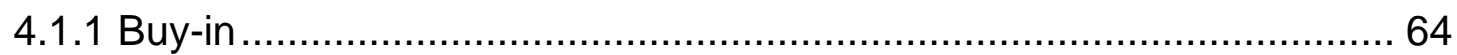

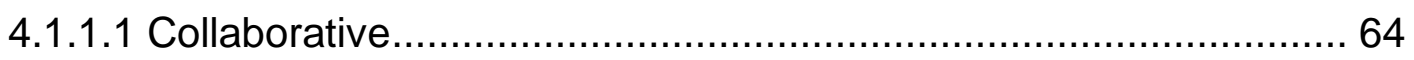

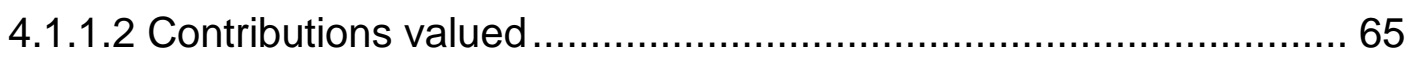

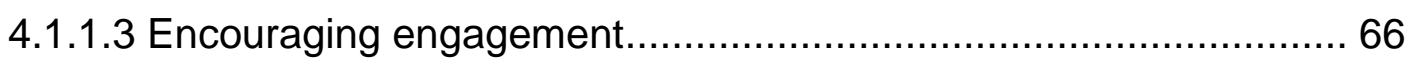

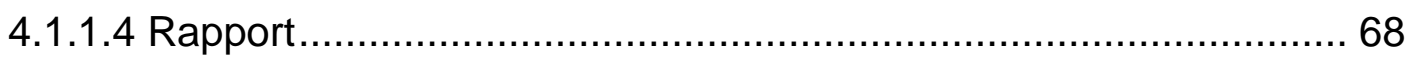

4.1.1.5 EP view of consultation and Consultee view of consultation ......... 70

4.1.1.6 EP view of EPs and Consultee view of EPs .............................. 73

4.1.1.7 Willing to engage ....................................................................... 75

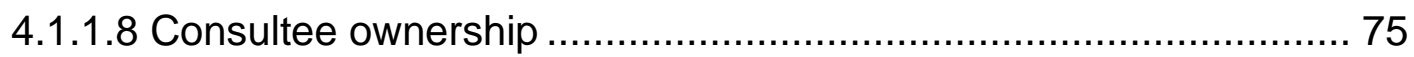

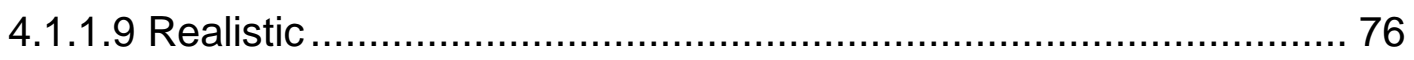

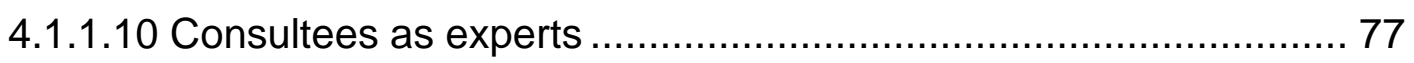

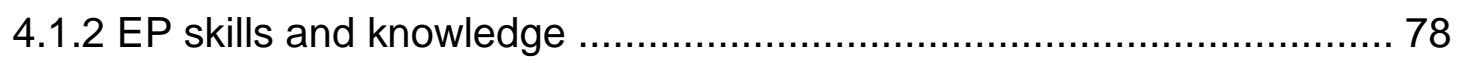

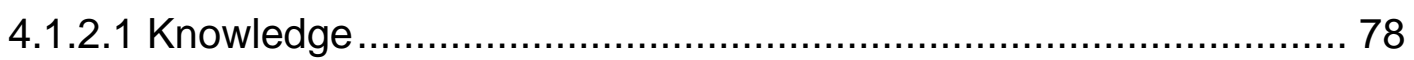

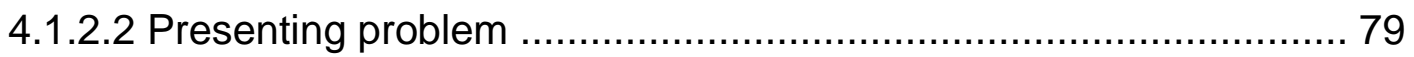

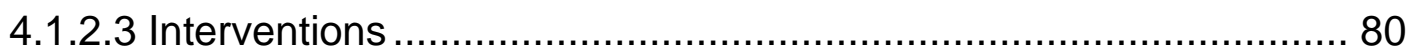

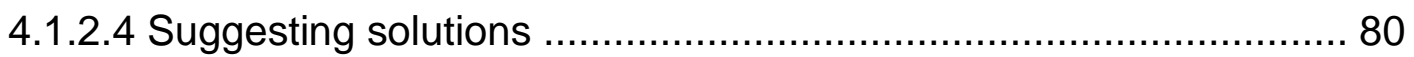

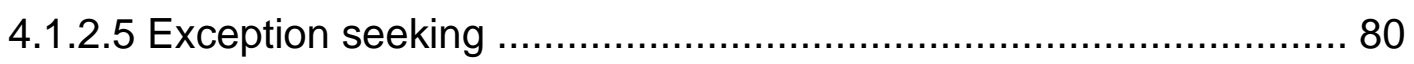

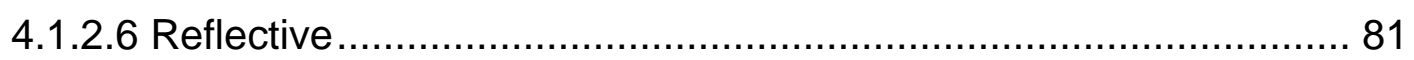

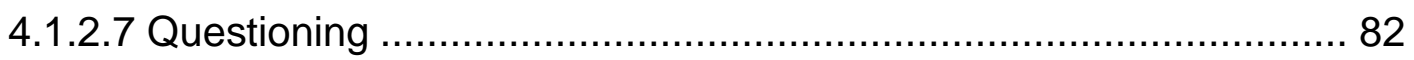

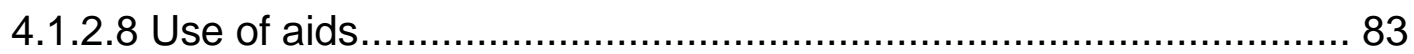

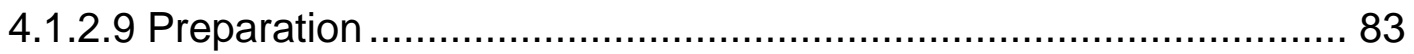

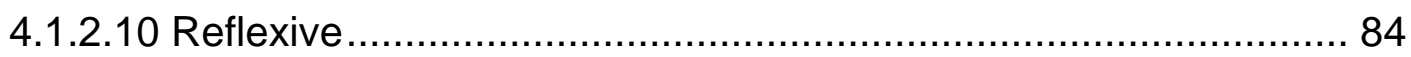




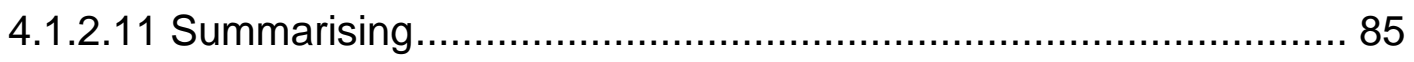

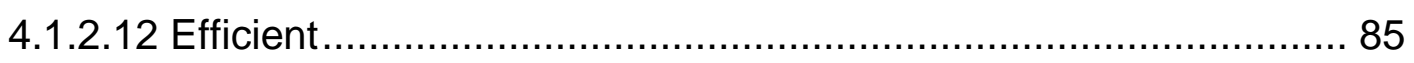

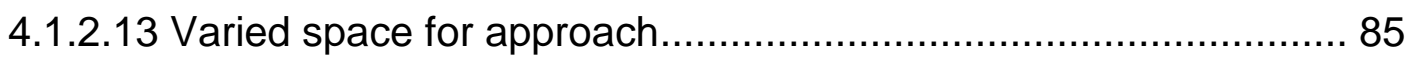

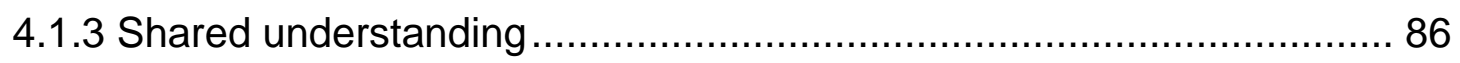

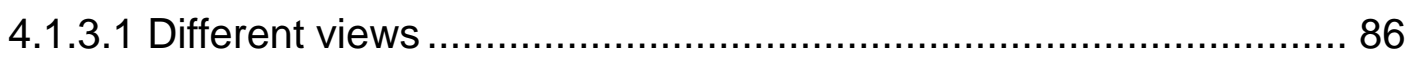

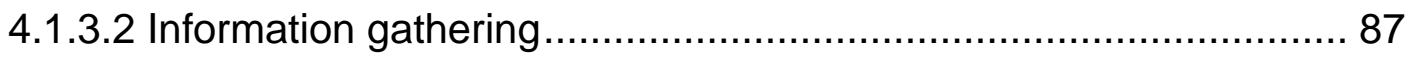

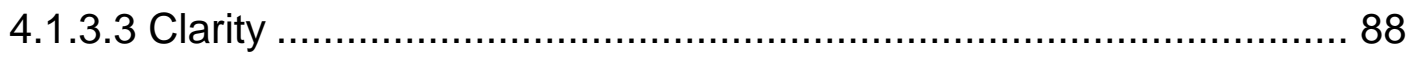

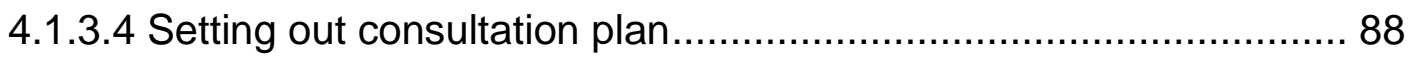

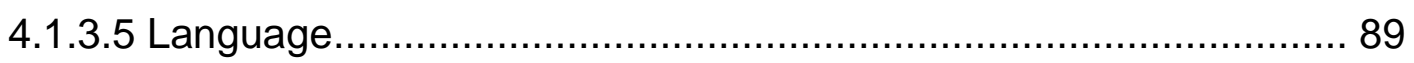

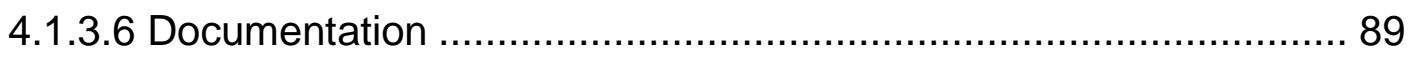

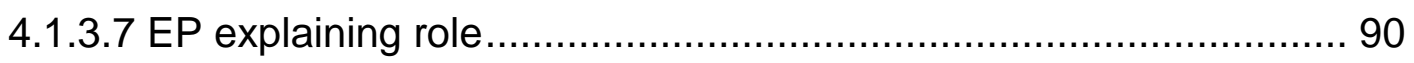

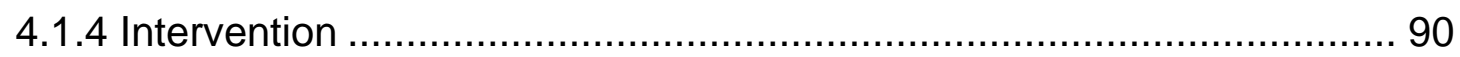

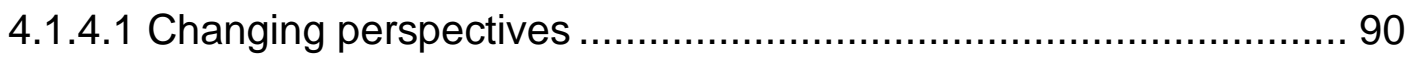

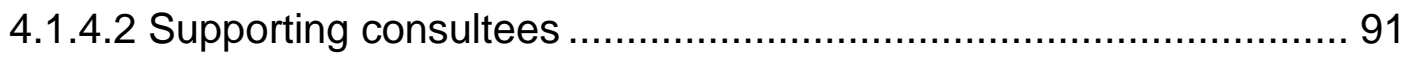

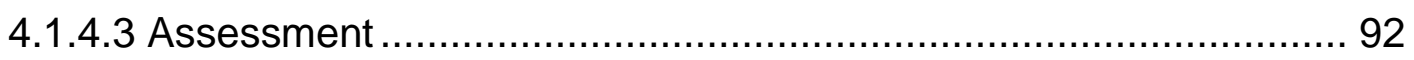

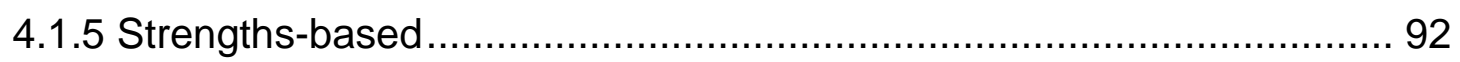

4.1.5.1 Empowering individuals ........................................................ 92

4.1.5.2 What's already working.......................................................... 92

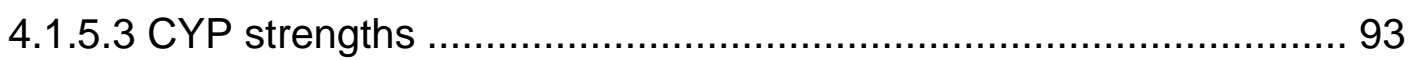

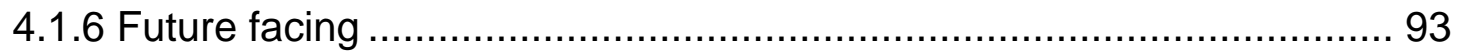

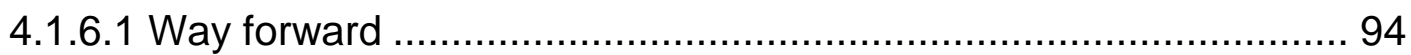

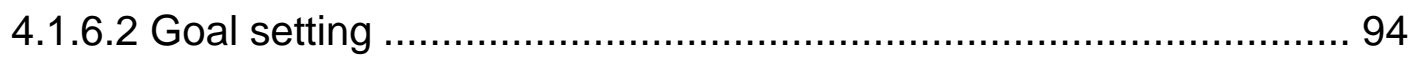

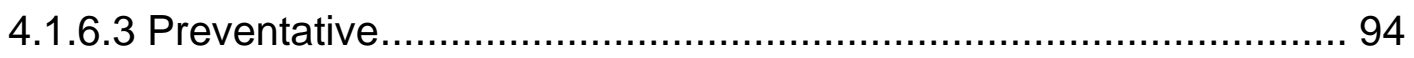

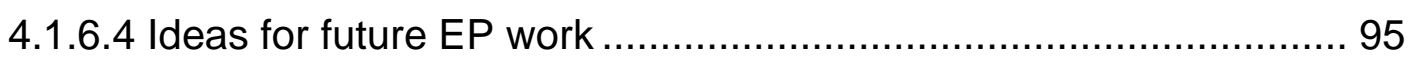

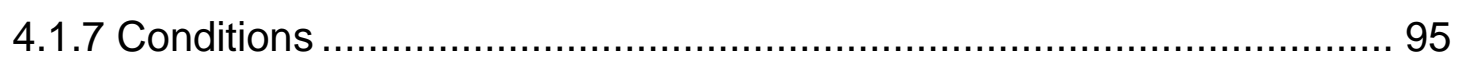

4.1.7.1 Key people

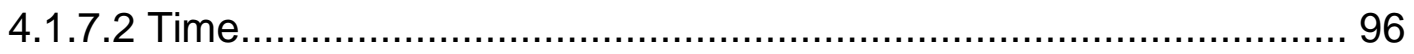

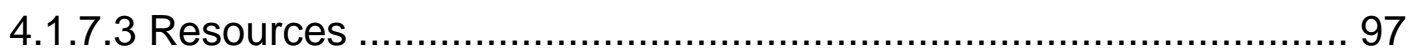

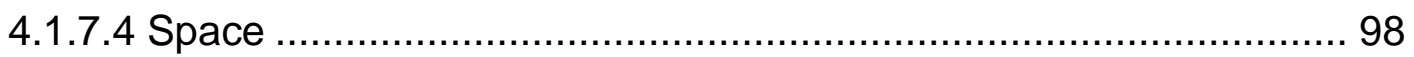

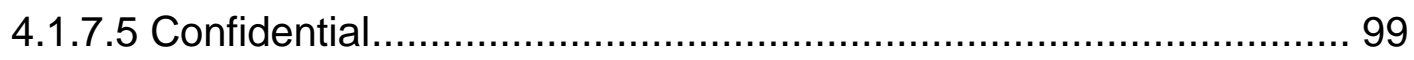

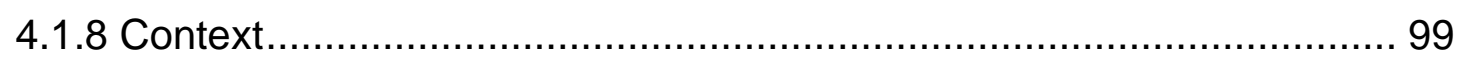

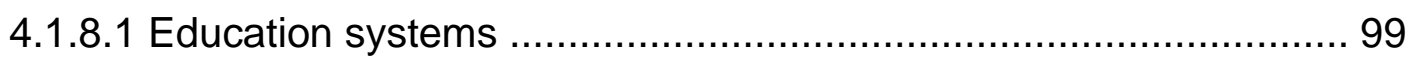

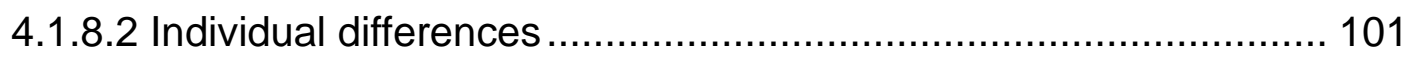

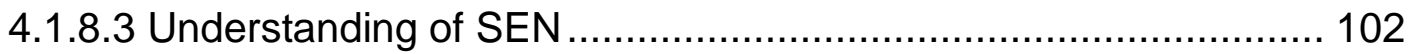

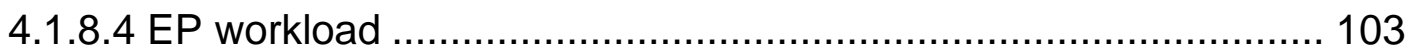




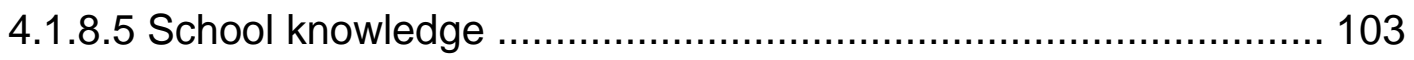

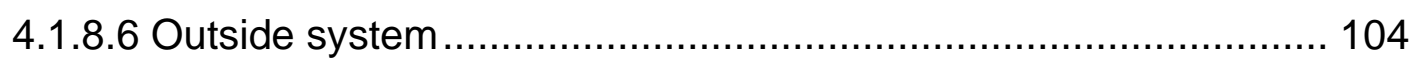

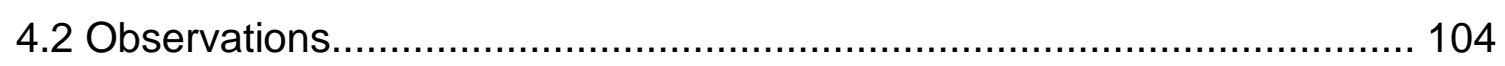

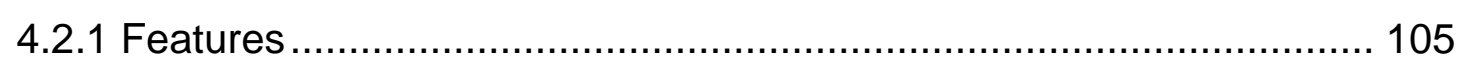

4.2.2 Qualitative description of consultations ........................................ 109

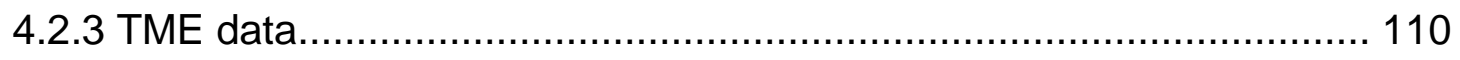

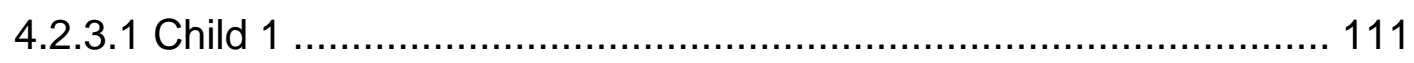

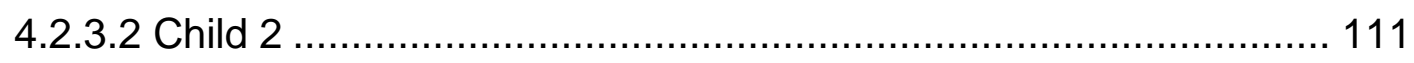

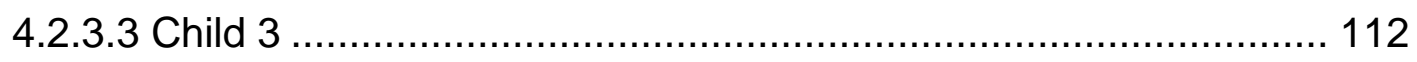

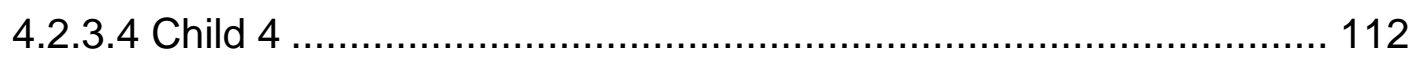

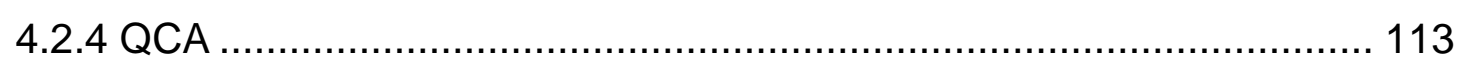

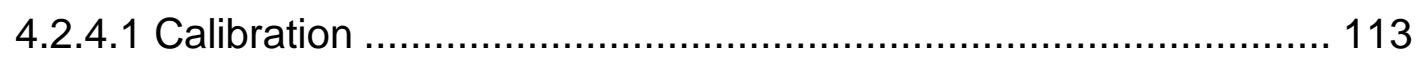

4.2.4.2 Truth table and Boolean minimisation...................................... 116

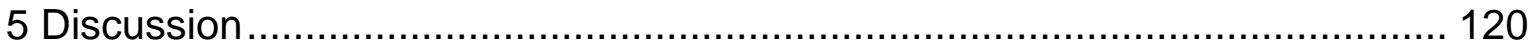

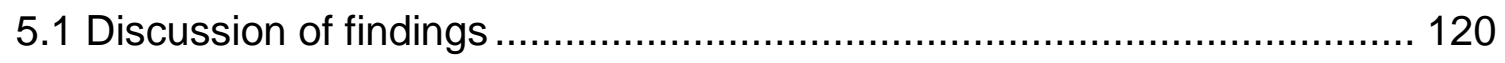

5.1.1 What are the core features of an effective consultation? .................. 120

5.1.1.1 What do EPs believe are the key features of an effective

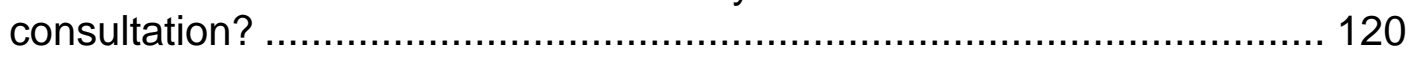

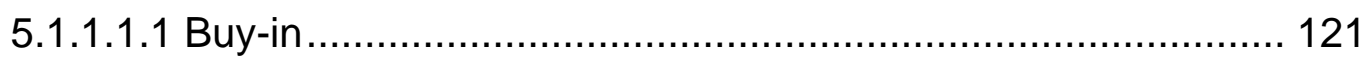

5.1.1.1.2 EP skills and knowledge ................................................. 123

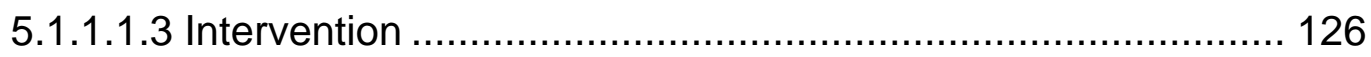

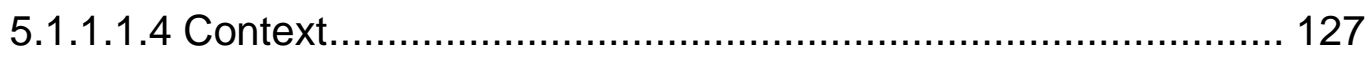

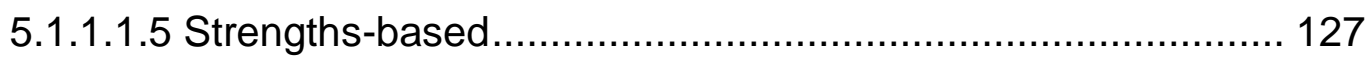

5.1.1.1.6 Shared understanding ................................................... 128

5.1.1.2 What do EPs believe are the barriers to effective consultation? .. 130

5.1.1.3 What do EPs believe makes those features effective? ............... 132

5.1.2 Which combination of features of consultation are seen with progress

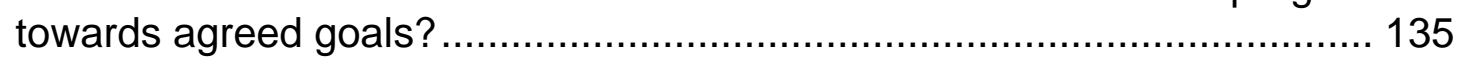

5.1.2.1 Non-formal analysis of features and goals.................................. 135

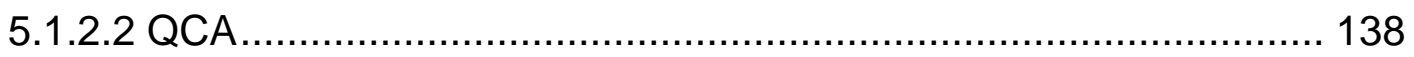

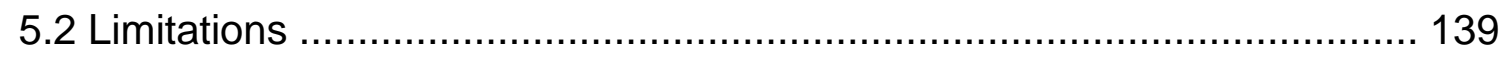

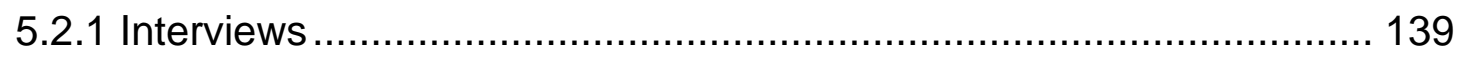

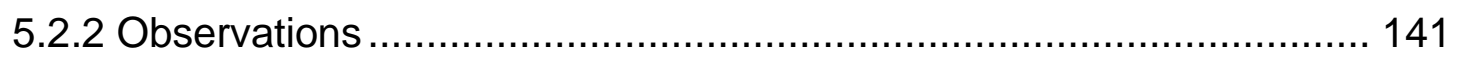

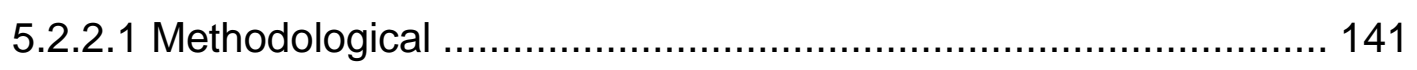

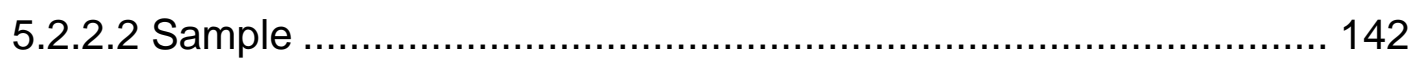

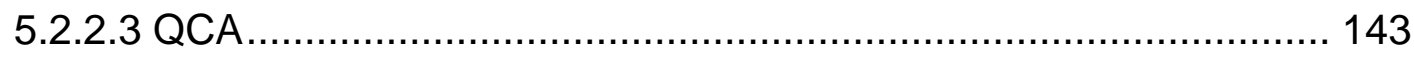




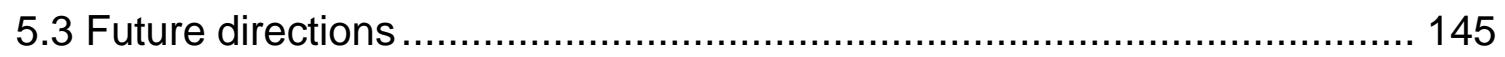

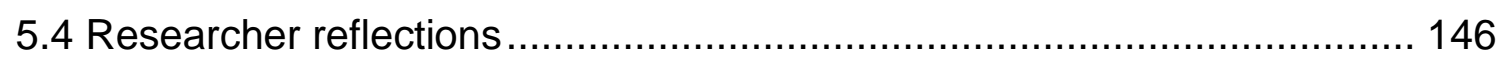

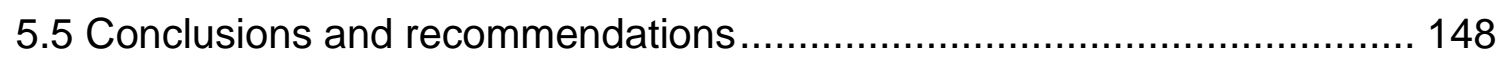

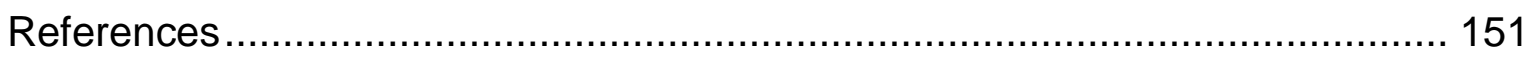

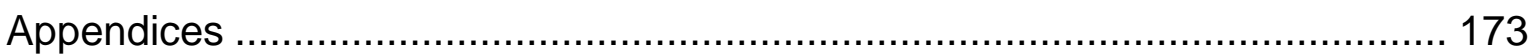

Appendix A: Breakdown of consultation, child, EP, and consultees .............. 173

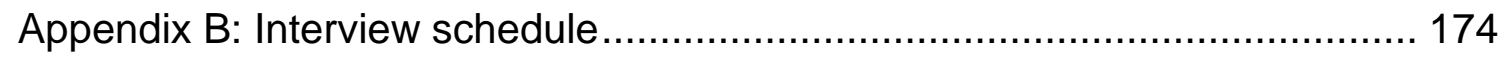

Appendix C: Definitions of features of consultation .................................... 175

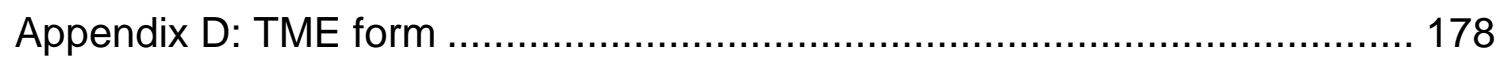

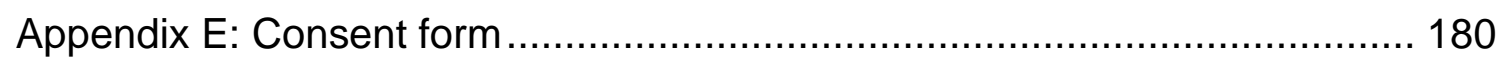

Appendix F: Definitions of inductive codes for features of consultation .......... 183

Appendix G: Definitions of inductive codes for what makes the features effective

Appendix $\mathrm{H}$ : Breakdown of the number of interviews the features were recorded in and how many total times across all interviews ...................................... 188

Appendix I: Correspondence between the deductive and inductive codes for the effective features of consultation and what makes them effective .................. 191

Appendix J: Baseline, expected, and actual TME ratings for each goal ......... 192

Appendix K: Combination of features after Boolean minimisation (and which

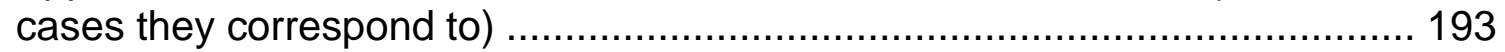

Appendix L: Features of consultation and recorded change for each goal ..... 195

Appendix M: Checklist for effective features of consultation......................... 196

\title{
List of figures
}

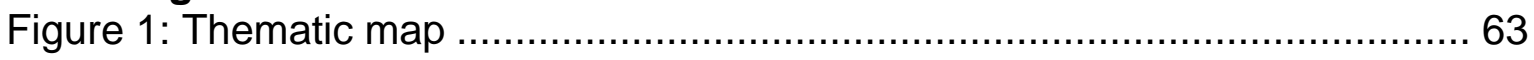

\section{List of tables}

Table 1: Summary of features by consultation .............................................. 107

Table 2: TME goals with ratings for baseline, expected, and actual.................. 112

Table 3: Calibrated table of features by change for each goal .......................... 115

Table 4: Truth table of features by change for each goal ................................ 119

\author{
Abbreviations \\ CBC - Conjoint Behavioural Consultation \\ CYP - Children and young people
}


EP - Educational Psychologist

EPS - Educational Psychology Service

GAS - Goal Attainment Scaling

ICC - Intraclass correlations

IRR - Inter-rater reliability

LA - Local Authority

MAP - Making Action Plans

PATH - Planning Alternative Tomorrows with Hope

QCA - Qualitative Comparative Analysis

$R Q$ - Research question

SENCO - Special Educational Needs Co-ordinator

SMART - Specific, measurable, achievable, realistic, and time limited

TA - Thematic analysis

TME - Target Monitoring Evaluation

TEP - Trainee Educational Psychologist

YARC - York Assessment of Reading Comprehension 


\section{Introduction}

This research sought to systematically explore several important strands related to the use of consultation in EP practice. The first element is to identify what EPs believe are the key features of consultation. This will allow EPs and TEPs to gain an informed understanding of what the core features of consultation are. The difficulty for TEPs in gaining a clear understanding of the core features of consultation has been previously identified (Kennedy et al., 2009). This is primarily due to the small amount of research exploring what happens during a consultation (Kennedy et al., 2008). As such, a thorough analysis of what a wide range of EPs believe are the key features will help elucidate this fundamental but often misunderstood strand of EP work (O'Farrell \& Kinsella, 2018).

The second element explores to what EPs believe are the effective features of consultation, what makes said features effective, and what the barriers are to effective consultation. It is not enough to merely know what the features of consultation are. EPs operate within systems which require demonstration of efficacy and improved outcomes for CYP (British Psychological Society, 2019). EPs therefore need to know what features of consultation lead to positive change for CYP, what makes these features effective, and what the barriers to effective consultation are.

The third element relates to an analysis of what combination of features of consultation correspond with improved outcomes for CYP. Whilst delving into the views of experienced and informed users of consultation gives some insight, thorough exploration requires the analysis of this complex phenomenon through multiple methodologies (Meyers et al., 2014). This is because doing so provides a 
more meaningful interpretation of the data and phenomenon (Tashakkori \& Teddlie, 2010) and because it allows exploration at more than one level of analysis (Hughes, 2016).

The rest of this chapter explains in detail what is understood by 'consultation' as a form of working within an educational psychology context. The scope of consultation within the UK will be detailed to provide an understanding of the larger context for the use of consultation and the issues this presents. Gaps in the academic literature will then be highlighted. The rationale for this work will then be explored and an overview of the structure of this thesis will be given.

\subsection{What is consultation?}

Consultation takes many different forms across contexts and countries.

Consequently, there is not a universal definition of consultation as conducted by

EPs. This raises an important problem for any EP who wishes to engage in consultation or analyse its efficacy. Within a western context, it fundamentally involves problem solving between consultants (EPs) and consultees. The consultee is most often a teacher who knows the Child or young person well, but it can also be parents and/or Special Educational Needs Coordinator (SENCOs). In joint school-family consultations, it is generally agreed prior to the consultation that at least one member from the child's family unit and the school will attend. These individuals collaborate to devise and establish interventions to help support and find solutions for the client, the CYP (O'Farrell \& Kinsella, 2018). Consultation is considered a form of 'indirect' work as the theory is that the EP can enact the most change for CYP by meeting and working with those around CYP (Gutkin \& 
Conoley, 1990). Direct work with the child or young person is often conducted, though is not mandated.

Consultation has become the model of service delivery for many Educational Psychology Services (EPS) (Sheridan et al., 2017). Most EPS in the UK have moved towards a predominantly consultation-based service (O'Farrell \& Kinsella, 2018). This is in contrast with what is viewed as a more traditional model which predominantly involves individual casework, typically including the administration of a cognitive assessment (Kratochwill \& Stoiber, 2002; Larney, 2003).

The consultation framework utilised most in the UK is the Wagner model (Wagner, $2000,1995 a, 1995 b)$. Thus, for a majority of EPs, consultation is defined as "a voluntary, collaborative, non-supervisory approach, established to aid the functioning of a system and as inter-related systems" (Wagner, 2000, p. 11) through "purposeful [conversations] which [use] techniques of listening, clarifying, problem-solving, challenging, questioning and reflecting" (Munro, 2000, p. 55). As a result, EPs work with those closest to the child or young person. However, this is not as experts telling them how to help the child or young person; their role is to help empower them to solve their own problems. Wagner believes that taking the role of the expert is "deskilling" (Wagner, 2000, p. 12) for the consultees as the EP assumes a position of power. Being an expert for Wagner is therefore more than just having detailed knowledge about a range of relevant topics; it is the assumption of an elevated position in the power dynamic which can lead to the dismissing of the views of the consultees. Being collaborative, with equal 
participation between those involved, and bringing in the voices of those involved is therefore fundamental to the Wagnerian model of consultation.

The focus is not only on the child or young person but their relations with others and the many different environments they are in, such as home, school, and their wider community, ideas derived from (Bronfenbrenner, 1995). There is an understanding of the interactions between these layers and the need to consider a child holistically. This support is provided by asking questions, analysing presenting problems and helping others think differently, agreeing on potential interventions, and then reflecting on the whole process so progress can be made.

\subsection{How prevalent is consultation in the UK?}

The move towards a consultation-based model of service is reflected in government legislation. The Special Education Needs: Code of Practice characterises consultation as one of the main services of EPs (Department for Education, 2015). Several studies have also found it makes up a large percentage of their time working with schools. One such study is Shannon \& Posada (2007). In this work, researchers delivered questionnaires to $44 \mathrm{EPs}$, asking for the EPs to self-report how often they undertook different types of work, including consultation or case work. 32 responded, with most reporting they spent most of their time engaging in individual level work. $91 \%$ of the EPs who were engaging in individual level work stated consultation was the main activity performed. However, the authors did not provide a definition of consultation nor ask the EPs to provide a definition of consultation. Given that consultation takes many different forms and there are a wide range of views on consultation between EPs and other 
stakeholders, ensuring everyone has the same definition of the process is crucial. Without it, one cannot be sure different EPs are engaging in consultation in a similar way and that the schools understand the process. Participants may have reported they used consultation, but in practice their methods may be very different. Because of the limits of self-report, we do not know if such a disparity exists in this study. On the other hand, the EPs who responded were from a large range of locations across the UK, thus increasing the representativeness of the data and our confidence that the results can apply to other EPs.

Another study exploring the prevalence of consultation in the UK comes from Leadbetter (2000). For this research, the authors sent questionnaires to all Principal Educational Psychologists and asked about their models of service delivery. Consultation was reported as one of the most frequently used models. However, there was only a return rate of $58 \%$, with those not returning almost certainly not randomly distributed. There is therefore uncertainty around the amount of bias in the results. If the non-returns were randomly distributed on key variables, such as whether the EPs has recently experienced organisational changes, then a low return rate would not introduce bias into the results. But this is unlikely. As such, the results of certain PEPs who may have different results from the norm are missing. This presents a coloured picture that may not accurately reflect the experience of EPs in the UK

\subsection{Gaps in the literature}

Although consultation forms the bedrock of many EPs work and the model of service delivery for EPS, EPs often struggle to articulate what a consultation 
model of service entails. Leadbetter (2004) states there is little research which explicates the structure and process of consultation. This situation has not improved over the following years, with the few studies examining this typically only focusing on one EPS or a small number of EPs (Cording, 2011; Leadbetter, 2006; Pipher, 2013). These limitations prohibit one from developing a broad picture of how consultation is performed in the UK

This lack of clarity subsequently has a significant impact on EPs ability to measure the efficacy of consultation. If a clear definition and set of features of consultation has not yet been established, assessing the efficacy of it is very difficult. To demonstrate that consultation is effective, the mechanisms through which consultation leads to positive change need to be measured. As such, the key features need to be identified and then linked with recorded progress for CYP. If the key features are not known, EPs putatively engaging in consultation cannot be certain that they truly are using consultation. They also cannot be confident that the practices they are using within consultation lead to positive change for CYP. Given the need of EPs to demonstrate the efficacy of their work (Fallon et al., 2010), this poses serious problems for their ability to work in an ethical and effective manner.

\subsection{Rationale}

The purpose of this research was to gain an insight into what EPs believe are the effective features of consultation, why they believe they are effective, what the barriers to effective consultation are, what happens during an EP-led consultation, and what combination of features are seen when compared to rated progress 
towards agreed goals. Gaining an understanding of what EPs believe are the core features of consultation allows EPs to understand what is essential for a consultation to occur. Exploring what they believe are the effective features and why can help guide future EPs and TEPs to increase the efficacy of their consultations.

Having a more fine-grained understanding of when different features are seen and how frequently would provide valuable insight into what are the core feature of a consultation. This could then be cross-referenced with the ratings of progress as measured by TME. It can also be used to explore how accurate EPs are in their judgements as to what they think are effective features of consultation. The correspondence between the combination of observed features and progress is important because all EPS are expected to be able to demonstrate efficacy. This efficacy is generally conceived of as improvement for the CYP the EP is working with (Connor, 2010). It is therefore important that EPs can substantiate claims of efficacy for certain methods, such as consultation. Given this, the present study seeks to draw a link between what features occur in consultations and are seen with rated progress. By understanding what the core features of consultation are and which features make it effective, this will inform the professions understanding of what is required for a consultation to occur and how to increase the chances of engaging in consultations which lead to positive outcomes for CYP.

Mixed methods were chosen because of the desire to explore the phenomenon (effective consultations) more completely than a single methodology could provide (Robson \& McCartan, 2015). Mixed methods have been previously used to 
examine consultation at different levels whilst respecting the complexity of the systems it is used in, for example Benn et al. (2008). The method chosen for the qualitative arm of the research was interviews, as this is one of the best tools to thoroughly explore the views of those who are most knowledgeable about the phenomenon (Meyers et al., 2014). As such, EPs were interviewed to gain an understanding of their views of the effective features of consultation as they have first-hand experience of when consultations are and are not effective.

The most appropriate quantitative approach to accompany the interviews is observations. This is because of the value of observing real-world consultations and systematically examining the features present. Previous arguments have been made that the qualitative exploration of consultation is insufficient; observation of real-world consultations is essential to accurately examine this process (Henning-Stout, 1994). Mixed methods also help to offset the weaknesses of each approach and increase the strength of possible inferences (Robson \& McCartan, 2015). Equal weighting was given to each form of evidence, and each can be used to inform the other and provide more depth.

\subsection{Thesis structure}

This thesis is comprised of five chapters. Chapter 2 provides a detailed theoretical background to this work, identifying previous research which has sought to explain what key stakeholders' views towards consultation are, what are understood to be the key features of consultation, and previous attempts to assess the efficacy of consultation. 
Chapter 3 details the methodology employed to address the research questions. A theoretical justification for the chosen methods is also provided. The procedure for each arm of the research is given, along with the data analysis and a critique of each method.

Chapter 4 begins by laying out the results for the qualitative results. A detailed analysis of the codes and emerging themes is provided. The quantitative results are then given. The initial observations are presented, followed by the two stages of QCA.

Chapter 5 critically analyses the findings and draws links to the extant research. The limitations of the research, including critiques of the methodologies and practical limitations of the samples, are then explored. Reflections by the researcher are then provided. Finally, conclusions are drawn and links to EP practice are made. 


\section{Literature Review}

A literature review was conducted to see what previous research had identified as the consultees and EPs views of consultation, what the main features of consultation are, and what the main tools of analysing the efficacy of consultation were. Various databases, including Web of Science and Scopus, were searched using the key words "educational psychology," "consultation," and "efficacy." Further reading was identified from the references lists of several papers used. Key references, such as Kennedy et al. (2008), were given to the researcher by their supervisor to set a baseline for the literature review. Due to the paucity of published research, especially for assessing the efficacy of consultation, the grey literature (Paez, 2017) was also examined. The grey literature refers to documents not published in journals or commercial publications, such as doctoral theses, unpublished articles, and independent reports.

The purpose of this chapter is to first establish what consultation is believed to be according to the stakeholders (consultees and EPs). Then, the relevant literature detailing previous attempts to identify the key features of consultation will be examined. An explanation of the two most common theoretical models will also be provided. The Local Offer literature of London Boroughs will be analysed to gain an understanding of how some EPS advertise themselves and their public portrayal of consultation. Then, literature seeking to evaluate the efficacy of consultation will be evaluated. The context of this thesis will then be highlighted, leading to the research questions which motivate this piece of research. 


\subsection{What are consultees views on consultation?}

Prior to exploring what occurs in a consultation, understanding what those involved (EPs, teachers) believe it to be is valuable. This is because if consultees are to play an active role in consultations (as all models of consultation state they should), their views of consultation need to be understood. That way, any misunderstandings can be cleared up and consultation can be effective. To serve this end, the following section explores stakeholders' views of consultation as detailed in the relevant scientific literature. O'Farrell \& Kinsella (2018) interviewed three groups containing a teacher, an EP, and the parents of the child. The teachers and parents reported that while they appreciated and saw the value of consultation, there was a lack of understanding regarding its process and nature. All three teachers implied they viewed the EP as the external expert, who had specialist knowledge and access to resources which they wanted. This is in direct contrast to the sentiments expressed by the EPs in this study. They explicitly stated they were not experts and tried to distance themselves from that sentiment. This concept is fundamental to many models of consultation, including Wagner (1995b). This research was conducted in the Republic of Ireland. Here, consultation has only become the dominant model of service delivery in recent years. Thus, UK based teachers and SENCOs may have a better understanding. However, few pieces of research have been conducted to explore understanding of this important strand of EP work.

Dennis (2004) interviewed SENCOs at twelve schools to better understand their views on EP work. One of the core themes raised by the participants was a wish for EPS to "publicise more the range of things it has to offer and good/innovative 
practice." The exact number of schools which held this belief is unknown as that information was not reported in the paper. Regarding consultation, there was a large heterogeneity in the school's understanding of it. Some schools were fully aware of the consultation model of service delivery and preferred it to previous models. Such models focused on direct work, including assessment of CYP using cognitive assessments. However, other schools either did not understand the consultation model or were only partially aware of it but preferred other models which placed a primacy on child-focused individual work. They reported they believed the consultation model involved "too much talk, not enough action" (Dennis, 2004, p. 22) and thus did not value it as highly.

This lack of understanding of consultation is found in other countries as well. Many Australian EPS have also shifted their focus from an assessment-based to a consultation-based model of service delivery. But they also experience a lack of clarity in understanding among stakeholders regarding the meaning and process of consultation (Bell \& McKenzie, 2013). However, some EPs do not report this problem. In the U.S.A., those who work with school psychologists (as EPs are called) show a greater consistency of understanding of consultation in schools. There is also a larger evidence base for the efficacy of their form of consultation. This is because consultation as practised in the U.S.A. is almost exclusively Conjoint Behavioural Consultation ( $\mathrm{CBC}$ ). $\mathrm{CBC}$ is defined as "a strength-based, cross-system problem-solving and decision-making model wherein parents, teachers, and other caregivers or service providers work as partners and share responsibility for promoting positive and consistent outcomes related to a child's academic, behavioural, and social-emotional development" (Sheridan \& 
Kratochwill, 2007, p. 25). CBC has been shown to be effective for CYP over a wide range of settings and for many presenting problems (Sheridan et al., 2017). This hegemony of practice allows for a consistent definition and implementation and is likely one of the reasons consultation in the U.S.A. is better understood and valued by stakeholders (Reddy et al., 2000). It also means its efficacy can be assessed more readily, such as by conducting a randomised control trial conducted as done by Sheridan et al. (2012).

On the other hand, the lack of understanding by key stakeholders (SENCOs, teachers, and parents) may not truly reflect the modern-day conception of consultation in the UK. Most of the research reporting these findings is roughly 15 years old. It is reasonable to presume stakeholders have become more familiar with it, given how prevalent it is. A more recent paper exploring this is Cording (2011). For this work, the authors interviewed 10 school personnel (such as Head teachers and teachers) and 9 EPs in a Welsh Local Authority (LA). The aim was to elicit their understanding of the kinds of work they believed EPs conducted. There was a general alignment between the views of the school personnel and the EPs themselves. But the school personnel stated they greatly valued the EPs expertise in diagnosing and alleviating presenting problems. This shows that despite there being a shared understanding of what EPs do, there is still a divide in what stakeholders value about EP work.

\subsection{What are consultants' views on consultation?}

Most EPs have a positive view of consultation, with the Local Offer literature from many EPS stating their model of service delivery is consultation, such as 
Kensington \& Chelsea (Royal Borough of Kensington \& Chelsea, 2019). Some EPs believe they provide a unique method of working through their use of consultation (Ashton \& Roberts, 2006). Ashton \& Roberts (2006) sent questionnaires to both schools and EPs asking for them to comment on the work EPs engage in. 22 questionnaires (out of 58) were returned from mainstream primary schools and eight (out of nine) EPs completed the questionnaire. 'Statutory assessment work,' 'Closed tests' and 'Expert role' were the most frequently provided parts of EP work that were classed as unique by SENCOs. Few or no other agencies were judged by SENCOs as providing a similar or the same service as EPs. 'Individual assessment and intervention' and 'Consultation' were the aspects of EP work the EPs themselves believed were unique to them, as no other service provided these. This shows a clear disparity between the views of EPs and key stakeholders within consultation (SENCOs). They also reported that SENCOs typically valued more traditional EP work, such as individual assessment and giving advice. The SENCOs did not value consultation, nor give evidence they had a complete understanding of it. However, these results should be interpreted with caution. The small sample limited to one LA undermines our ability to generalise the results to a wider context. It also only collected data from mainstream primary schools, further limiting the scope of these results. Yet one of the main results, namely the lack of understanding regarding the nature of consultation, has been replicated by research in other school settings (Dennis, 2004; O'Farrell \& Kinsella, 2018). 


\subsection{What are the main features of consultation?}

Once a common understanding of what the stakeholders believe consultation is has been created, an analysis of the common features of consultation can occur. The following section will evaluate the relevant literature regarding the features of consultation. Henderson (2013) used focus groups with clusters of SENCOs across a small LA to gain an understanding of their beliefs about the mechanics of consultation. The researchers sat in on five different Primary SENCO Network meetings and worked to gather their views. Henderson (2013) presented the participants with statements about parts of the consultation process. Their task was to sort them depending on how often they believed the statements to be a part of a consultation. The mostly commonly given features of consultation were: discussing issues with relevant parties; information gathering; and it being a reflexive process with a focus on collaboratively crafting solutions. They also conducted semi-structured interviews with EPs, children who were receiving EP involvement, and their parents. It being a collaborative and problem-solving process, with a focus on solutions, and the development of positive working relationships between those involved were the two main themes. The use of focus groups to identify SENCO beliefs regarding the nature of consultation and interviews with the stakeholders allowed comparison between the stakeholders' expectations and the reality of consultation. However, given the researchers did not directly observe consultations but relied on self-report, the conclusions that can be drawn regarding how consultations are conducted are weakened. This is because of the disparity between self-reports of behaviour and real-world instances of behaviour (Argyris \& Schon, 1992). 
Kennedy et al. (2008) thematically analysed the voice recordings of 17 EP-teacher consultations. These individual case studies (Robson \& McCartan, 2015) were supplemented by a pre-consultation questionnaire completed by EPs to establish their espoused theory for consultation. A comparison could then be made between the recordings and participants' self-report to see whether their espoused theory aligned with the recorded behaviours. The authors report a high correspondence between the EPs espoused theory and theory in practice as EPs predominantly engaged in behaviours dictated by their espoused theory. The most common behaviours by EPs were working collaboratively, typically with those most involved (predominantly parents) using either the problem-analysis framework or SolutionFocused approaches (a detailed account of these models of consultation will be provided in the following subsection). By recording the consultations, the authors could gather data from a larger number of consultations than they could have if they sat in on every consultation. However, there was a low granularity of analysis. The researchers only assessed whether features of the espoused theory appeared at all during the consultation. Thus, the analysis only shows that during a consultation, EPs brought in ideas from their espoused theory at least once. There was no analysis of how frequently the ideas appeared and when during the consultations. It therefore cannot tell us how great a part these concepts from the espoused theory played in the consultation, merely that they were present.

Nolan \& Moreland (2014) observed seven consultations between five EPs, a teacher, and at least one parent. A week later, the researchers conducted semistructured interviews with all EPs and teachers and some of the parents. Several key themes arose from the observations and interviews. These were: empowering 
those involved in the consultation; working collaboratively; the importance of each participant in the consultation recognising the valuable knowledge from others; reviewing outcomes; and EPs using their expertise to support others (without emphasising their role as the "expert"). The use of both observation and interview generates a lot of data about these 7 consultations, giving a very detailed understanding of the process. It also allows corroboration between data collection methods. However, the small sample size limits the generalisability of the findings. These results therefore need to be replicated with different configurations of participants and in other school settings.

O'Farrell \& Kinsella (2018) found teachers appreciated consultation as they felt empowered to support the pupils who had been referred. According to Jones \& Frederickson (1990), this empowering of consultees rather than fixing the consultees problems or simply giving advice, is part of the definition of consultation. Dennis (2004) found that EPs and SENCOs saw several key issues relating to the successful implementation of a consultation model: the EP having a detailed knowledge of the system (school) they were working in; addressing issues at multiple levels (rather than just on the individual level); positive relationships between the EP and SENCO; and empowering staff to successfully address their problems, rather than doing it for them.

Dickinson (2000) \& Munro (2000) examined how consultation had been implemented in their EPS (Lincolnshire and Buckinghamshire respectively). Behaviours and approaches which helped support the successful implementation of consultation across both EPS included: having purposeful conversations; EPs 
using their psychological knowledge during consultations; and all parties involved deciding on interventions as well as reviewing past and current interventions.

Factors that were only reported in Munro (2000) included: engaging in preventative work; improving outcomes; and engaging in multi-level collaborative work. Unfortunately, these papers are based on the author's reflections on the implementation of consultation in their LA and do not give the views of anyone else or provide much in the way of data to support their findings. Readers must therefore take them at their word.

Smillie \& Newton (2020) explored how EPs gain the voice of CYP, which has been identified as an essential part of the consultation process (Department for Education, 2015). Valuing the voice of CYP also aligns with the Bronfenbrenner theory of viewing CYP at the centre of a complex web of interconnected systems. The model Involving CYP in the assessment, planning, and review stages of EP has been put forward as beneficial because of increased motivation and feeling of responsibility for change and can be done using a range of theories, such as Solution-Focused approaches (Roller, 1998). This research explored one feature (voice of CYP) in a wide range of EPS using a mixed methodology, thus allowing a detailed exploration of said feature. However, this research only explored the views of EPs regarding eliciting the voice of CYP, ironically denying CYP a say in how their views are collected and whether it is effective. As such, there is a lack of research detailing how CYP believe their views can be effectively collected and factored into the work for them. 
This research builds on a previous piece of work by the lead researcher. This first work explored what EPs believe the key features of a consultation are and what happened in an initial consultation between at least an EP and a school staff member. This was done through a novel questionnaire asking EPs to rank features of consultation according to their importance and thematically analysing transcripts of consultations. During the consultations, the two most frequent features of consultation were 'Understanding the presenting problem' and 'Working together to come up with solutions.' EPs rated these as core features of consultation in the questionnaire, as well as improving outcomes for young people. Whilst this research assessed what EPs believe the core features are and what the features are of an initial consultation, the small sample size ( 3 observed consultations and 8 EPs completing the questionnaire) means the results are hard to generalise beyond the immediate consultations.

Although these studies typically only focused on a small number of participants, the consistency in results allows fundamental features of consultation to be gleaned. The studies also cover a wide range of EPS, so the results are not limited to a specific region. This increases the generalisability of the findings. However, despite these consistencies, there is still a great deal of heterogeneity in consultation models and practice. EPs can state they are engaging in consultation, but without more information or a previously established working relationship, those involved (parents, teachers, etc.) are unlikely to know what to expect with a consultation. An arguably more serious consequence is that assessing the efficacy of consultation is very difficult. If consultations are not ergodic due to the very wide range of features, any assessment of consultation may not be valid for 
consultations performed by an individual EP. Therefore, assessing the efficacy of consultations is difficult. This is against the backdrop of EPs working within 'traded services' (Lee \& Woods, 2017), where the ability to demonstrate efficacy is highly valued. It therefore behoves EPs to gain an understanding of the consistent features of consultation. This will allow some assessment of which combination of features are sufficient to lead to improved outcomes for CYP.

\subsubsection{Models of consultation}

The theoretical models of consultation have been explored in a number of papers. The two most common are the problem-analysis framework (Monsen et al., 1998) and solution-focused techniques, derived from Solution-Focused Brief Therapy (De Shazer, 1985). The problem-analysis framework is related to behavioural consultation (Bergan \& Kratochwill, 1990) and is divided into four stages: problem identification, problem analysis, intervention implementation, and intervention evaluation (Sheridan et al., 2000). Those working directly with the young person, such as teachers, are involved throughout (Kennedy et al., 2009). This framework operates under the assumption that 'subsequent actions and interventions will be more successful because they are based upon a more accurate analysis of presenting difficulties' (Woolfson et al., 2003). This thorough understanding of the presenting difficulty allows the EP to generate 'initial guiding hypotheses based upon psychological theory and research about the nature and causes of the presenting problem situation' (Woolfson et al., 2003). These hypotheses serve as the guiding force behind discussions with consultees and help identify other areas to be explored. This model has been found to be "highly effective in some executive areas' (Kelly, 2006) but criticisms have been levelled at it. One such 
criticism relates to the perceived inflexibility of it (Wicks, 2013), leading to the updated model with greater flexibility and bi-directionality (Monsen \& Frederickson, 2008).

This model is in contrast with the other most common model that informs consultation: a Solution-Focused approach. This is characterised by greater interest in the solutions to presenting problems rather than the problem itself. This is because those who employ solution-focused ideals believe that a focus on the problem is not necessary to effect change (De Shazer, 1985). Times when the problem is not as severe or is absent, called 'exceptions' (De Shazer, 1994), are explored. This is to help emphasise to the client that they have the skills and resources to overcome their own difficulties, as they have done so in the past (De Shazer, 1985). The EP helps facilitate this discussion of exceptions and helps the client realise their own resources to overcome their issues (Rhodes \& Ajmal, 2004). Co-operation between the client and therapist is fundamental to the success of this approach (De Shazer, 1984). Given this work was originally created for adults in a clinical setting, it had to be adapted for use by EPs in schools. Ajmal \& Rees (2001) detailed the 6 pragmatic assumptions for use of SF approaches in schools to help EPs use this model within their practice. A recent meta-analysis on the efficacy of solution-focused approaches in a number of settings found that all studies included stated that at least one measure reported a positive impact of solution-focused approaches. However, the low typical sample size of the included studies raises concerns around the validity of significant results reflecting a true result (Button et al., 2013). 


\subsection{Local Offer literature}

To gain an understanding of what EPs at different LAs understood consultation to be, the Local Offer literature was examined. This information was found on the LA's websites and detailed what services the EPS provided. Despite almost all services having moved to a consultation-based service delivery (Dinkmeyer \& Carlson, 2016), over a third of LAs did not explicitly mention consultation. Of those that did, the most cited feature was working with relevant parties, such as teachers. The second most common was improving outcomes for CYP, with the importance of looking for solutions (including the use of Solution-Focused approaches) also being mentioned frequently. What this shows is that for the LAs that mention it, the EPs working there have explicitly stated the importance of collaborating with those closest to the CYP and the necessity of improving CYP's outcomes.

\subsection{Assessing the efficacy of consultation}

There have been calls for assessing the efficacy of EP work for decades, such as Cline (1994), but this has become even more important since the almost complete shift to 'traded services' (National College for Teaching and Leadership, 2014). 'Traded services' marks a shift in funding towards existing service organisations needing to generate income from schools (seen as customers) to either partially or fully financially support itself (Woods, 2014). Many EPs feel a pressure from schools to both provide something tangible for customers and to demonstrate the effectiveness of their work, so schools buy their services again (Lee \& Woods, 2017). EPs are also expected to use evidence-based tools and to critically evaluate their practice (British Psychological Society, 2015, Standard 4.8; Health 
\& Care Professions Council, 2015, Standard 12.1) as part of the requirements of practicing as an EP. It is therefore very important for EPs to understand what aspects of consultation are effective in eliciting change.

However, measuring such change is difficult. As Kennedy et al. (2008) notes, due to the complex nature of the interactions between consultant, consultee, and client it is difficult to decide what to measure and how to do so. Several methods have been put forward, but none have gained ascendancy yet. One method used by some EPS (Hampshire EPS, 2010) is the Target Monitoring Evaluation (Dunsmuir et al., 2009). TME is based on Goal Attainment Scaling (GAS), which was developed by Kiresuk \& Sherman (1968) to evaluate the outcomes of mental health interventions. TME is a streamlined form of GAS, with the added advantage of increased granularity in evaluating progress in relation to expected progress. TME involves the negotiated development of SMART goals between the EP and the consultees. To examine the suitability of using TME forms with consultations, Dunsmuir et al. (2009) incorporated TME forms into the practice of eight assistant EPs in one county and 13 EPs based in two Local Authorities. During the initial consultation, after the goals had been decided upon, each participant rated how far along on a 10-point scale the child currently was towards each goal. They then stated how far they expected the child to be when they had their review consultation. 6-8 weeks later, during the review consultation, each participant rated how far the child had actually progressed, which was compared with how far they were predicted to progress. Interviews were conducted with teachers, SENCOs, and headteachers, who gave positive feedback on the easy and efficiency of the process, as well as how the tool helped focus on setting of 
targets. Two of those interviewed had experience with GAS and stated they preferred TME. Focus groups of EPs and assistant EPs elicited positive views towards the tool, as well as considerations of implementation.

This pilot study gives evidence for TMEs efficacy in assessing progress in response to EP intervention. However, the limited detail provided in the report means we do not have a fine-grained understanding of the strengths and weaknesses of the tool. Monsen et al. (2009) assessed the efficacy of assistant EPs using TME and focus groups with stakeholders. Both measures found assistant EPs to be beneficial to EP work. This work was conducted in one EPS; therefore, the generalisability of the findings is limited. Given that TME is a quantitative assessment of efficacy and the focus groups produced qualitative data, direct comparison of efficacy between the two measures is difficult. As such, strong conclusions about the validity of TME when assessing educational psychology work cannot be drawn.

There have been a few studies which have attempted to compare TME with other quantitative measures of change, such as Connor (2010). In this thesis, the author compared TME with other, more established forms of progress measurement in domains like reading, such as the York Assessment of Reading Comprehension (YARC). They report that there was broad agreement between the TME and other forms of assessment; when other forms of assessment found improvement, this was reflected in the reported change through the TME forms. However, while TME may be useful for identifying progress in individual children, it was not clear how it could be used to assess the quality of the work from the EP. There were also 
some difficulties regarding the use of it, as there was disagreement between some consultants and consultees regarding target setting and the voice of the child.

A recent paper (Eddleston \& Atkinson, 2018) comparing different consultation evaluation tools excluded TME because it did not reach the inclusion criteria. Here, TMEs streamlined nature counted against it as it was not sufficiently thorough enough to be evaluated. This means there is limited evidence for its efficacy as a tool. However, as Dunsmuir et al. (2009) states, "the strengths of GAS are maintained but the TME system is more streamlined and user friendly" (p. 67). We can therefore have increased confidence in the suitability of TME as a measure of change, given that GAS has been shown to be a useful tool (Roach \& Elliott, 2005) and it shares fundamental similarities.

\subsection{Context}

This project was greatly shaped by the coronavirus (COVID-19) pandemic and the subsequent response by the British Government. Because of this, the research was conducted during unprecedented circumstances. All EPs (and workers in general) had to work remotely from home. This brought up unique concerns for how EPs worked, as they were not allowed to see any adults or CYP in person. However, this also presented the profession with an opportunity to further develop their professional practice with regards to consultation. Because almost all contact between members of different households was prohibited, consultations conducted remotely became the most appropriate (and occasionally only) way for EPs to work. The importance of consultation was therefore increased by the sudden demands placed on the profession by the global crisis. This also, 
therefore, increased the importance of identifying effective features of consultation and which combination of features led to positive change for CYP.

To support EPs and TEPs during this novel working environment, several documents, such as Bhardwaj et al. (2020), and one piece of research (Association for Educational Psychologists, 2020) were disseminated during this time, detailing guidance as to how EPs can work ethically within the context of a lockdown. This included conducting consultations using either phones or video call software, such as Microsoft Teams or Zoom. There were concerns regarding the safety and privacy of Zoom technology (Paul, 2020) so Teams was encouraged by many EPS. This shifted the way the research could be conducted: consultations could not be observed in person and many EPs were not engaging in consultation. The timeline of the research was changed as a result, with the observation of consultations pushed back to September 2020 when it was hoped they would resume by.

\subsection{Research questions}

Given the lack of strong theory in this area of research, research questions were developed but statistical hypotheses could not be drawn. Thus, it is exploratory research (Kimmelman et al., 2014). The general aim of this research was to identify, through observations and interviews, what the key features of consultations that lead to change for CYP are. This was done by asking EPs what they believed the effective features of consultation are, what makes them effective, and then observing consultations and systematically noting which features occurred. This allowed the comparison of said features with progress 
towards agreed goals for various CYP and whether they reflected the views of EPs. As such, the research questions (RQs) were:

1. What are the core features of an effective consultation?

i) What do EPs believe are the key features of an effective consultation?

ii) What do EPs believe are the barriers to effective consultation?

iii) What do EPs believe makes those features effective?

2. Which combination of features of consultation are seen with progress towards agreed goals? 


\section{Methodology}

\subsection{Epistemology and research paradigm}

To explore these questions, a mixed methodology was employed, making use of quantitative and qualitative research methods. It was informed by a scientific realism epistemology. Scientific realism can help approach difficult problems in social science as it considers the complexity of the situation in which they occur (House, 1991). It can be viewed as a pragmatic approach (Robson \& McCartan, 2015) as it is less concerned with philosophical dualisms, such as rationalism versus empiricism, and more with practical considerations of issues and potential solutions (Johnson \& Onwuegbuzie, 2004). Mixed methodology aligns with a pragmatic approach as it is not beholden to one method of exploring a research topic; it sees the benefits of both for exploring a research question in different ways (Denscombe, 2008). Multiple methods of inquiry were employed because it is generally believed using different means to explore research questions brings greater rigour (Creswell \& Creswell, 2003). Data can be triangulated with one another, with evidence corroborating, refuting, or adding nuance to each other and increasing confidence in one's findings (Munafò \& Smith, 2018). Mixed methodology research designs can be divided along a key dimension: paradigm emphasis (Johnson \& Onwuegbuzie, 2004). This refers to whether one strand of the research (quantitative or qualitative) is given greater emphasis during analysis. Because equal weight was placed on both forms of inquiry, this was an 'equal weight' paradigm emphasis piece. An explicit account of the ways in which the qualitative and quantitative arms of the research relate to one another is provided. 


\subsection{Participants}

Ethical approval was obtained from UCL the Institute of Education's Ethical Committee. The inclusion criteria for both arms of the research were: an EP or TEP who used consultation as part of their practice. There were no requirements as to how frequently or recently it had to be used, nor experience or location. Nor were there requirements around the definition of consultation, just that EPs believed themselves to be engaging in consultation. This was to try and elicit a wide a range of views on consultations from practicing EPs. For the interview and observation, participants were recruited via the researcher's EPS. Convenience sampling was therefore used. This was because participant recruitment for the observation was judged to be difficult and the researcher would have greater success by asking participants they already had a professional relationship with. The interview also recruited participants by sharing calls for participants on a popular mailing list for EPs and other education professionals (EPNET) and social media (Twitter). Participants were also asked to share the call for participants with other EPs at their work. Thus, a mixture of convenience and snowball sampling (Robson \& McCartan, 2015) was employed for the two arms of the research.

Prior to participating, each participant gave informed consent. It was explained to them they could withdraw from the study at any point and their data would be destroyed. All the data from participants who consented would be stored anonymously on the Open Science Framework, an open-source project which allows open collaboration between scientists by providing a platform to store and share data and materials. 
30 EPs of varying roles and locations were interviewed. Participant's roles included TEPs, maingrade EPs, specialist EPs, senior EPs, and Principal EPs. The participants worked in locations such as London, Yorkshire, Wales, and the Republic of Ireland.

6 different consultations for 4 children were observed. The children were not present for any of these consultations. These consultations were led by 2 EPs. Child 1 had one joint home-school consultation. Child 2 had one parent consultation and one school consultation. Child 3 had one parent consultation. And child 4 had one school consultation followed by one parent consultation. See Appendix A for a full breakdown of which consultations involved which EPs and consultees and were for which children.

\subsection{Materials}

All materials, along with raw data, are released under a CC-BY license, thus allowing re-use of materials, and improving reproducibility and transparency (Nosek et al., 2012). They can be accessed at: https://osf.io/6px7q/ in the 'Methods' folder. Almost all materials and software used were Free/Libre and Open-Source Software (Stallman, 2016).

\subsubsection{Interviews}

A semi-structured interview format was used because an interview schedule was developed (Appendix B) which served as a checklist of areas to be explored with a given question order and wording. However, the order and wording were allowed to change given the flow of the interview. Additional questions were used to further develop an interviewee's answer (Robson \& McCartan, 2015). Interviews were 
chosen because they allow the interviewee to explain in detail their thoughts and were judged to be the suitable means to explore the first RQ. EPs have the greatest knowledge about consultation and are thus in the best position to be able to explain what the effective features of it are. Semi-structured interviews were chosen because the researcher conducted all the interviews and could thus explore answers in greater detail given their knowledge of the area. However, given this intimacy with the research questions and purpose of the study, there is a risk the researcher may ask leading questions to further a certain outcome. Thus, the core questions were agreed prior to the first interview to try and minimise bias.

The interviews were of the focused type as the questions centred around the key theme of consultation (Merton et al., 1990). The core of this theme related to why EPs use consultation, what EPs believe the key features of consultation are, why they are effective, what the barriers to consultation are, and what is the unique contribution of consultation. Barriers were explored because exploring this can help reveal what the effective features of consultation are as often barriers are a lack of an effective feature or the opposite of an effective feature. The unique contribution of consultation was asked to further explore what EPs believe makes consultation effective. This was so that the RQs being explored could be asked about in different forms without repeating any questions.

Probes (interview devices to elicit more information) were employed by the researcher to further develop the interviewee's responses. To achieve this, 'laddering questions' (questions phrased in a variety of ways asking for the 
interviewee to expand on their answer) and 'summarising techniques' (summarising what has just been said by the interviewee to prompt more information), as well as 'addition probes' to maintain the flow of the conversation (Zeisel \& Eberhard, 2006).

\subsubsection{Observation}

\subsubsection{Systematic observation}

The quantitative arm of the research involved systematic observations of consultations between an EP and either the parent, class teacher, or both. Thus, it was a naturalistic observation as the participants were observed in their typical environment without any interference from the researcher (Vigliocco, 2001). Observation was chosen as it helps overcome the often-recorded discrepancy between what people say they do and how they behave in the real-world. This has been reported in such wide-ranging fields as smartphone use (Andrews et al., 2015) to driving behaviours (Kaye et al., 2018).

Systematic observation was chosen because of the previous research identifying features of consultation. The researcher therefore judged that all the relevant observable features had been identified prior to data collection. These observable features were developed into a coding scheme (see Appendix $C$ for the definition of each feature) to identify categories over the course of a set period. The categories were defined and operationalised prior to data collection (Croll, 1986). They were derived from the relevant literature and were mutually exclusive. The categories were limited to what was explicitly said because this would help reduce the amount of interpretation needed for behaviours such as non-verbal interactions. Thus, features were defined as utterances by participants within the 
consultation. This was done to minimise the amount of inference the researcher had to use when deciding whether a category was observed (Croll, 1986).

Models of consultation, such as Solution-focused and problem-analysis, were broken down into their constituent observable parts, such as planning/implementing interventions and exploring strengths. These two were chosen as they are often cited as the core models by EPs (Kennedy et al., 2008). This was so the categories were more fine- grained, and which specific features of the models were used during consultations could be identified. Commonly cited concepts in the literature such as 'collaborative' were split into explicit examples of those concepts, such as Everyone's contributions valued.

Event sampling was used as the absolute and relative frequency of events was of interest (Robson \& McCartan, 2015). A sequence record was also used to provide information as to the order in which the features were seen, thus providing information about transitions (Robson \& McCartan, 2015). Time sampling was not chosen so no events were missed because they fell outside of the time intervals. However, the length of time each feature occurred for was lost. Whilst this information would be valuable to see how long each feature lasted for, rather than just how frequently it occurred, it was decided that the risk of missing feature due to the researcher focusing on correctly marking the time of each feature outweighed the benefit of gaining that information.

\subsubsection{TME}

A TME form (Appendix D) was used to assess progress towards goals that were agreed by all those in the consultation. TME requires the participants to agree on 
SMART (Specific, Measurable, Achievable, Realistic and Time-bound) targets for the child related to any area of difficulty, for example difficulties with using number bonds up to 20. Using a 10-point Likert scale (Likert, 1932), the consultees judge where the child currently is for the chosen area. A ' $b$ ' for baseline is written next to that number. The consultees then predict where they believe the child or young person will be in 6-8-weeks' time. They write the letter 'e' for expected next to this number. After the specified period, consultees then judged how much progress the child or young person had made and indicated this by writing the letter 'a' next to the chosen number.

TME was chosen because it is designed to fit in with the consultation framework (Dunsmuir et al., 2009). Its streamlined nature allowed it to be incorporated into the observed consultations with minimal disruption to the flow of the consultation. This was valuable as the EPs observed did not use TME as a typical step in their practice currently, although they had in the past. Therefore, to preserve the integrity of the observation, as little disruption by the research as possible was sought. TME is a simple method to identify change for CYP towards agreed goals and produces a single number. This can then be included in the analysis of the identified features and what combinations are present when change is judged to have occurred.

An issue with TME is that it is used as a tool to assess the efficacy of consultation, but many events occur between the baseline and actual rating. Many of these events will not be because of the consultation and the implementation of interventions agreed in the consultation will typical not be orchestrated by the EP 
(Gutkin \& Curtis, 1999), so how much progress can be attributed to the consultation is unknown.

The reliability and validity of TME are also in question. Dunsmuir et al. (2009) state that the reliability of GAS has been demonstrated, for example Kaplan \& Smith (1977). Dunsmuir et al. (2009) assume validity of TME if the goals align with the recommendations from Cardillo \& Choate (1994). However, reliability and validity cannot be transferred from one measure to another, even if the latter is derived from the former (Flake et al., 2017). Researchers have also cautioned against using single-item measures for constructs (Diamantopoulos et al., 2012). There have also been recent analyses of the validity of GAS which judged that there is "insufficient information to assess the validity of GAS" (Gaasterland et al., 2016, p. 19). Therefore, the suitability of TME to measure progress is called into question. However, it was judged to be suitable because it allows the specification of goals to the needs of individual participants. However, the strength of the conclusions drawn on the effect consultation has on progress towards the goals was reduced because of the concerns around validity and reliability.

\subsection{Procedure}

Prior to data collection, it was decided the quantitative arm would be conducted first, starting in March 2020 and continuing until March 2021. Interviews would be conducted in the autumn of 2020. Thus, a concurrent triangulation design was planned (Creswell \& Creswell, 2003). Both the quantitative and qualitative arms of the research would be conducted simultaneously and independently. The results were to be compared to see whether the conclusions drawn align with one 
another. This was done for practical rather than philosophically informed reasons. It was agreed beforehand that collecting observation data would be more difficult, as finding consultations with all the required participants who were also willing to be observed is unlikely. It was therefore felt that having a longer window of opportunity to collect data was the reasonable course of action.

However, due to the COVID-19 pandemic, all in person consultations were cancelled across the UK to comply with the government-mandated lockdown (Cabinet Office, 2020). Whilst many EPs offered consultations to their respective schools, most found they delivered far fewer consultations during the lockdown than usual. Those who delivered consultations typically did so via telephone, eliminating any chance of observation by the researcher. In response, data collection for the interviews was brought forward to start in March 2020 and observations of consultations would occur once consultations could be observed by the researcher. The research was therefore adapted to use a sequential transformative design (Creswell \& Creswell, 2003). This type of mixed methodology involves one method preceding the other. Either the qualitative or the quantitative arm of the research project is conducted first. The methodology does not require one be used before the other, so practical reasons may determine the order of research. The results from both strands are interpreted together, with one informing the other.

\subsubsection{Interviews}

Interviews were originally planned to be in person with EPs in the researcher's EPS. However, because of the global pandemic, all non-essential in person 
meetings were banned. They were therefore switched to video or phone call interviews. This necessitated a choice in video call technology. Because of the increased familiarity of the public, ease of use, and improved security features (Zoom, 2020), Zoom was judged to be appropriate for the purposes of this research. Because of the sudden increase in proficiency and willingness of many EPs to use phone and video call technology, the parameters of the participant recruitment for the interviews were widened to all EPs. This decision was made because of a desire to increase the number of participants and thus the range of views on consultation. Informed consent was gained prior to participation (see Appendix E).

Semi-structured focused interviews were used to elicit EP views with regards to the core features of consultation, the features of an effective consultation, the barriers to effective consultation, and what is the unique contribution of consultation. Participants were interviewed using a mixture of phone and video call technology. Data collection took place between 31/03/2020 and 28/05/2020. All interviews were recorded with an Honor 10 lite phone, and an anonymous transcript made.

\subsubsection{Observation}

Observations were conducted between 20/11/2020 and 14/01/2021. After gaining informed consent from all participants, the researcher observed the consultation unfold as normal. The researcher used the observation schedule to mark when and how frequently different features occurred. As each feature was observed during the observation, a 1 was written in the corresponding column of the 
observation schedule. This would continue sequentially, with only one feature being recorded in each column until the conclusion of the consultation. The features were then summed.

At the end of the consultation, the participants (EP, class teacher, and/or parent) were asked to collectively identify 1-3 goals for the child or young person. This was done using a TME form which the EP introduced the participants to. Goals were suggested by the consultees or by the EP (if the consultee was unable to think of a suitable goal). It was then agreed by all participants. Participants rated, on a scale of $1-10$, where the child or young person currently was towards that goal (by writing the letter ' $B$ ' for 'baseline' next to the number) and where they expected them to be in 6-8 weeks (by writing the letter ' $E$ ' by the number). In 6-8 weeks' time, participants would be contacted by the researcher via email to rate how far along the child or young person had progressed towards that goal. This judgement was represented by the letter ' $A$ ' (for 'actual') along the same rating scale.

After six weeks had passed, contact was made via email with the consultees. This was because it was judged to be sufficient time for the participants to respond within the 8-week window recommended by TME (Connor, 2010). All consultees responded within 8 weeks. For all but child 4 , this period fell over the Christmas holidays. The upper limit was therefore chosen to give the children as great a time as possible in school receiving support. A second national lockdown was announced prior to the start of the spring term 2021. All children except child 3 remained in school during this lockdown. 


\subsection{Piloting methods}

To ensure rigour in the methodologies employed, each method was piloted prior to data collection. This was to check that the interview questions were understandable and suitable and that the observation schedule categories were discrete and easily interpretable.

\subsubsection{Interview schedule}

The interview was piloted with a Trainee Educational Psychologist to check for flow and whether the interviewees understood the questions. The TEP commented on the definition of "components" in question 5. The word was changed to "features" and a clarification statement developed to be provided in the interviewees, along with a definition if required.

\subsubsection{Observation schedule}

To establish inter-rater reliability (IRR), an anonymous transcript of a previously recorded consultation was analysed for features using the observation schedule. Three raters, including the researcher, assessed the transcript for features of consultations sequentially. Intraclass correlations (Shrout \& Fleiss, 1979) were calculated between the three raters. The relative frequency of each category was calculated for each rater and compared with one coder's (the researchers) results. Because frequency counts were used, intraclass correlations (ICC) were suitable as the data is continuous. To calculate ICC, four factors must be decided upon prior to calculation (Hallgren, 2012). A two-way model was used because the raters weren't randomly selected from the population. Given that a non-timed sequence record design was chosen for the observation schedule, good IRR was defined as consistency in the ratings because it was more important that raters 
provide scores that are similar in rank order. A single measures ICC was calculated because the reliability of the other two raters needed to generalise to ratings of one coder (the researcher). And finally, a mixed model was used because whilst the findings want to be generalised to wider population, the raters were not randomly chosen from a population and thus cannot be treated as random. This model was applied using the irr package (Gamer et al., 2019) in the statistical programming language $R(R$ Core Team, 2017). This produced an ICC of 0.471 which, according to guidelines provided by Cicchetti (1994) are 'fair.'

\subsection{Data analysis}

This chapter will detail the process of analysing both the qualitative and quantitative data, including steps taken. A critique, with reference to the relevant literature, of these methods will also be provided.

\subsubsection{Interviews}

The interviews were thematically analysed to explore RQ1 and its sub-RQs. Braun \& Clarke (2006) identify 6 stages to the process of TA: familiarizing yourself with your data; generating initial codes; searching for themes; reviewing themes; defining and naming themes; and producing the report. Codes were instances of features of consultation discussed by the participants as this was the first step in 'data reduction' (Miles \& Huberman, 1994) by organising it into meaningful groups (Tuckett, 2005).

\subsubsection{TA process}

The anonymous transcripts were thematically analysed using the software NVivo 12, a qualitative data analysis tool. This was done through uploading the 
transcripts as text documents into the software. A mixed or hybrid TA approach (Fereday \& Muir-Cochrane, 2006) was employed. This incorporates inductive and deductive TA. Inductive TA is driven primarily by the data (Boyatzis, 1998) and deductive TA is theory-driven with codes derived from said theory (Crabtree \& Miller, 1992). In NVivo, utterances by the participants were highlighted and a deductive code was selected, an inductive code was generated, or an inductive code was selected. As such, the TA was "guided, but not confined, by the [deductive] codes" (Fereday \& Muir-Cochrane, 2006, p. 88). The a priori codes identified were developed from the scientific and Local Offer literature. Inductive codes were either classed as 'features' of consultation or 'what makes these features of consultation effective.' For the features of consultation, inductive codes were either words used by the interviewees that related to features of consultation that they believed were effective or were features that shared a common idea. One such example is "exploration" and "different perspectives" having the core idea of discussing a topic from a variety of angles and gaining 'Different views.' For 'what makes these features of consultation effective,' these inductive codes were derived from interviewee utterances relating to why they believed certain features of consultation were effective.

To check the accuracy of codes and split previously identified inductive codes into more fine-grained codes, the second stage in TA was repeated three times. This iterative process forms a key part of TA (Rice \& Ezzy, 1999) and should be methodological to ensure rigour (Attride-Stirling, 2001). During the TA process, transcripts were regularly checked against the recordings to ensure accuracy. 
A thematic map of codes was created using TikZiT, an open-source project for creating diagrams (Kissinger, 2019). This was to visually represent all the codes and aid in the generation of themes. Boyatzis (1998) defines a theme as a pattern contained within one's data which summarises the observations through description. This helps to interpret the explored phenomenon. Semantic themes (that which is explicitly said) were found and analysed (Boyatzis, 1998) with interpretation of their significance and implications (Patton, 1990). TA identified 32 inductive codes, as well as the 15 deductive codes, relating to what features EPs believed were effective for consultation. 6 codes were identified for what made said features effective (see Appendix F for the definitions of the inductive codes, Appendix $G$ for the definitions of the codes relating to what makes the features effective, and Appendix $\mathrm{H}$ for the breakdown of the number of interviews which each code was identified in and the total number of codes for each feature). These were combined to create 8 themes: Buy-in, Conditions, Context, Strengths-based, Shared understanding, Intervention, Future facing, and EP skills and knowledge. These could then be combined to create two overarching themes: Internal factors (features relating to the factors endemic to a consultation) and External factors (features relating to things happening around a consultation).

There was no direct correspondence between the deductive and inductive codes of the features of consultation to what makes those features effective. This us because many interviewees talked in more general terms as to why consultation was effective, rather than limiting their focus to the discussion of specific features. Examples of thids include "collaborative" and "clarity" rather than specific observable features. However, some links can be made between them (see 
Appendix I) and the codes relating to 'what makes the features of consultation effective.'

\subsubsection{Critique of TA}

TA was chosen because it is flexible since it is not bound to a phenomenological epistemology, such as methods like Interpretative Phenomenological Analysis (Smith \& Osborn, 2003). Nor does it limit one to only inductive code theme development and therefore the ignoring of previously identified theory, such as Grounded theory (Strauss \& Corbin, 1994). It is also described by Braun \& Clarke (2006) as being "accessible" to those with less experience in qualitative methods (p.81). Semantic themes were chosen because the focus of this research is on the features of consultation and how they relate to effecting change for the children or young people the consultations are about. Therefore, an analysis of the "underlying ideas, assumptions, and conceptualizations, and ideologies" (Braun \& Clarke, 2006, p. 84) was not deemed an appropriate level of analysis.

However, because of the reduced depth of analysis performed during TA, important themes and ideas could be missed. As it just describes the data, it arguably has "limited analytical and interpretative properties" (Eddleston, 2016, p. 91). This lack of depth gives TA its flexibility, but it runs the risk of being biased which undermines validity (Willig, 2008). To counter this, all the data was made publicly available to allow independent analysis and critique (Smith et al., 1986).

\subsubsection{Observations}

6 observations were conducted for 4 children. After the tabulation of features of consultation using the observation schedule, the number of features across each 
consultation was summed. Qualitative notes were made on the demeanour and enthusiasm of the consultees. The data from the TME forms for all goals was collected and a value of 'change' was calculated for each consultation. This was done by subtracting the 'baseline' rank from the 'actual' as research suggests most TME forms report a positive change because of the consultation (Dunsmuir et al., 2009; Monsen et al., 2009). To explore the relationship between the presence of features and reported change, Qualitative Comparison Analysis (QCA) was used, with the QCA package for R (Dușa, 2018). QCA allows the comparison of cases with the help of formal tools and with a specific conception of cases (Rihoux \& Lobe, 2009).

\subsubsection{QCA process}

The foundation of QCA involves the identification of cases, conditions, and an outcome. Each consultation forms a QCA case, the theoretically derived features of consultation are the conditions, and the difference between 'baseline' and 'actual' is the outcome. QCA involves the analysis of the frequency of different conditions to explore which combination of conditions (both presence and absence) led to a measured outcome variable.

QCA is based on Boolean algebra and set theory. Conditions are identified and can either be 'present' or 'absent' and sets are formed based on combinations of these conditions being present or absent. QCA flattens the data according to theoretically derived thresholds so combinations of conditions can be compared. The final step of QCA is Boolean minimisation where complex expressions of conditions which produce the same outcome are reduced to simpler expressions. 


\subsubsection{Crisp-set QCA}

Crisp-set QCA (Ragin, 1987) was used as the features were mutually exclusive and bivalent; they could be classed as either 'present' or 'absent.' After establishing the outcome and conditions, Marx \& Dusa (2011) give the following stages for crisp-set QCA:

1. Convert the outcome and conditions into binary conditions.

2. Code each case for each condition separately.

3. Check the truth table for contradictory configurations.

4. Analyse the model and interpret after deriving parsimonious solutions.

Given this framework, the raw scores were then calibrated so the conditions were either classed as 'present' or 'absent' for each case (Dușa, 2018). The threshold was defined as the mean, which is one method suggested by Thiem \& Duşa (2013) when plotting the data does not provide clear thresholds or there is not a theoretical justification for a threshold. Therefore, cases where the number of observations of the condition was greater than the mean were classed as 'present.' Cases where the number of observations of the condition was less than the mean were classed as 'absent.' Any condition which does not vary at all (either it is always present or absent) was excluded as it is a constant (Rihoux \& Ragin, 2009). This creates a dichotomous data table (Rihoux \& Ragin, 2009) which can be non-formally analysed to explore patterns of conditions relating to the presence of the outcome.

After this calibration, a truth table is created to systematically examine the combinations of different causal conditions to the presence or absence of the 
outcome (Balodi, 2016). A truth table represents all the possible combinations of causal conditions seen in the data. Each row is a distinct configuration and may contain one or more case. Configurations can be classed as "1" (present), "0" (absent), or "contradictory." Contradictory configurations (where the same configuration of conditions leads to different outcomes) must be resolved prior to Boolean minimisation. This is typically done by changing the sufficiency inclusion cut-off point for the truth table to allow more combinations of features, such that there aren't any contradictory configurations (Dușa, 2018). Sufficiency for inclusion is also calculated, which gives a score as to whether the combination is sufficient for the outcome.

To establish whether a configuration can be combined, Boolean minimisation is used. This can be summarised as: "if two Boolean expressions differ in only one causal condition yet produce the same outcome, then the causal condition that distinguishes the two expressions can be considered irrelevant and can be removed to create a simpler, combined expression" (Ragin, 1987, p. 93). This therefore provides the simplest combination of conditions from the data which lead to the outcome.

\subsubsection{Critique of QCA}

QCA is characterised as a "many variables, small N" approach (Lijphart, 1975, p. 159) because it is used when there are few cases but many potential causal variables. This makes it suitable to analyse the potential causal features in relation to change because there are a small number of observed consultations but a lot of variables (features). QCA also does not require the researcher to specify a single 
causal model, as is typical with most statistical techniques. Rather, it allows the identification of "the number and character of the different causal models that exist among comparable cases" (Ragin, 1987, p. 167).

QCA also allows for "multiple conjunctural causation" (Rihoux \& Lobe, 2009, p. 3) as different combinations of factors can produce the same result. It can also reveal causal asymmetry (configurations with the presence and absence of the same condition leading to the presence of the outcome). Necessary and sufficient conditions can be identified, as well as core and peripheral conditions (Rihoux \& Lobe, 2009). 


\section{Results}

The subsequent chapter summarises the results from the two arms of the thesis. The layout will follow the structure of the RQs, with the interview data presented first to explore what interviewees believe are the effective features of consultation. The observation data will then be presented to gain an understanding of what features are seen in consultations, which consultations saw change for the CYP, and which features were necessary or sufficient for the observed change.

\subsection{Interviews}

The thematic map of codes and features (see Figure 1) was derived from analysing the codes for similarities around their nature to give themes (Braun \& Clarke, 2006). For example, the essence of codes such as 'collaborative' and 'contributions valued' related to the consultees viewing the consultation as a good use of their time and believing that it would lead to change for CYP. This buy-in was linked to the outcomes and suggestions from the consultation being realistic, as consultees would be more likely to do what had been suggested and believe it would have a positive impact. By treating the consultee as an expert in their area of knowledge, this would help increase their buy-in to the process of consultation and be more willing to engage.

EP skills and knowledge was identified as many of the effective features of consultation were related to the EP having expert knowledge of viable solutions or through their understanding of psychological models. These all increased the efficacy of consultation. Through EP skill with regards to their expert knowledge and ability to ask questions, for example, consultation could be an efficient means to enact change. Consultation also allowed for EP skill to be shown by being a 
flexible model of working, such that EPs could a wide range of their skills and knowledge to help CYP.

Shared understanding was identified as these features all related to the gathering of different views to ensure everyone involved understood the situation. This was aided through the EP using clear language and documenting what had happened during a consultation.

Intervention as a theme related to the fact a consultation itself could be an intervention. By actively changing the perspectives of consultees in the consultation, change could follow from this. Consultation can also be a vehicle to support consultees emotionally and therefore help CYP through the emotional needs of core people in CYP's lives being met, meaning they are better able to support CYP. Consultation was also identified as being a part of the assessment process and as such is a form of intervention.

Strengths-based was identified as a theme as three codes directly related to building on the strengths of those involved and the child or young person. This was through upskilling the consultees and reminding them of the relevant attributes they already possess, as well as highlighting what was already going well for the child or young person and what strengths they have.

What follows is a more detailed description of each constituent code. 


\section{Figure 1}

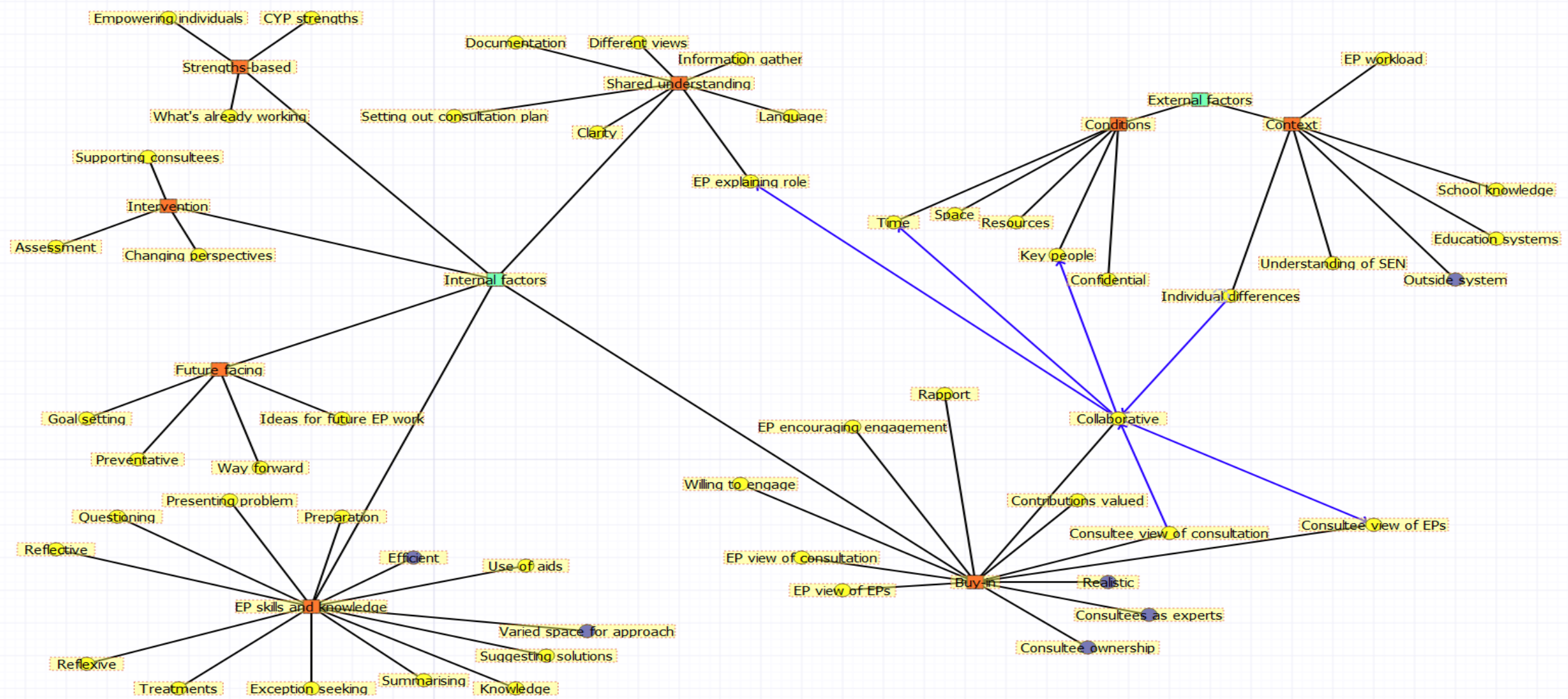

Figure 1: Thematic map

Note. Light blue square: over-arching theme, orange square: theme, yellow circle: feature of consultation code, dark blue circle: what makes the feature effective code, black line = connection from code to theme to over-arching theme, blue line = connection between code (with arrow pointing to direction of influence). 


\subsubsection{Buy-in}

This theme related to the importance of EPs creating a bond with those involved, including the consultee(s) and other school staff members not directly involved in the consultation, and using this relationship to facilitate change.

\subsubsection{Collaborative}

One of the fundamental and most oft cited features for creating buy-in was making consultation collaborative. Within the consultation, this was achieved through a variety of factors. One of the key ones was making sure there was equal participation, such that everyone had a voice and different perspectives were heard: "effective consultation shouldn't being a meeting where one person dominates, whether that may be a psychologist or anyone else" (Interview 11) and “it's like we're all involved, we're all at the same level, we just come at it from a different perspective" (Interview 7).

If there is equal participation, there is a greater chance that everyone involved has the same understanding of the situation and the child or young person: "to bring everyone together, and to co-create and co-construct a shared narrative" (Interview 11). Misunderstandings can be cleared up (Interview 5) and this helps everyone feel involved in the process and ensure that the consultation is collaborative. The creation of a shared narrative can also include the creation of a shared agenda. This helps guide the consultation so it is more effective as it is meeting the needs of those involved and everyone agrees to it: "I think a really fundamentally important part of that consultation is ensuring that we do have that shared agenda; we know why we're there together and we all agree what we're doing there together" (Interview 24) and "to arrive at a joint action plan, joint for the 
school and the parents, school are always involved as well, so it's more collaborative" (Interview 10).

This shared agenda can be established by identifying what everyone is hoping to get from the consultation:

...it would always start with a question about what are your best hopes from our meeting together? What are your best hopes from our work together? Because if we don't start with that question... then we don't know where we're trying to get to. (Interview 27)

By working collaboratively with those involved, EPs can facilitate collaboration between the home and school. This can potentially support both by helping maintain morale and creating a sense of shared responsibility:

...there is something that goes on often, not always, in the room when you've got the family, and school together, the, you do you do bring that sense of, 'We are working on this together; you are not alone school in this, you are not alone parents in this, we are doing this together.' (Interview 5)

\subsubsection{Contributions valued}

A related code, and one which can facilitate a collaborative consultation, is the idea that everyone who is present in the consultation should feel able to contribute. Not only this, but they need to believe that what they say will be taken on board: 
...where I would like to think that their views, their knowledge, their understanding is just as valid as mine... we are equal participants in this. (Interview 13)

...equal participation... as far as possible, or that everybody participates and that everybody feels valued, everybody feels that what they had to say is useful. (Interview 20)

This can help give power to those who may not typically have it in the school environment, thus helping create a more level playing field and therefore a more collaborative consultation: "schools are by nature very hierarchical. So if you've got a TA they're often not seen as the same as... a SENCO or a head teacher's views but in that situation they are." (Interview 1)

\subsubsection{Encouraging engagement}

Removing power dynamics within a consultation was seen by many participants as an important part of the EPs role within consultation. This formed part of the code 'EP encouraging engagement.' The EP must try and create a space so no consultee feels intimidated and in which all relevant people can contribute, even if they cannot physically be present:

...the psychologist trying to level power dynamics is a really key, a really key part of any consultation and that... that's in relation to ourselves, as a professional with a doctorate normally, but also in relation to the family and the teacher, or the family and the school. (Interview 2) 
...balance of people's voices in the rooms. So... making time for those that might not be able to be present in the meeting to hear their views and voices. (Interview 27)

This code related to any effort by the EP to attempt to include the voices of the relevant parties. One of the ways that this is is achieved is through "active listening" (Interview 1). A key idea related to the EP facilitating others to participate:

I'm there to help facilitate the group in thinking about ways forward. (Interview 15)

...giving a space where people can listen to other people's perspectives, then you take away the bulk of what it is that you're... using to try and make a difference. (Interview 21)

Not only does the EP need to facilitate others, but also challenge potentially harmful narratives and navigate difficult situations:

Being careful and being prepared to challenge. (Interview 25) ...sometimes a... mediation role because... we work in complex and messy situations. And it's not always that people are going to agree, or even really want to hear what they have to say. So there's that... control in the, the floor that happens in a consultation, which doesn't happen in other types of conversation. (Interview 3)

Being able to read body language was identified by a few EPs as being important for facilitating engagement: 
you try to do an online meeting, you lose the gesticulations, you lose... being able to point at things or being able to... look at their faces better and realise, 'Oh, they're not understanding, I need to change the way I'm explaining it' or something. I think you lose so much because it's that non-verbal feedback that you get, that allows you to know where you are at with the relationship, to know the way you can develop within that consultation. (Interview 24)

However, this was not universal. A few EPs found that using technologically mediated (tech) consultations did not lead to a decrease in quality of the relationship. One EP experienced her consultees asking for telephone consultations and that these were effective (Interview 16).

\subsubsection{Rapport}

The difference between in-person and tech consultations relates to another core feature, which is the development of a rapport with those involved in consultations. Within the consultation, an EP must quickly develop a rapport so that the consultees feel comfortable talking about potentially difficult topics:

...trust and credibility and shared mutual respect, I think are at the core of any consultation. You know, they value what I offer because I'm in touch and the fact they get on well with me, that almost therapeutic relationship. (Interview 7)

...built up that trust and sense of safety, that it's okay to express their worries, that you can get quite a lot of information. (Interview 10) 
The EP needs to not only develop a rapport with those involved but encourage relationships between consultees: "building attuned interactions in a meeting with parents, with teachers, and then hopefully between them as well. It just kind of gets everyone on the same page, hopefully gets everyone pointing in the right direction" (Interview 30). This is especially important when relationships between the home and school have broken down: "sometimes you have a breakdown between parents and the school... you can be a person in between, and try and get that working through that... which is... a key feature of consultation. (Interview 4)

Several EPs talked about the importance of having a good relationship with the school. A good relationship between the school (generally understood to mean at least the SENCOs and potentially Senior Leadership Team) helps consultation to be more effective: "If it's going to be successful model in a school, I think the need is... time for the EP to build a relationship with the school is important. (Interview 23). The reason the relationship is crucial for improving consultation is that when the EP has developed a good relationship with the school and they are mutually supporting one another, it is easier to create an environment which fosters collaboration:

...when you know the school especially, and they're supporting you in supporting the parents and the staff to do that, then you see it a lot more". (Interview 1)

...schools are often hesitant to adopt consultation as the main method of EP work: some of the SEN schools that I work with have a very rigid way 
of seeing the EP role and what we do, and they're, they're view is, more often than not, my role as an EP is to go in, do an assessment, write a report, and that's it... so in those instances, I find it much harder to sell consultation as a, as a model. (Interview 11)

However, several EPs spoke of using their relationship with the school to change how they approach EP work and what the EP can do in the school:

...once you build a relationship with schools, and you've been working in it, you can shift things, you can move things around, to... working with a bit more control, > getting them to see how... it can be more effective, working with consultation, not doing just lots of assessments. (Interview 4)

That's how you change it. I think that the relationship is super important. (Interview 23)

\subsubsection{EP view of consultation and Consultee view of consultation} An important feature of consultation that relates to rapport is the understanding that the consultees, EP, and school have towards consultation. The conception EPs and consultees have of consultation impacts on whether they buy-in to the process. If they do not see consultation as a collaborative process, they are less likely to engage with it in an effective way and believe it is a good use of their time. How the EP and consultees view consultation can have a large impact on a consultation and its efficacy. A belief shared by many interviewees was that "both parties... know how consultation works" (Interview 24) and this "might depend on people's constructs of what consultation is" (Interview 29). Interviewees had an 
overwhelmingly positive view of consultation, highlighting its versatility and alignment with their values:

...consultation, I think, is a, is a framework with the complexity that matches the complexity of the concerns that are being raised... we're looking at concerns at an individual and a group and a systemic level. (Interview 21)

I don't think you can be inclusive without using a consultative model. (Interview 25)

Though many interviewees identified the value of consultation and the importance of clearly understanding it and what it involves, many also pointed out that there is a large heterogeneity of practice among EPs: "I think that concept of what a consultation is will vary from one EP to another" (Interview 24). There are also EPs who do not value it and prefer a more traditional style of assessing CYP and then writing a report. As one interviewee said: “I know there's a lot of EPs out there that continue to work in that way and I think, I think that's one of the barriers to shifting more to a consultation framework" (Interview 17). One interviewee, who had recently attended a course on consultation provided by their EPS, stated:

I'm not sure a lot of EPs really understand what it is. Being able to communicate that... even on that consultation course that I mentioned I went on, I was really surprised that people, people very open and very honest, and they said, 'We've been saying we've been using consultation, but we actually have not. We've realised now that we haven't really been using consultation.' (Interview 22) 
This makes it difficult for consultees to gain a clear understanding of what consultation is and has led a few EPs to call for clearer communication and "being better at communicating... what it is and what it can do" (Interview 22). One of the reasons it is important consultees understand what consultation means is so they can see the value in it. Many interviewees described how some of the schools they work in do not appreciate it fully:

...if I could click my fingers and change something on a systemic level, it would be the attitude toward consultation because I I really view them as an investment. If you invest in a consultation, you're going to get better work and and outcomes. Whereas, sometimes they can be viewed as an expensive hurdle you have to get over to get a standardised score. (Interview 2)

I think there are some schools that... have a negative view of consultation. Because of that. It's, it's more complex procedure I think, people realise. (Interview 10)

I think we need to educate our schools more about 'This is what the process is,' because we say in sales blurb 'We do a consultation' and... and then the schools are still stuck in that... old way of thinking. (Interview 28)

A recurring comment centred around the differences between primary and secondary schools, with primaries typically being more willing to engage with them: 
...most primary SENCOs are very open to whatever I suggest. And they're quite open to different ways of working, as long as they have a report to use as evidence... for EP involvement, so it has that element of of a tick box. But most primary schools are very open to different ways of looking, I would say, but secondaries definitely aren't. (Interview 18)

\subsubsection{EP view of EPs and Consultee view of EPs}

Another relevant strand to the different perceptions of consultations is how the consultees view EPs and their role. This relates to the theme of Buy-in because if both or either party view the EP as the expert who will fix the problem for the consultee, they will not buy-in to the collaborative nature of the consultation. This threatens the efficacy of the consultation. Several interviewees talked about how they were viewed as gatekeepers to resources or as someone who would fix the situation independently of any work by the consultees:

...the associations that staff or parents can have of us as being, kind of, the deciders of resources. So we will go in and we will say, and we will think we are there to support to think about what we can do for this child, and they will think we are coming in to say 'Yes you can have any EHCP [Education, Health, and Care Plan]' or 'Yes you can have extra money.' (Interview 1)

...if school are new to that way of working and they are used to having an EP come in and... tell them what to do. I do notice that sometimes there's a bit of confusion... especially from some teachers who are, 'Why are 
you asking me, aren't you supposed to tell me what I need to do?' (Interview 11)

The consultee view of EPs also affected how receptive a school is to consultation because "it very much comes down to the school's view of my role" (Interview 14). Several EPs talked about wanting to change the views of the consultees in the consultation.

How the consultees view the EP can be changed in the consultation itself: "You're modelling how psychologists think... they might think a psychologist is on a pedestal or whatever, but you're modelling that psychologists are like everybody else" (Interview 7). To help level this power dynamic, EPs often try to present themselves as not having a privileged position, as some interviewees talked about "not putting themselves in an expert position" (Interview 27). This is because "It's the process of discussion itself... that leads to, kind of, outcomes, rather than taking on an expert model." (Interview 14). However, a few EPs pushed back against the framing of the EPs non-expert stance as it can be counter-productive: "I think... sometimes EPs can go too far the other way in not being the expert... it's a little bit disingenuous, because sometimes we've got a lot of good ideas to offer" (Interview 27). How strongly they take on the role of the expert was independent of the importance of most EPs placed on being empathetic and supportive:

...you're in the situation as a human being, but also trying to be a psychologist as well, and they're quite difficult to do at the same time. (Interview 14) 
I think you need to be an ally, and a guide, but not be, 'I know what you should do and you should do this.' (Interview 23)

\subsubsection{Willing to engage}

A feature that almost two thirds of the interviewees identified was the willingness of the consultees to engage in the consultation process:

...the effectiveness is because of engagement, critical thinking process thinking, and then plan your own action plans, which you're also engaged in. (Interview 5)

....at the same time, to know that the reason that everyone is around the table for this consultation is to try and shift that thinking in some way. And usually... just by nature of showing up everybody does want that, even if they don't necessarily believe it to be possible, which is why I think those features of consultation are effective. (Interview 3)

...just general engagement from either the parents or school, and the willingness to, to change; the willingness to change their practice. (Interview 5)

\subsubsection{Consultee ownership}

Several interviewees talked about how these features are effective because they help create a sense of consultee ownership of the situation. By being collaborative, the consultees are more likely to buy into the process of consultation and are therefore more likely to feel they can be an active agent in supporting the child or young person: 
...when people are active participants in a process, any process, they would be more likely to follow through with what has been agreed in terms of, whether that would be actions, whether that would be a specific approach that needs to be put in place. (Interview 11) ...they retain some sense of ownership and some... sense of responsibility for putting in place what comes next. (Interview 20) ...the point of that conversation is to leave something behind for the people who actually have power to do things and if you don't have the ir buy-in, then it's totally pointless. I'm struggling to think of a method, outside of consultation, where you could get that buy in and that information share and get to any kind of meaningful endpoint. (Interview 3)

\subsubsection{Realistic}

Another commonly discussed mechanism for effective consultations was the increased chance of realistic recommendations and outcomes being established. If the ideas generated are more co-constructed and built on shared knowledge, they are more likely to be feasible:

...it also allows for reality, so if you've... hopefully you're not getting ideas or strategies that are completely unworkable. So it should be based within the practice of the class teacher. So it isn't... somebody coming in and going, 'Well, you need to do this three times a day with... dah, dah, dah, dah, dah.' (Interview 21) 
...the feedback we get from parents that things are very grounded in reality, that the ideas that we're talking about makes sense because they come from a position of understanding and making sense of whatever is being brought into the room and... helping to manage some of the complexity. (Interview 27)

If these suggestions are created collaboratively, then the consultees are more likely to buy-in to the process of consultation and are more likely to put in place the recommendations:

I think if you have a really good consultation and you can actually problem solve together, and the people that you're consulting with, actually come up with some of the ideas, then it's much more likely for those interventions to happen. (Interview 20)

This greatly increases the chance of the consultation having a positive impact for CYP.

\subsubsection{Consultees as experts}

The final code from this theme relates to treating the consultees as experts of their own area:

I try to make it collaborative because... my stance is that we all bring our own expertise; they're experts as parents, they're experts on their child... and as teachers, they're experts on ... teaching that child and teaching in general. (Interview 8) 
I think they're effective because, we're capitalising on that idea that people are experts in their own lives. (Interview 22)

If the consultees are seen as having valuable knowledge to bring to the discussion, they are more likely to be an active participant in it. They are therefore more likely to buy-in to the consultation and fully engage with it, thus increasing the efficacy of the consultation.

\subsubsection{EP skills and knowledge}

The other most common theme related to the psychological knowledge and skills EPs need to use when engaging in consultation.

\subsubsection{Knowledge}

The most common code across all themes was in relation to the models of consultation and general psychological knowledge that the interviewees believed EPs needed to have to facilitate an effective consultation. The "use of theory and reference to the evidence base" (Interview 2) was identified as an important effective feature of consultation. Commonly discussed models and frameworks included being solution-focused (Interview 1), person-centred (Interview 16), trauma and attachment informed (Interview 13), and using Wagner's model of consultation (Interview 17) and the COMOIRA model (Interview 25). Other specific psychological areas included using principles from Narrative Therapy (Interview 17), an ecosystemic model (Interview 2), social constructivism (Interview 6), as well as psychologies such as positive psychology (Interview 9). Some interviewees saw their role as "sharing... and disseminating psychological theory" 
(Interview 18) and that consultation "helped [them] really use psychology with [their] schools" (Interview 11).

The use of a model was often spoken positively as "[giving] the consultation a structure" (Interview 11) and for one interviewee they were the most important part:

...for me, the models of psychology are the number one priority, they have to be systemic and interactionist so that all behaviour is seen as a function of the person and the situation. So that if a concern is being described, we want to be looking at finding out about what was happening at the time or when it was happening. (Interview 27)

The problem-analysis framework was named by one interviewee as their main model of working (Interview 3). The core step of planning and implementing interventions was mentioned by eight interviewees. One of the key stages of Solution-focused approaches (suggesting solutions) was explicitly mentioned by 11 interviewees and another key step (exception seeking) was discussed by five.

\subsubsection{Presenting problem}

Many EPs mentioned specific features within different models. One such feature was exploring the presenting problem from the problem-analysis framework (Monsen et al., 1998):

...getting an idea of what their main concerns are because when it feels very big, it's really the problem feels very big, the issue with the child is very messy. There's a lot going on, it can be hard to know where to start. 
So focusing them down is something that I do where I'm like 'What's your main concern?' (Interview 8)

This code also involved "further clarification around the difficulties" (Interview 11) and a discussion of "What are the conditions around it" (Interview 12).

\subsubsection{Interventions}

Another code relating to the problem-analysis framework was the discussion of interventions for CYP. This involved "planning recommendations" (Interview 2) and using the consultation "as a space where we can really drill down into exactly what you mean when you say 'A social skills group'” (Interview 2) as you can decide what the intervention is specifically for.

\subsubsection{Suggesting solutions}

Another frequently mentioned model was the Solution-focused model (Murphy, 1997). A key part of this model is suggesting solutions and several interviewees brought this idea up. These are typically recommendations "to be done at home and at school" (Interview 12) Several EPs stated they were happy to make recommendations but simultaneously did not want to dominate the consultation (Interview 11). The importance of taking on board what the consultees said was also voiced by a few interviewees so that the EP does not make recommendations that have already been tried (Interview 13).

\subsubsection{Exception seeking}

Another code relating to the Solution-focused model was the discussion of times when the main difficulty is reduced or absent: 
...building all those principles of, yes, psychology that we're trained with, and we're taught to use: exception seeking (Interview 24)

...finding out about other contexts when it was similar and other contexts when it was different, so that you're able to hypothesise about what's happening (Interview 27)

\subsubsection{Reflective}

A feature mentioned by almost all participants centred around the importance of being reflective. This included the use of "reflective listening" (Interview 1) and "[checking] back in with people... working with them just to understand, have they progressed on that journey" (Interview 16). Many interviewees brought up the importance of checking with the consultees "whether we did what we wanted to do, and if not, what still needs to be done?" (Interview 21).

The importance of being reflective was not limited to within the consultation; the structure of consultation itself should also incorporate reflection:

...it might be nice within models that we have with schools, if there's a definite agreement that there is follow up or a review, if it's not by me, if it's by someone in the school, because that, that, kind of, ensures that what's discussed in the consultation is actually... implemented and monitored. (Interview 14)

I also like to have a consultation as a feedback meeting at the end to... revisit what we've discussed in the first session, and obviously, by that time, I'll have gathered information from other sources to use that other 
information to further inform what is going to be done about the situation and to answer their referral question. (Interview 9)

This reflective structure extends to the gaining of feedback from consultees. The importance of feedback was mentioned by several interviewees, for example: "we have to treat it as a cyclical process which has to be reviewed and evaluated so that we can use that feedback to improve practices" (Interview 1). Learning from peers through observation and critical reflection with colleagues was also highlighted:

I would hope that I'm a reflective practitioner and also... having other people observe consultation, is really helpful in terms of trying to figure out, sometimes, what's going on, what made a difference. (Interview 21) ...peer supervision is really helpful in terms of... helping your practice because obviously, you've got all that shared... ideas and knowledge and bouncing off each other in the team. (Interview 9)

\subsubsection{Questioning}

The use of question was discussed by more than half the interviewees, using questions like "I wonder what would happen if?' 'What do you think might happen if?'” (Interview 25) to explore possibilities and develop understanding. More banausic questions are asked to explore a situation to gain a fuller understanding (Interview 5) as well as exploring the context (Interview 27). However, as the consultation progresses, questions can be used to get the consultees to think about what change would look like for the child or young person and how they could go about achieving it (Interview 8). Not only is the content of the questioning 
important, but the manner in which they are asked is a key factor "how EPs are asking those questions, and the types of questions they're asking and... the timing of those questions" (Interview 15).

\subsubsection{Use of aids}

A third of interviewees discussed types of supports that they use in their consultations. Tools based on person-centred psychology, such as Planning Alternative Tomorrows with Hope (PATH) and Making Action Plans (MAPs), was brought up by Interviewees 16 and 17. The use of metaphors was endorsed as means to safely explore difficult topics (Interview 12), as well as "the Japanese problem-solving fish" and "blob trees" (Interview 10).

\subsubsection{Preparation}

Several interviewees highlighted the importance of being prepared for a consultation, where the "psychologist pools all that information, formulates the hypothesis, types down what questions they want to ask" (Interview 20). This increases the chance of the consultation being effective:

I think doing really thoughtful preparation is essential to to effective consultation, and I think sometimes there just isn't time for that but but really spending some time to think about... what, what do we know? What what do I, what am I hoping to get out of this?" (Interview 13)

This preparation, of "being in the right headspace yourself" (Interview 13) extends to the consultees as them not being prepared can hamper the efficacy of a consultation: 
I think for a lot of the time, what limits my consultations is, they're just... caug- maybe a teacher is... caught on the cuff, they weren't really expecting me to meet them there... but there they are. So they haven't really had time to... gather their thoughts beforehand. (Interview 20)

\subsubsection{Reflexive}

Another important feature of an effective consultation was the EP being reflexive. This involves critically analysing, in the moment, "How's my body language affecting the person that l'm speaking with?' 'How did that question go down?' 'Was it understood?' Am I helping this person?'” (Interview 10). This process involves being "flexible and responsive" (Interview 21) and "adaptable" (Interview 30) which can be inhibited by the use of a consultation script (Interview 30). One interviewee discussed the importance of:

...being aware of what's going on in the discussion and what the function of the discussion might be for the consultee at any one time. For example, if the adult is clearly struggling with the child, they might be looking for empathy... and understanding, so very much giving that but recognising that that in itself won't necessarily move things on. So trying to be aware... of what the function of their use of language is at the time and what they're trying to elicit from me. (Interview 14)

Another interviewee discussed the importance of being sensitive to "anything that might be... difficult for potentially parents to talk about" (Interview 15). This process of being reflexive also helps prevent the EP "[imposing] my construct on the situation" (Interview 25). 


\subsubsection{Summarising}

Several EPs mentioned that summarising or paraphrasing (Interview 19) what has been said in a consultation is an important feature of consultation. This includes "re-speaking back to people what they've told you" (Interview 17) and "[giving] a summary of what I think I've heard from the different people" (Interview 5).

\subsubsection{Efficient}

The most frequently cited reason for consultation being effective was that it is an efficient way of practising. This includes the simple fact that "more children get to have EP input" (Interview 11) because it is possible to "talk about multiple students and put multiple things in place as a result of that [consultation]" (Interview 15). It is a tool to "gather information from different sources quickly" (Interview 2) which helps "generate, hopefully accurate as possible, hypotheses" (Interview 30). Consultation also can "effect change at a higher level and a greater level" (Interview 12) and there can be a "ripple effect... across policy level or across class or a group or even a whole school" (Interview 16). This means that "sometimes you might only need one or two consultation sessions to make some good change" (Interview 17).

\subsubsection{Varied space for approach}

Another key mechanism through which consultation is effective is its versatility. "Consultation is flexible" (Interview 21) and a "process that evolves all the time" (Interview 24). They allow for the use of "different strategies, different components" (Interview 10) to meet the needs of the consultees. Because consultation can be flexible, it can adapt to a situation and therefore have a greater chance of a positive impact: 
I think the logistics of a consultation can remain the same, but the impact of a consultation can really vary. And... I don't know how many other tools we have available that that's the case for. So, if I think about the logistics for doing the BAS, or the logistics for doing a CBT session, I think that you very quickly become constrained by the way they were set up, whereas, the logistics for a consultation, getting some people in a room for a certain amount of time, allows for a flexibility. So... sometimes halfway through a consultation, you'll discover a piece of information that is crucial and up until now completely unknown, and you can change tack. (Interview 2)

\subsubsection{Shared understanding}

This theme centres around the importance and ways in which EPs create a common understanding of the situation between themselves and consultees.

\subsubsection{Different views}

Almost every interviewee brought up the importance of gaining the views of different people and "gaining multiple perspectives" (Interview 21). This includes "the voice of the child, voice of the family, voice of the teacher" (Interview 17). It is particularly important to bring the voice of the child or young person: "being quite child centred... bringing the pupil voice into that discussion... [as] it's often not appropriate to have the student in the room, especially if they're younger" (Interview 15). A few interviewees talked about the importance of gaining the views and including those with power in the system: 
I think in some ways, as well, in consultation, making sure trying to involve, at some stage or at some level, people within a school or organisation who hold power. So that might be a head or a deputy head. Just because they have a lot of power within that system, to reframe. (Interview 17)

...we are trying to become more active within the local authority as well. And I think that's very important. Because otherwise if you work as an EP service in isolation, without connects-strong connections with the senior leadership team within the local authority, and with the senior leadership team within the schools, nobody's gonna listen. (Interview 23)

Consultation also allows for the "understanding [of] different worlds views, different cultural... constructs" (Interview 17) and one interviewee stated, "when people start to tell stories of things, it gives you some quite good insights into how they think and where... they're stuck in their thinking" (Interview 12). By gaining different views from consultees, the EP is better placed to make informed hypotheses (Interview 20). When there is a disagreement between home and school, consultation is an effective vehicle to "bring that... discrepancy into the room and discuss it and see if we can come up with it with a kind of compromise or a way forward that... meets the needs of both parties, and particularly for the student as well" (Interview 15).

\subsubsection{Information gathering}

A related code was the EP gathering information not directly related to the main concern: "I find a lot out about the child, their background, and... about the parents 
or family and what's going went around them" (Interview 8). This included "[gathering] information from across the four areas of SEND" (Interview 2). This helps "inform [their] assessment" (Interview 9). However, a number of interviewees made the point that consultation is much more than simply gathering information: 'the word 'consultation' might sometimes be interchangeably used with, actually, what's really an information gathering process" (Interview 24).

\subsubsection{Clarity}

Over half the interviewees talked about the importance of gaining clarity in a variety of ways. This included for "what the process might look like" (Interview 20) as well as "clarifying what people are saying, what the parent is saying, what the SENCO is saying, what the class teacher is saying" (Interview 4). This done in the service of "understanding the situation better and exploring and understanding it better" (Interview 5). This allows for the EP to draw these strands together and "come to some kind of conceptualisation towards the end" (Interview 5).

\subsubsection{Setting out consultation plan}

The establishing, by the EP, of the general structure for the consultation was cited by more than half the interviewees as an important feature of consultation. This was often done by exploring with all those involved "what we're hoping to get from the meeting, from the consultation" (Interview 24) because this "gives it a clear direction... [a] frame, [a] boundary" (Interview 14). It also helps "[manages] everyone's expectations" (Interview 14) and allows those involved to know if they have achieved what they wanted to achieve within the consultation (Interview 13). 


\subsubsection{Language}

Several interviewees brought up the importance of the language used within a consultation. This had two main strands: potential language difficulties due to English as a second language and the use of jargon by the professional. One of the barriers to effective consultation is "lack of English language, from parents. It's not always possible to have a translator... and even if you do... there are barriers... it's difficult going through a third person. You have no idea... how accurately they're translating" (Interview 5). The other facet related to the technical language that is pervades psychology and how this is understood by the consultees:

It takes a much higher level of skill to have a meaningful consultation with somebody who does not have... the privilege of having... lots of education, and... [a] big vocabulary and high level of verbal skill, than it does... for us to sit around in a team surrounded by people who are educated to doctorate level... But when you really need to try and get meaningful information in a respectful way from from somebody who finds language very hard, that's... a whole... nother level of professional skill. (Interview 3)

\subsubsection{Documentation}

Documentation refers to the making of notes and summarising the contents of the consultation. One EP stated it was "[their] least favourite part of the job... But unfortunately, it's really important, because I think you've got an opportunity to write down and, kind of, what they call a narrative, like rescue the words" (Interview 17). Another expressed more uniformly negative views towards 
documentation: "what... will make consultations: not having to flippin' write them up afterwards, we'd get twice as many done... I don't understand why l'm writing about, the magic happens in the room" (Interview 22). However, others were more positive: "I think the written record is helpful of a consultation" (Interview 5) as it gives another opportunity to give advice at a later date (Interview 30).

\subsubsection{EP explaining role}

A small number of interviewees stated that making sure the consultees understand what their role is within the consultation is important: "try and clarify what my role is and what it isn't" (Interview 14). This included "[explaining] [their] involvement" (Interview 14) and, to help this process, one interviewee talked about "[doing] role of the EP insets, which we would offer every year, that talks about consultation and the model of psychology and what's going to happen in the meeting" (Interview 27).

\subsubsection{Intervention}

Another theme which arose was the value of consultation as an intervention in and of itself. This was done through three mechanisms: providing a space for the EP to change consultees perceptions; emotionally supporting consultees, and consultation being part of the assessment process.

\subsubsection{Changing perspectives}

One of the main ways in which interviewees talked about changing perspectives was around "extending the thought processes of the people involved" (Interview 10). A common idea among the interviewees was that the consultation "facilitates that process of developing new meaning and new knowledge around a young 
person, or whatever the issue might be... reframing the way that people see it, which I think is a key element of change within consultation" (Interview 17). The EP should also help others "not [think] about a problem within a child, but [think] about a young person and how they interact with the environment that they are in" (Interview 13).

This change can also happen at a policy level, as one interviewee stated that consultation was the best vehicle to help schools become more inclusive (Interview 23). Consultation can also be used to help realign people's priorities and view towards those involved. Because of the highly pressurised nature of the systems we work in, "family, and school can quite often fall out of sync and having a conversation together reminds everyone, they're on the same team" (Interview 2).

This perspective change was not limited to the consultees views towards the CYP or situation; it extended to their views of consultation itself. One interviewee talked about how for "[their] schools, once they were introduced to [consultation], and once they tried it, they really liked it" and they could appreciate that "consultation is a good model" (Interview 11)

\subsubsection{Supporting consultees}

Another point many EPs made was that consultations can often be used to help emotionally contain and provide support for the consultees: ...there is also something about consultation with schools that I find that can be emotionally containing for staff who perhaps are highly distressed (Interview 13). These "therapeutic benefits" (Interview 2) in a "therapeutic style of meeting" (Interview 
22) often come through high levels of "acceptance and empathy" (Interview 13) because often consultees want to "communicate with someone... how challenging it is for them" (Interview 17). However, this was an area in which a few EPs judged that tech consultations were less effective as "not being able to be physically there, as the sounding board, as their containing person... I couldn't be that... in a virtual environment" (Interview 17)

\subsubsection{Assessment}

A few interviewees saw the consultation as "part of the assessment process" (Interview 3) and as a "powerful way to carry out assessment" (Interview 19). This is because consultation can "[lay] the foundation for an application for an EHCP assessment" (Interview 2).

\subsubsection{Strengths-based}

Another emergent theme centred around the focus of consultation: it being strengths-based as it focuses on bringing out the skills of the consultees, highlighting what work is already having a positive impact for the child or young person, and discussing the positive qualities of the child or young person.

\subsubsection{Empowering individuals}

One of the key features of an effective consultation is "helping people to identify their own resources" (Interview 10) and "activate better existing skills and knowledge and competence" (Interview 13)

\subsubsection{What's already working}

One aspect which was frequently discussed was the exploration of what was already working for the child or young person. Interviewees talked about "[trying] 
to build more of a strengths-based and positive outlook, and look at what's working well, to shift things on" (Interview 22) and "trying to find what has been tried, what has worked" (Interview 28).

\subsubsection{CYP strengths}

The exploration of the strengths and positive qualities of CYP was also mentioned by several interviewees, such as: "it's exploring skills and competencies alongside the problem" (Interview 27). A common idea was the consultations help reinvigorate the consultees and using the skills they already have:

“... building on what they potentially knew, but didn't really know what to do with it and... empowering and recognising that they were potentially able to sort out themselves." (Interview 19)

“... a decent consultation... can help them feel empowered and perhaps a little bit reinfused about what their role could be." (Interview 13)

A related idea was the empowering of those the consultees engage with, as a "rising tide lifts all boats, in the sense that the person to whom I can give the consultation will very often generalise the advice from one case to another, from one session to another, from... one class to another" (Interview 7)

\subsubsection{Future facing}

The final theme of the super code Internal factors focused on the idea of the consultation as helping to give a path forward for the consultees. This included the creation of goals for the child or young person and the nature of consultation helping to prevent problems for other CYP in the future. 


\subsubsection{Way forward}

Over a third of the interviewees talked about how the nature of an effective consultation gives consultees a structure for how to move forward in supporting CYP: "it provides a mechanism to think about the future and to move forwards" (Interview 15). Through consultation, the EP can "elicit change or move people forward in a positive way" (Interview 22) as well as identify the relevant support for CYP (Interview 5). This is different from identifying specific goals for CYP as consultations aren't "always about solution finding because ways forwards aren't always solutions" (Interview 3).

\subsubsection{Goal setting}

For almost a third of interviewees, the identification of outcomes for CYP to work towards is an important feature of consultation:

“... for it to be consultation, I think there needs to be a clear, focus on finding, even if it's not a solution, but on coming up with a plan and... having a clear goal in mind." (Interview 11)

“... [a] key component is goal setting, actually, and thinking about futures, and what the next steps would be." (Interview 17)

However, one interviewee argued that not identifying clear goals does not "necessarily make it an ineffective consultation" (Interview 3).

\subsubsection{Preventative}

Because of the emphasis on upskilling consultees within consultations, an EP using consultation can help prevent issues arising with other CYP within the school: 
"when you're working with a teacher or with families or with different staff, actually the learning might be, the focus might be around a specific child, but actually that learning and that reframing can then be taken and be used preventatively with other young people or in the classroom" (Interview 17)

By using consultations in different ways, such as regular features of school life, "they would become more preventative" (Interview 14).

\subsubsection{Ideas for future EP work}

A few interviewees brought up the importance of using consultations to talk about and negotiate future EP involvement regarding the child or young person (Interview 24). This might include an observation of them in class (Interview 4).

\subsubsection{Conditions}

The first theme of the super code External factors related to the conditions of the consultations, including who was involved, how much time was set aside for the consultation, and the space in which it was held.

\subsubsection{Key people}

Almost every interviewee cited having "all the key stakeholders" (Interview 11) involved in the consultation as a key aspect. Consultation was widely regarded as an "indirect service method" (Interview 17) so involved working with a range of people, including "the SENCO, the class teacher, and both the mum and dad of that child" (Interview 11). Many interviewees state that it was crucial to have "the person that has most knowledge about the child" (Interview 10) or the "people who are most concerned" (Interview 21). This included the person who "has the most 
influence" (Interview 14) as they will be the person who will implement the agreed interventions.

A number of interviewees highlighted the importance of bringing the voice of the child or young person into the consultation, either by actively involving them in the consultation (Interview 21) or through those that know them well (Interview 15).

Many interviewees identified difficulties with conducting consultations in secondary schools:

...if you've got multiple people working with a young person, and actually the more people you have, the less anybody feels any responsibility for them... you're trying to find that person who is most concerned and actually they don't exist. (Interview 13)

...it's very difficult to get parents, teachers, parents and teachers around the same table, at the same time. (Interview 18)

\subsubsection{Time}

Over two thirds of the interviewees brought up time as an important part of a consultation. This mainly took the form of interviewees stating that the biggest barrier to effective consultations was a lack of time within the consultation, for example: “I don't think you can have, say an, effective 20-minute consultation. It's not a consultation" (Interview 26). This is because you need time for those involved to move beyond the "black and white way of thinking" about labels (Interview 18). 
A related issue centred around the amount of time bought in by schools. Because the majority of interviewees either worked for fully traded services or as private EPs, the schools they worked with only had a limited amount of contact time. This led to several interviewees discussing the difficulty of bringing about change with schools because of the time limits placed on them (Interview 12).

This was an area where tech consultations provided an advantage, as EPs can save time by not travelling between different schools (Interviews 13, 17, \& 29).

\subsubsection{Resources}

Resources was often cited important feature to consultations. This had several dimensions, including the ability of the consultees to enact change for CYP due to resource constraints:

The biggest barrier I come across is people saying, 'Well, that's lovely and I think we've come up with some fabulous ideas. However, I don't think management will let me do that'... So top-down squashing... it's budgetary, it's time-bound, it's people saying, 'Well, we don't have the physical resources to be able to do that.' (Interview 16)

... we might have all the ideas in the world around how someone might be supported. And it doesn't, I guess, affect the consultation in itself so much but it affects, it does affect the type of dialogue we might have around, schools and just the lack in, the workforce, the lack in staff, they're lacking the resourcing to really support some of these young people in the way that we would like them to be. I think that shapes consultations. (Interview 17) 
Another dimension is the resources school have to allow staff the time off from lessons to fully engage with a consultation: "schools thinking 'We don't have the time and the capacity to free up staff to come and, come and sit and have a consultation'” (Interview 15).

A third dimension related to the resources available to the schools to buy in EP time:

... I've certainly got schools that repeatedly say to me that they would love more EP time but they can't afford it in a traded environment and lots of... competing things that they have to spend money on. (Interview 21)

\subsubsection{Space}

A number of interviewees identified the importance of creating a space for effective consultations to occur. This encompassed both the physical space of the location and the mental space to be able to deal with complex experiences:

... sometimes people have asked to do consultations in rooms where there are other people and it's just messy. (Interview 2)

I think the room that you meet in is quite important and the way that it's set up... so... it doesn't seem like an interview situation. (Interview 9)

This aspect is particularly important for tech consultations as these almost always occur in the EP's and consultee's home:

... it can be difficult for staff to really, and parents, to really engage with the process, if they've got children running around and things going on. 
So... doing it where they can't have a separate space, emotionally as well as physically, can be tricky. (Interview 14)

... having to make sure that doors are secure, so children can't run in at particular points. (Interview 24)

\subsubsection{Confidential}

Several interviewees brought up the importance of confidentiality for what was discussed in the consultation: "we want to have a confidential place to reflect" (Interview 22). This helps "contribute towards building that kind of environment where people feel happy to share" (Interview 15). The importance of confidentiality was made more important for many interviewees by the unexpected transition to tech consultations in response to the COVID-19 pandemic, with several identifying issues around security, for example: "the first step is finding an effective platform that's got enough safety features for us to be able to... carry out a consultation" (Interview 10).

\subsubsection{Context}

The second code within the External factors overarching theme was related to the general context that consultations are conducted within.

\subsubsection{Education systems}

EPs work within many systems. These can all impact on individual consultations and on how EPs work through consultation. For example, "there are schools who don't particularly value [consultation] and just want us to do assessments" (Interview 5). As one interviewee stated, "all the work of the EPs is determined by the context in which it's set and by the organisational agendas in which it's set" 
(Interview 10). Several interviewees talked about the bureaucracy of the education system impacting on consultations and EP work as a whole:

...[the] role of the EP is less problem solving, it's more ticking a box, more bureaucratic exercise rather than a solving facilitation. (Interview 10)

...there is a bureaucracy around an education, health care plan, in terms of certain reports being written, certain hurdles being gone through and certain assessments taking place. And so... we're not doing any thinking, we're merely following a bureaucratic process. (Interview 6)

Other wider systemic issues related to how society as a whole sees additional needs:

...the medical model is so predominant... And I often find that those explanations for, learning and development and behaviours, can dominate conversations... ADHD, ASD ... they are definitely a barrier to creating more effective, positive change. (Interview 17) ...there's enormous pressure, ever increasing pressure on schools, to get results. And... [that's] antithetical to consultation. (Interview 25)

A number of EPs identified operating in traded services as a barrier to consultation:

...I feel like it's the situation in which we work, the whole traded model, which means that consultation is, an addition... we just have to do it to 
get the information. It's not... valued as... a way of working in and of itself. (Interview 8)

...I find within a traded service, you're quite constricted, in lots of ways about what the school expect in terms of the use of your time. (Interview 9)

...I feel like... particularly in the traded service model, that dynamic is really hard to manage. And... it's been a real difficulty to introduce consultation as a working modelling in many of my schools. (Interview 11)

Another issue that was identified was the views that school staff had towards change because of the people with more power in the system: "SENCOs feeling unable to make change because of the head teacher" (Interview 23).

\subsubsection{Individual differences}

Almost five sixths of the interviewees brought up the characteristics of those involved in the consultation as an important feature of a consultation. The personalities, histories, and on the day mood of the consultees will likely impact on a consultation:

... that's going to play out in the room, in different ways, depending on the circumstances, the resilience of individuals, position, their own history, etc, etc. And will play out differently day to day, with the same people. (Interview 25)

... there are parents who just don't like coming into school, are barred from school... have such a difficult relationship with school that is not 
possible. Physically can't get there because of health issues or younger children. (Interview 5)

I think there's always going to be a level of... personality involved, that with some people, it is easier to... get that... feeling of engagement higher than it is with others... I think there is some variability, just because of human nature and the different personalities of the people that you meet. (Interview 12)

The personality of the EP was identified by a few interviewees as potentially impacting on a consultation, for example: "I think the personality of the individual EP can have a big impact" (Interview 24). EP confidence in their own skill and knowledge was also identified as an important feature (Interview 14).

This variability in the presentation of consultation was viewed as a potential negative for consultation; if a teacher or parent was told they had to attend a consultation they "wouldn't know what to expect because it would depend so much on the individual" (Interview 11) because "everybody has gone on their own and done totally different things" (Interview 23).

\subsubsection{Understanding of SEN}

A few interviewees stated that the way a school understands additional needs within an education context can have an impact on consultations. Some schools cleave to a more traditional 'within-child' understanding of additional needs, particularly secondary schools (Interview 14). As such, it is much harder to encourage these schools to adopt consultation as a way of working (Interview 11). 


\subsubsection{EP workload}

Almost a third of interviewees identified the amount of work EPs typically do as being a barrier to effective consultations. This was because the volume of work prohibits being able to fully engage with a case:

... when you are on the day job, and you are 24-7 doing EP stuff, and you have... a stupid amount of cases and a stupid amount of schools and you cannot think... you are running on... empty (Interview 23) ... you're so tired and stressed... you're not really thinking as well... you can't reflect on it and come up with different ideas and solutions because... you just have to get that written, get it sent off, and get on to the next thing. (Interview 9)

One interviewee identified the positive benefit of moving to tech consultations because "I have a lot more time in my day, which means that I actually have a lot more space to think about children and cases" (Interview 18).

\subsubsection{School knowledge}

A few interviewees stated that having "in depth knowledge of schools and how they work" (Interview 7), in particular secondary schools (Interview 22), helped their consultations be more effective. One interviewee explained that having good knowledge of the whole system differentiated EPs from clinical psychologists because EPs are "fluent... in that... understanding and situational context" (Interview 21). 


\subsubsection{Outside system}

Almost a third of interviewees stated that the EP working outside the school system helped their consultations be more effective. This was through a few mechanisms. The first related to the ability of an outside agent to ask potentially difficult questions:

I think being an external person helps... you are able to ask some of the questions of parents that school can't, you can also ask questions of school that parents [can't] and take on that more challenging aspects. (Interview 5)

The second related to the benefit of not becoming overly fixated on or held back by potential negative events and perspectives within the system:

... we have to get meta to the situation and not get too bogged down and immersed in the nitty gritty. So keeping meta and keeping perspective on it, I think is a skill that EPs can bring, that really helps. And that's the beauty of not working in the system, is the beauty of going in and out of schools. (Interview 27)

\subsection{Observations}

The quantitative half of the research involved the observing of 6 consultations with the features identified by the researcher. 10 goals were agreed across the consultations. Progress towards agreed goals were then calculated through TME forms and the relationship between the observation of features and progress was calculated using QCA. 


\subsubsection{Features}

Table 1 summarises the cumulative frequencies of each feature for each consultation. The most frequently observed feature was Understanding the presenting problem, followed by CYP strengths, and then Info gather. 3 features were observed on zero occasions (School knowledge, EP explaining role, and Planning/implementing interventions). Understanding the presenting problem was observed the most frequently in every consultation, often twice as frequently as the next most observed feature. CYP strengths was the next most frequently observed, followed by Information gathering. 

Table 1

Table 1: Summary of features by consultation

\begin{tabular}{|c|c|c|c|c|c|c|c|c|c|c|c|c|c|c|}
\hline $\begin{array}{l}\text { Consultatio } \\
n\end{array}$ & $\begin{array}{l}\text { Sc } \\
h \\
k n \\
w\end{array}$ & $\begin{array}{l}\text { Empw } \\
r \\
\text { indivi } \\
d\end{array}$ & $\begin{array}{l}\text { Idea } \\
\text { s } \\
\text { futur } \\
\text { e EP } \\
\text { work }\end{array}$ & $\begin{array}{l}\text { Set } \\
\text { out } \\
\text { pla } \\
n\end{array}$ & $\begin{array}{l}\text { EP } \\
\text { explai } \\
n \text { role }\end{array}$ & $\begin{array}{l}\text { EP } \\
\text { usin } \\
g \\
\text { exp } \\
\text { kno } \\
\text { wl }\end{array}$ & $\begin{array}{l}\text { Plan/impl } \\
\text { interventio } \\
\mathrm{n}\end{array}$ & $\begin{array}{l}\text { Sum } \\
\mathrm{m}\end{array}$ & $\begin{array}{l}\text { Unders } \\
\text { presen } \\
\text { proble } \\
\mathrm{m}\end{array}$ & $\begin{array}{l}\text { Everyone } \\
\text { s contrib } \\
\text { valued }\end{array}$ & $\begin{array}{l}\text { Discus } \\
\text { s what } \\
\text { alr } \\
\text { workin } \\
\mathrm{g}\end{array}$ & $\begin{array}{l}\text { CYP } \\
\text { strength } \\
\mathrm{s}\end{array}$ & $\begin{array}{l}\text { Sugges } \\
\mathrm{t} \\
\text { solution } \\
\mathrm{s}\end{array}$ & $\begin{array}{l}\text { Info } \\
\text { gathe } \\
r\end{array}$ \\
\hline $1(\mathrm{j})$ & 0 & 1 & 0 & 3 & 0 & 8 & 0 & 1 & 29 & 20 & 7 & 17 & 9 & 11 \\
\hline $3(p)$ & 0 & 0 & 4 & 5 & 0 & 8 & 0 & 10 & 46 & 8 & 8 & 7 & 0 & 7 \\
\hline $4(\mathrm{t})$ & 0 & 0 & 1 & 4 & 0 & 1 & 0 & 4 & 42 & 12 & 10 & 8 & 0 & 10 \\
\hline $4(p)$ & 0 & 0 & 10 & 6 & 0 & 10 & 0 & 11 & 18 & 5 & 5 & 5 & 8 & 5 \\
\hline
\end{tabular}

Note. Sch knw = School knowledge, Empwr individ = Empowering individuals, Ideas future EP work = Ideas for future EP work, Set out plan $=$ Setting out consultation plan, EP explain role $=$ EP explaining role, EP using exp knowl = EP using expert knowledge, Plan/impl 
intervention $=$ Planning/implementing interventions, Summ $=$ Summarising, Unders presen problem = Understanding presenting problem, Everyones contrib valued = Everyone's contributions valued, Discuss what alr working = Discussing what's already working 


\subsubsection{Qualitative description of consultations}

The first consultation was a joint home-school consultation with the child's teacher and parent. Both consultees were receptive from the beginning and engaged with the consultation. For the final 10 minutes, the parent had to leave to go and pick up another child. Whilst they were present in the consultation, their attention was diverted as they were driving. It was during this time that the goals for their child were agreed.

The second consultation was a teacher consultation for child 2. The teacher was engaged from the start of the consultation but was very stressed due to overwork and stated this during the consultation. When the topic of identifying goals for the child was brought up, they started crying. This was because of the perceived pressure of another metric (which they believed would show no progress for the child) and they had to be emotionally contained by the EP. After being supported, they were able to identify one goal for the child.

The next consultation was for the parent of child 2. They were attentive during the consultation and fully engaged for its entirety. With support from the EP, they identified three goals for their child.

The consultation for child 3 was a parent consultation. They gave their full attention to the consultation and was joined by their partner for the final 20 minutes, who also fully engaged. The parent identified one goal for their child.

The first consultation for child 4 was with the child's teacher. In this consultation, the EP used the Cognitive Abilities Profile (Deutsch \& Mohammed, 2009). This is a framework based on Dynamic Assessment (Feuerstein et al., 1995) which seeks 
to explore "identify patterns of cognitive strengths and difficulties and then jointly plan, intervene and systematically monitor progress" (Deutsch, 2021). The consultee was engaged throughout and at the conclusion of the consultation identified one goal for the child.

The second consultation for child 4 involved the child's parents. They gave their full attention, although one expressed frustration at having to repeatedly explain their child's needs to different professionals. They identified one goal for their child.

\subsubsection{TME data}

Ten goals were identified for the four CYP. Table 2 summarises the goals for each child and with whom the goals were created. It also shows what baseline rating was given, the expected value 6-8 weeks later, the actual rating, and the corresponding progress for the CYP. Appendix $J$ presents all TME ratings in a line graph (Wickham, 2016). There was one unit of reported change for six of the ten goals. One goal (from the parent of child 2) was judged to have made two units of progress since the baseline rating. Regarding the three goals which were judged to have not made progress, two were given by the parents of the children and one by the teacher.

In relation to goals between consultees for the same child, there was no consistency. Two goals were shared across both teacher and parent (child 1 and child 2). For child 1, the teacher stated they had progressed from a ' 3 ' to a ' 4 ' regarding their ability to accept play requests from other children. The parent of child 1 did not believe they had made progress over the 8 weeks, though they 
agreed with the baseline and expected rating. For child 2, the teacher judged they had not made progress regarding their ability to name their emotions without pausing for an extended period of time (remaining at ' 3 '). The parent stated that child 2 was at a ' 5 ' at baseline and had progressed to a ' 6 ' eight weeks later.

\subsubsection{Child 1}

The joint home-school consultation for child 1 identified two goals, with one being judged by both parent and teacher and one by only the teacher ${ }^{1}$. Child 1 was judged to be at a ' 3 ' for the baseline for all their goals. The expected change for the goals was two or three points greater. The actual progress after 8 weeks was judged by their teacher as being one for both goals. Their parent judged they had not made any progress on the identified goal.

\subsubsection{Child 2}

For child 2, there was a teacher consultation followed by a parent consultation. Their teacher identified one goal and rated them currently at a ' 3 ' and expected to rate them as a '7' in 6-8 weeks' time. 8 weeks later, their teacher rated that no progress had been made. Their parent identified three goals for them. They rated the baseline for two of the goals as ' 5 ' (one of which was the shared goal with the teacher) and one of them as ' 3 .' They expected to rate their child as ' 8 ' in 6-8 weeks' time for the goals with the baseline of ' 5 ' and at ' 5 ' for the goal with a baseline of ' 3 .' The actual progress was one for the shared goal, two for the second goal with a baseline of ' 5 ' and one for the goal with a baseline of ' 3 .'

\footnotetext{
1 The parent did not judge the second goal because they stated they did not understand what the goal meant.
} 


\subsubsection{Child 3}

Child 3 had only a parent consultation and one goal identified. They were given a baseline of ' 3 ' and were expected to be rated at a ' 4 .' 8 weeks later, the actual rating was a ' 3 ,' showing no progress.

\subsubsection{Child 4}

Child 4 had a teacher consultation and a parent consultation. One goal was identified for each, although they were different. The teacher gave the child a baseline of ' 2 ' and an expected rating of ' 4 .' 8 weeks later, they rated child 4 as a ' 3 ,' thus showing a change of one. The parents gave a rating of ' 3 ' for a distinct goal (emotion regulation) and an expected value of '5.' The actual rating given was '4,' also showing a change of one.

\section{Table 2}

Table 2: TME goals with ratings for baseline, expected, and actual

\begin{tabular}{llllllll} 
EP & Adult & Child & Goal & Baseline & Expected & Actual & Change \\
\hline 1 & Teacher & 1 & $\begin{array}{l}\text { Solving maths } \\
\text { problems up to } \\
10\end{array}$ & 3 & 6 & 4 & 1 \\
1 & Teacher & 1 & $\begin{array}{l}\text { Accept play } \\
\text { requests }\end{array}$ & 3 & 5 & 4 & 1 \\
1 & Parent & 1 & $\begin{array}{l}\text { Accept play } \\
\text { requests }\end{array}$ & 3 & 5 & 3 & 0 \\
2 & Teacher & 2 & $\begin{array}{l}\text { Not pausing } \\
\text { when naming } \\
\text { emotions }\end{array}$ & 3 & 7 & 3 & 0 \\
2 & Parent & 2 & $\begin{array}{l}\text { Not pausing } \\
\text { when naming } \\
\text { emotions }\end{array}$ & 5 & 8 & 6 & 1
\end{tabular}




\begin{tabular}{llllllll} 
EP & Adult & Child & Goal & Baseline & Expected & Actual & Change \\
\hline 2 & Parent & 2 & $\begin{array}{l}\text { Joining sounds } \\
\text { up and reading } \\
\text { unfamiliar words }\end{array}$ & 5 & 8 & 7 & 2 \\
2 & Parent & 2 & $\begin{array}{l}\text { Using phoneme } \\
\text { knowledge for }\end{array}$ & 3 & 5 & 4 & 1 \\
2 & Parent & 3 & $\begin{array}{l}\text { unfamiliar words } \\
\text { Maintaining a } \\
\text { conversation }\end{array}$ & 3 & 4 & 3 & 0 \\
2 & Teacher & 4 & $\begin{array}{l}\text { Learning self- } \\
\text { esteem }\end{array}$ & 2 & 4 & 3 & 1 \\
2 & Parent & 4 & $\begin{array}{l}\text { Managing } \\
\text { frustration when } \\
\text { instructed }\end{array}$ & 3 & 5 & 4 & 1
\end{tabular}

\subsubsection{QCA}

To gain a deeper understanding of which combination of conditions lead to change, crisp-set QCA was performed for each goal. Therefore, the results from consultations with more than one goal were duplicated to allow analysis for the individual goals. The first step of QCA necessitated the flattening of the data so the features and change were either classed as 'present' or 'absent,' The mean was used as the threshold as there was no theoretically justified threshold. Features which were not observed once were removed.

\subsubsection{Calibration}

Table 3 shows the calibrated table of features. After calibration, EP using expert knowledge was the most frequently occurring feature. Suggesting solutions and Information gathering were the next most observed features. For the parent consultation of child 2, because the number of times each feature was seen was below the mean, no features were classed as present. However, change was 
judged to have occurred for each goal. For the other goals which recorded change, three contained EP using expert knowledge, Suggesting solutions, and Information gathering. Two contained Empowering individuals, Setting out the consultation plan, Everyone's contributions valued, and CYP strengths. 
Table 3

Table 3: Calibrated table of features by change for each goal

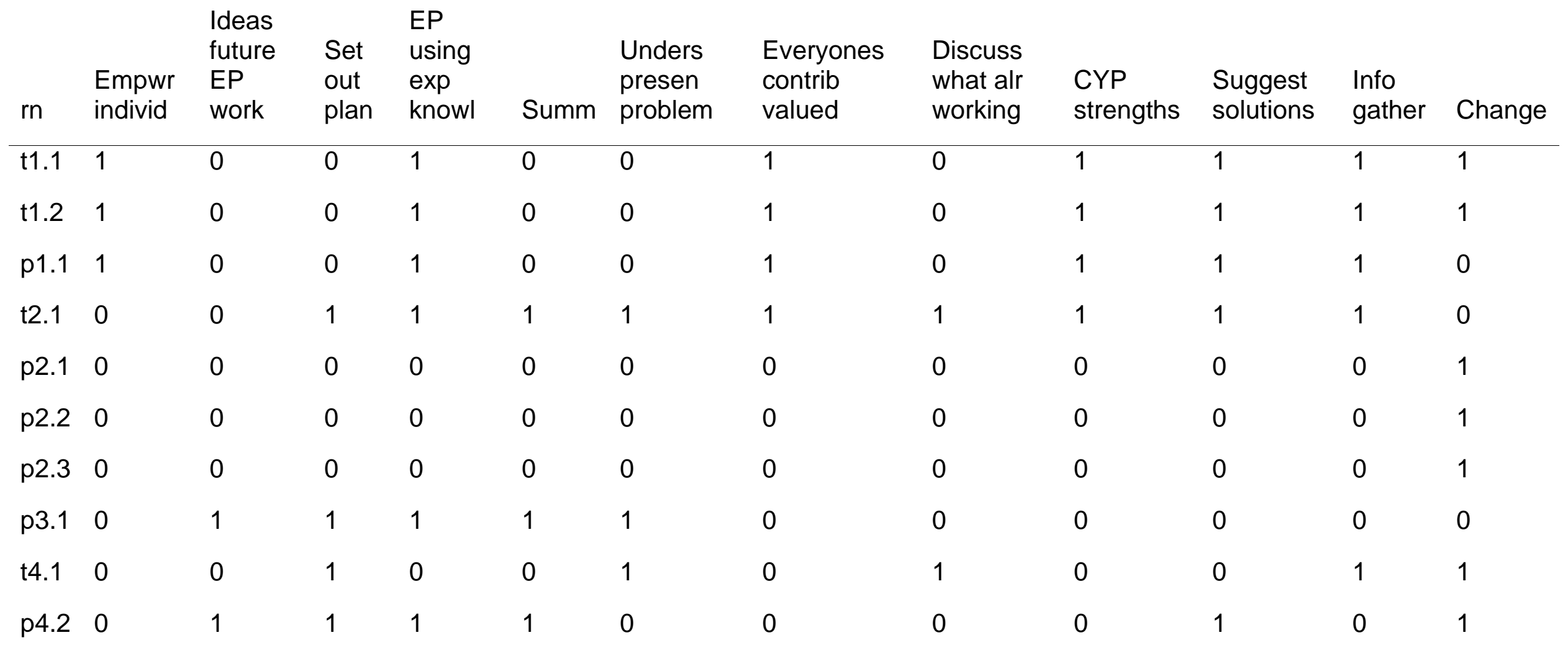




\subsubsection{Truth table and Boolean minimisation}

To further reduce the complexity of the data, the calibrated table was converted into a truth table where cases with either identical conditions or cases with one condition different were collapsed. This produced Table 4. Table 4 shows the combination of different conditions, whether change was observed or not (Outcome), the number of cases which this combination corresponds to (n), the sufficiency inclusion score (incl), and the cases which are included within this combination (cases). There were no contradictory configurations. The sufficiency inclusion score of 1 indicates that this combination of features is necessary and sufficient for change. The score of 0.66 suggests this combination is not as strongly necessary or sufficient for change (as only two of the three cases or $66 \%$ saw change).

Boolean minimisation was then performed on the truth table to demonstrate the simplest combination of conditions which were sufficient for change to be observed. This led to three combinations (see Appendix $\mathrm{K}$ for breakdown of the combinations and the cases they correspond to).

The first combination of features which was sufficient for change was the absence of Empowering individuals, the absence of Ideas for future EP work, the presence of Setting out the consultation plan, the absence of the EP using expert knowledge, the absence of summarising what has previously been said, the presence of Understanding the presenting problem, the absence of Everyone's contributions valued, the presence of Discussing what already works, the absence of CYP strengths, the absence of Suggesting solutions, and the presence of Information gathering. This corresponded to the teacher consultation for child 4 . 
This suggests that the EP establishing the consultation plan at the beginning of the consultation is important for helping bring about positive change for the CYP. During the consultation, exploration of the presenting problem and what is already working for the CYP, as well as the EP gathering more information about a range of topics, is sufficient for change to be seen. It also suggests that the EP not valuing the contributions of those involved or not empowering individuals does not prohibit change. This is also true for the EP using their expert knowledge or suggesting solutions, as the absence of these features were also calculated as being sufficient for change.

The second combination sufficient for CYP change corresponded to the parent consultation for child 4 . Said combination of features was: the absence of Empowering individuals, the presence of Ideas for future EP work, the presence of Setting out the consultation plan, the presence of the EP using expert knowledge, the presence of Summarising, the absence of Understanding the presenting problem, the absence of Everyone's contributions valued, the absence of Discussing what already works, the absence of CYP strengths, the presence of Suggesting solutions, and the absence of Information gathering. This again suggests that establishing the plan for the consultation at the beginning of the consultation is a valuable feature. Over the course of the consultation, discussing potential ideas for work the EP can do in the future is an important feature. The EP using their expert knowledge, as well as summarising what has been said by the consultees and suggesting solutions for the presenting problem were sufficient for change. This combination also suggests that the EP not empowering individuals or valuing everyone's contributions did not stop progress from being recorded. A lack 
of discussion of what was already working and the strengths of the CYP, as well as exploration of the presenting problem, did not impede positive change being observed for the CYP.

The third and final combination, which came from the parent consultation for child 2 , was the absence of all features. This result was seen because the calibration of the features. Given that this consultation had a relative low number of recorded features, calibration led to it being classed as having no features present. 
Table 4

Table 4: Truth table of features by change for each goal

\begin{tabular}{|c|c|c|c|c|c|c|c|c|c|c|c|c|c|c|}
\hline $\begin{array}{l}\text { Empower } \\
\text { individ }\end{array}$ & $\begin{array}{l}\text { Ideas } \\
\text { fut } \\
\text { EP } \\
\text { work }\end{array}$ & $\begin{array}{l}\text { Set } \\
\text { out } \\
\text { plan }\end{array}$ & $\begin{array}{l}\text { EP } \\
\text { using } \\
\text { expert } \\
\text { knowl }\end{array}$ & Summ & $\begin{array}{l}\text { Unders } \\
\text { presen } \\
\text { problem }\end{array}$ & $\begin{array}{l}\text { Everyone } \\
\text { contrib } \\
\text { valued }\end{array}$ & $\begin{array}{l}\text { Discuss } \\
\text { what alr } \\
\text { working }\end{array}$ & $\begin{array}{l}\text { CYP } \\
\text { strengths }\end{array}$ & $\begin{array}{l}\text { Suggest } \\
\text { solution }\end{array}$ & $\begin{array}{l}\text { Info } \\
\text { gather }\end{array}$ & Outcome & $n$ & incl & cases \\
\hline 0 & 0 & 0 & 0 & 0 & 0 & 0 & 0 & 0 & 0 & 0 & 1 & 3 & 1.0000000 & $5,6,7$ \\
\hline 0 & 0 & 1 & 0 & 0 & 1 & 0 & 1 & 0 & 0 & 1 & 1 & 1 & 1.0000000 & 9 \\
\hline 0 & 0 & 1 & 1 & 1 & 1 & 1 & 1 & 1 & 1 & 1 & 0 & 1 & 0.0000000 & 4 \\
\hline 0 & 1 & 1 & 1 & 1 & 0 & 0 & 0 & 0 & 1 & 0 & 1 & 1 & 1.0000000 & 10 \\
\hline 0 & 1 & 1 & 1 & 1 & 1 & 0 & 0 & 0 & 0 & 0 & 0 & 1 & 0.0000000 & 8 \\
\hline 1 & 0 & 0 & 1 & 0 & 0 & 1 & 0 & 1 & 1 & 1 & 0 & 3 & 0.6666667 & $1,2,3$ \\
\hline
\end{tabular}

Note . Empower individ = Empowering individuals, Ideas fut EP work = Ideas for future EP work, Set out plan = Setting out consultation plan, EP using expert knowl = EP using expert knowledge, Summ = Summarising, Unders presen problem = Understanding presenting problem, Everyone contrib valued = Everyone's contributions valued, Discuss what alr working = Discussing what's already working 


\section{Discussion}

This chapter explores the findings from this piece of research with regards to the research questions, with links to the extant literature. The aim of this study was to gain insight into the core features of an effective consultation. This was done through interviews and observations of real-world consultations (combined with statistical analysis of theoretically derived features). To evaluate this aim, the RQs in relation to the results were explored, followed by a critical analysis of the research. Implications for the EP field are discussed and suggestions for future work informed by this research are provided. Researcher reflections on the process and conclusions are also detailed.

\subsection{Discussion of findings}

This section identifies the RQs and details the relevant strands of the results to allow analysis of them. Due to the large wealth of data, it is not within the scope of this thesis to provide exhaustive analysis of each code. Given this, key codes and ideas are drawn out and analysed.

\subsubsection{What are the core features of an effective consultation?}

To answer this $R Q$, it was divided into three sub-RQs which allowed analysis of this question in finer detail. This was done through interviews and the explicit views of EPs.

\subsubsection{What do EPs believe are the key features of an effective consultation?}

The 8 themes regarding the core features of consultation encapsulate a very broad range of aspects of consultation that a number of EPs (of varying levels of experience) believe are important for making consultation effective. The most 
frequently identified themes were Buy-in and EP skills and knowledge. There was a large disparity between the number of inductive and deductive codes. There was also a difference between the number of instances for each type of code, with the inductive codes being recorded more frequently than deductive codes. This suggests that the current literature does not accurately reflect EP's beliefs about effective consultation.

\subsection{Buy-in}

Buy-in referred to all the participants of the consultation, including the EP, believing that consultation is an effective method for enacting change for the child or young person in question. Believing that this was a valuable use of their time and that it could help the child or young person was believed by many interviewees to be essential for an effective consultation. Without this buy-in, consultees would not be willing to engage with the process or change anything as a result of the consultation. And if nothing changed, it is unlikely the situation would improve for the child or young person, and it is even less likely the EP could have a positive impact through consultation (Noell \& Gansle, 2014).

This buy-in could be established at two time points: prior to the consultation and during the consultation. Before the consultation, the consultees view of consultation had a large impact on whether they valued the process. If they understood what it was (via explanation or training) and believed that it could help, then the chances of the consultation having a positive impact improved. If they understood that they were an active member of the consultation and did not look to the EP as the expert who would fix the problem for them, then they could buy-in 
to the process and an effective consultation was more likely to occur. Hasselbusch \& Penman (2008) found that consultants being perceived as the expert was felt to have a limiting impact on the efficacy of the consultation and many participants shared this view. Buy-in was also facilitated by the EP not viewing themselves as the expert who was there to tell the consultees what they needed to do to solve the problem. Thus, prior to the consultation, buy-in for both the consultees and EP could be established through these mechanisms.

During the consultation, buy-in by those involved could be facilitated by the EP. By being collaborative and actively involving the consultees in the consultation, the EP could encourage their buy-in to the process. By giving the consultees the opportunity to voice their opinions and concerns and listening to them, this helped the consultees feel valued and an active participant in the process (Benn et al., 2008). Consultee voice has been identified as crucial for effective consultation (Newman et al., 2017) and these results further substantiate this idea. These all served to help create a rapport between the EP and consultees. This relationship was one of the most important features of an effective consultation, as without a trusting relationship between consultees and the EP, consultation cannot be an effective vehicle for change (Meyers et al., 2014). Rapport also formed the foundation for many of the ways consultation helped consultees, such as through changing consultee perspectives. This buy-in also greatly increases the chance of solutions being implemented, which is one of the main mechanisms through which consultation creates positive change (Meyers et al., 2014). 


\subsection{EP skills and knowledge}

This theme related to all the ways that EPs use the knowledge gained over the course of their training and professional practice. It has been argued that "[possessing] expert knowledge and skills in the field of educational psychology theory and practice is one of, if not the, most important requirement for effective consultation (Farrell \& Woods, 2015). This is reflected in the results, as every interviewee mentioned at least one example of expert knowledge they used in their practice. In addition, many explicitly talked about the importance of this knowledge for effective consultation.

Specific examples of this knowledge included core models of consultation, such as Patsy Wagner's model of consultation, as well as Monsen's Problem-analysis framework. Meyers et al. (2014) argue that effective consultation requires steps such as "problem definition" and other core parts of the Monsen framework. Several interviewees cited the Problem-analysis framework as their primary model and a core part of an effective consultation. However, few interviewees stated they strictly held to any one model. Many stated they used different elements from different models as and when appropriate. This paints a picture of consultation, as used by EPs, as an assortment of different skills and knowledge rather than strict adherence to one method. To date, there has been no examination of the efficacy between consultations when there is strict adherence to the model versus a more eclectic mix. It is therefore unknown whether this approach to consultation is as effective as strictly using a consultation model.

Another common model of consultation, Solution-focused approaches, was frequently mentioned and several EPs gave specific examples of tools they use, 
such as the miracle question and looking for exceptions. However, these individual tools were mentioned less frequently than references to the whole model. There is therefore potential uncertainty as to whether interviewees who state they use solution-focused approaches do so in the same way. As such, there will likely be a lack of consistency around the practice, making it harder to evaluate its efficacy. Exception seeking, a fundamental aspect of solution-focused approaches, was only explicitly mentioned by five interviewees. Due to the lack of strict adherence to any model, it is uncertain whether the interviewees therefore use this crucial solution-focused tool. The efficacy of consultation is therefore threatened and consultee confidence in the EP employing evidence-based practices is undermined.

This was the only code to be cited by every EP yet seems to run counter to the often-presented argument "I am not the expert." This may represent an epistemic conflict between EPs desire to not be placed in a position of power for fear of undermining consultee engagement, but also recognising the need to have expert knowledge to be able to lead an effective consultation. One of the reasons it was believed to be essential for effective consultation was because many believed it formed the bedrock of how the EP leads a consultation. This knowledge also helps provide a structure for the consultation, thus making it more effective (Wagner, 2008). This is because a structure can help keep the consultation focused on a single concern which can be tackled (Newman et al., 2017).

The ability to ask difficult questions and to know what questions to ask to move a situation forward were frequently given as a key feature of effective consultation. 
These questions, developed through training and experience, help identify the presenting problem and limits to this, as well as areas where they need more information (Hylander, 2017). By thoroughly preparing for the consultation, for example having questions prepared in advance, the efficacy of it can be increased. This is because it is easier to know what questions to ask and to keep to the structure. However, as some interviewees argued, keeping to the structure should not come at the expense of listening to the concerns of the consultees and being flexible to their needs. Without this, consultees risk feeling devalued and thus disengaging (Slonski-Fowler \& Truscott, 2004). This presents another difficulty for EPs who wish to use consultation effectively. Whilst this psychological knowledge is viewed as essential for effective consultation, it can undermine this method by being too rigid.

Being a reflective practitioner is often cited in the literature as a core component of being an EP, for example Sander et al. (2016), and many interviewees stated the importance of this feature. This reflectivity included personal reflection on one's own practice to aid professional development but also the seeking of feedback from the consultees. By engaging in these practices, interviewees believed one's consultations were more likely to be effective and help the consultees and CYP move forward. This critical analysis was not limited to after the consultation; being reflexive and critically analysing what one was doing in the consultation and how it was being received was believed to be an important feature of consultation. This reflects many articles advocating for the importance of reflexivity when working in education contexts (Bruno et al., 2011). However, this in the moment reflection 
was mentioned far fewer times than reflective and by almost a third of the number of interviewees who talked about reflection.

\subsection{Intervention}

One of the main mechanisms by which consultation could impact on the consultees (and by extension CYP) is through changing the perspectives of the consultees. This can be towards the situation, the child or young person, or consultation itself. Engendering more positive views of the child or young person has been cited as a key feature of consultation (Massé et al., 2013) and almost all interviewees highlighted the importance of this active component of effective consultation.

Providing emotional or therapeutic support to the consultees has been identified as another key part of effective consultation (Newman et al., 2017). When consultees are highly distressed or anxious, they are unlikely to be able to engage in consultation. Thus, emotionally containing them and bringing them to an emotional space where they are able to engage with the process of consultation is important. Atkinson et al. (2011) found that EPs often use therapeutic interventions with consultation. However, as a few interviewees identified, often this emotional containment requires time. It is difficult to fully provide this support in a single consultation. As such, one-off consultations with consultees may be less effective because of the emotional needs of the consultees. To engage with the consultation, they need therapeutic support. But often there is not time to fully provide this. The EP must therefore decide to either prematurely move the consultation to discussion of potential solutions or forego said discussion in favour 
of emotionally supporting the consultees. Making such a decision would be very difficult and could undermine the efficacy of a consultation if made wrong.

\subsection{Context}

Understanding the school is often cited in the literature as being an important part of consultation, for example: "If consultants are not internal to the organization, it is critical that they obtain insider knowledge" (Knotek, 2012). But very few interviewees stated such knowledge was important for effective consultation. This could reflect the interviewee's perception that knowledge about the school system is not a feature of consultation but is a prerequisite for consultation or an example of background knowledge, rather than an explicit feature. However, it reveals another disparity between how EPs view consultation and the academic literature. Another disparity relates to the emphasis placed on the impact of the individual personalities of the people who engage in consultation. Almost all interviewees made some comment regarding the importance of the types of people who take part and how this can impact the efficacy of consultation. However, this is a rarely discussed aspect of consultation in the literature. This may reflect the pragmatic stance EPs take when reflecting on their own practice and how the personality of their consultees or colleagues impacts a consultation. It may also reflect the more theoretical or idealised standpoint that various academic studies approach the issue from.

\subsection{Strengths-based}

Empowering consultees was frequently cited by interviewees as being an important feature of effective consultations. By supporting consultees to develop 
their latent skills, they could be in a better position to support CYP by increasing professional self-efficacy (Knotek et al., 2002). However, there was only one recorded instance of empowering consultees in this manner. This suggests that whilst EPs may state that it is an important feature, it is less likely to feature in a consultation (even one that leads to change). This may be because helping consultees to realise their ability to already support CYP may be difficult to do in practice, especially if the consultee is highly disempowered (such as during the teacher consultation for child 2).

A small number of interviewees discussed the importance of highlighting the strengths of CYP. This may be because this aspect of Solution-focused approaches is assumed to be present when interviewees talk about being Solution-focused in their consultations (18 interviewees mentioned this model explicitly). But without explicit confirmation, it is unknown how many interviewees believe that this specific part of Solution-focused approaches is important for consultation. The discussing of CYP strengths was observed in every consultation and had the second highest mean number of recorded instances. This may be because it is a relatively easy feature to include, given it can be as simple as a verbal acknowledgement of something the child or young person is good at. This is in contrast with other features within the Strengths-based theme, such as empowering consultees.

\subsection{Shared understanding}

Almost every interviewee talked about the importance of bringing in as many different voices as possible. This included parents, the child, or other adults who 
knows the child or young person well. This is because "being able to identify the unique perspective of those with whom a consultant is working are essential elements of building rapport and relationships" (Sander et al., 2016). This is also a core feature of Wagner's model of consultation and shows that EPs explicitly adhere to parts of this model. Several EPs also discussed the importance of bringing in the voices of those who hold power within the system, such as headteachers. However, the sharing of such voices was not observed in the consultations. The first consultation was a joint home-school consultation and therefore the views of the parent and teacher were included. But there was no direct involvement of either the child (such as the parent or teacher asking the child prior to the consultation what they wanted) or those with power. This same pattern was observed for the other consultations which were either just parent(s) or teacher consultations. There is the potential therefore that whilst actively incorporating the voice of the child and those with power in the system is endorsed by EPs, they often do not clearly feature in consultations. This also raises questions as to how much EPs use Bronfenbrenner's ecosystemic model (Bronfenbrenner, 1995) or adhere to the requirements of a core piece of legislation (Department for Education, 2015). This has ramifications for the efficacy of consultation as what is thought of as a key feature is ostensibly missing.

The establishing of the general plan for the consultation is frequently given as a crucial first step in an effective consultation (Meyers, 2002). This is to manage expectations and establish a purpose for the consultation. This was a sentiment shared by just over half the interviewees who cited purposes including negotiating the purpose of the consultation and using questions to establish what consultees 
hope to achieve. This feature was seen in every consultation and there were fewer observations of it in consultations which did not record change. This offers tentative supportive for it being an important feature for having an effective consultation, although other factors may have a stronger impact (such as individual differences).

\subsubsection{What do EPs believe are the barriers to effective consultation?}

The barriers to effective consultation were examined because through the exploration of factors which undermine the efficacy of consultation, it will reveal what is needed for an effective consultation to occur. Two of the biggest barriers brought up by interviewees were not having the key people involved or not having sufficient time. For a consultation to be effective, the people who are in a position to change things need to be involved. If they are not, they are unlikely to buy-in to the proposed change and make sure it happens. The efficacy of the consultation is also reduced if one is trying to elucidate a situation and someone who knows the child or young person is not present. Therefore, having the key people as part of the consultation is essential for it to reach its full potential of providing clarity and changing the situation (through perspective change and identifying support strategies).

Time constraints was identified as one of the main barriers to effective consultation. Therefore, an effective consultation needs time. The minimum time limit for an effective consultation was judged to be 30 minutes, although most interviewees preferred to have 45 minutes to one hour. This meant that the consultees did not feel rushed through the process, which undermines the efficacy 
of consultation (Webster et al., 2003). Having time also ensures that consultees could be properly supported emotionally before exploring solutions. Time has also been found to be essential for consultee empowerment and learning (D. M. Truscott \& Truscott, 2004). A lack of time has also been found to decrease the consultee's sense of ownership for the solutions (Babinski \& Rogers, 1998), which is one of the main mechanisms through which the features of consultation are effective (see section 5.1.1.3).

A perennial barrier to effective consultation is a lack of resources from the school. If the school does not have the resources to implement any of the devised solutions, it is unlikely the situation will improve for the child or young person. This lack of resources may also affect the consultees as they feel disempowered even before they have entered the consultation. They are therefore less likely to buy-in to the process of actively seeking change and taking ownership of the situation, because they feel like forces beyond their control are stopping them.

Another barrier related to the schools is the general effect of wider education systems, such as operating within the traded model or the EHCP process. Almost all interviewees referred to the impact education systems can have on effective consultation. The way a school operates was cited as a significant potential barrier for effective consultation. Because schools buy EP time, they may believe they have greater control over the nature of the work they are commissioning as customers (Lee \& Woods, 2017). This arguably constitutes a form of school knowledge, as an awareness of the school's values and how it understands EP work impacts on the efficacy of consultation. If a school does not value 
consultation, then they are less likely to provide resources for interventions or cover teachers' lessons so they can attend a consultation. These all undermine the efficacy of consultation. This idea relates to the importance of trying to include those with power in the consultation. If this can be done, or at least the consultees know that those with power see consultation in and of itself as worthwhile, then consultation is more likely to be effective as interventions are more likely to be put in place.

Seven interviewees made comments about the amount of work they have to do and how this negatively affects their consultations. The sheer volume of work means they felt they did not have the mental space to be able to fully engage in a given consultation because of stress and feelings of being overworked. This workload also prohibited them from being able to fully prepare for consultations, such as reading the case file prior to the consultation. This was felt to be a significant barrier to the efficacy of consultation. Previous research has identified the shift to traded services as being a significant factor in the increase of EP workload (Islam, 2013).

\subsubsection{What do EPs believe makes those features effective?}

The most frequently discussed reason that the identified features help ensure consultation is effective is that it is efficient. This took a few forms, such as being efficient for seeing more children in a short space of time (as opposed to direct work with children). Many of the benefits reflect some of the pressures interviewees felt. Several EPs discussed the need to use consultation because schools could not buy in more time but wanted psychological input for many 
children. They may have also perceived a need to demonstrate their value for money within a traded context (Lee \& Woods, 2017) and so emphasised the costefficient nature of consultation. However, consultation was also efficient because of its ability to have an impact wider than the consultation itself. Through empowering consultees, changing perspectives, and emotionally supporting consultees, consultation can have positive effects for consultees, CYP, and schools as a whole if they change policy as a result of an effective consultation.

The key reason identified for making such features as Collaborative, EP encouraging engagement, and Rapport effective was the fact it engendered Consultee ownership of the situation. By making the consultation Collaborative, by Empowering consultees, those involved feel better equipped to support CYP and more motivated to implement recommendations (Erchul \& Martens, 2012).

Another reason identified for making features related to EP knowledge and skills effective is the fact consultation presents a varied space for approach. By allowing a wide range of practices and skills to be used, consultation can be highly flexible to the needs of the consultees and CYP and thus be best suited to facilitate change. However, the fact consultation is a platform to allow various psychological tools and models to be used can be detrimental to EPs and consultees. Given the potential differences in practice, a consultee without prior experience is very unlikely to know what to expect prior to a given consultation. This undermines their ability to buy-in to the process and thus threatens one of the key mechanisms of effective consultation. 
A number of interviewees talked about the importance of being external to the school system. This being outside the school system meant that questions could be asked that otherwise could not be and an external perspective could be brought in (Cording, 2011). This is particularly valuable for when a situation feels "stuck," and consultees feel powerless. By being external, they may be able to see what is already working and give new recommendations for supporting CYP.

The giving of recommendations links to another mechanism through which these features of consultation are effective: that what is recommended is Realistic. By listening to the consultees and valuing their opinions, EPs are more likely to be able to make recommendations that fit within the context of the school and can be reasonably put in. If an EP makes a series of grand recommendations for the child or young person but the school does not have the means to implement them, then there is little chance the situation will improve. But by having a collaborative consultation, in which recommendations are co-created, the solutions are more likely to be feasible and therefore the chance of having an effective consultation and a positive impact is increased. This is associated with the final mechanism through which these features are effective: treating the Consultees as experts. By taking on board the views of the consultees and seeing them as having expertise to bring to the discussion, the consultation is more likely to be effective (S. Truscott et al., 2012). Consultees will be more likely to buy-in to the process if they feel valued and listened to and the recommendations are more likely to be relevant if those who know the school and the child or young person most are actively involved. Whilst there is theoretical evidence to suggest this an important feature, only a small number of interviewees explicitly mentioned this as a 
valuable mechanism for effective consultations. This reveals another instance of the disparity between what the academic literature highlights as important and what practicing EPs believe is important.

\subsubsection{Which combination of features of consultation are seen with progress towards agreed goals?}

\subsubsection{Non-formal analysis of features and goals}

A majority of the goals were judged to have experienced progress, bolstering the claim made in Dunsmuir et al. (2009). Of those which saw progress, patterns can be drawn. A qualitative examination of the correspondence between features of consultation and change revealed that consultations with fewer recorded instances of Understanding the presenting problem were more likely to see change. Such examples include the parent consultation for child 2 and the parent consultation for child 4 (see Appendix L for all observed features and change). There was also a greater number of instances of Suggesting solutions by the EP during consultations which saw change, such as the first consultation and the parent consultation for child 4 .

There was a disparity between what interviewees stated was important and what was observed in the consultations. Collaboration was given by almost every interviewee as a crucial feature. However, observable instances of this feature were less frequently seen than the EP exploring the presenting problem for a majority of consultations. This may represent a gap between what EPs say is important and what they do in a consultation when they are there to support a specific child or young person. It does, however, corroborate the importance of EPs using parts of models e.g., problem-analysis framework. This is because for 
each consultation the most frequently seen feature was Understanding the presenting problem. This is substantiated by the fact one of the EPs who was observed stated in their interview that the main model they use in their practice is the problem-analysis framework. On the other hand, this emphasis on exploring the depth and limits of the main problem may not reflect adherence to this model (and thus be evidence for the importance of using said model). It may just be an exploration of the main difficulties (and arguably the reason why the consultation was organised). The absence of other features of the Problem-analysis framework, such as discussing how to implement an intervention, is suggestive of the perceived need by EPs to fully understand the presenting problem rather than fully commit to a certain model. This suggests a disparity between how EPs say they work and what happens in a consultation.

The importance of the individual differences of the consultees was highlighted in these observations, as consultees who were more optimistic and less stressed were better able to engage collaboratively and not focus as much on exploring the negative aspects of the situation. Examples of these include the parent consultation for child 2 as the ratio between Understanding presenting problem and other features was more even. The teacher consultation for child 2 was also an opportunity to highlight the importance of emotionally supporting consultees, given how upset the consultee was and therefore unable to engage with one aspect of the consultation prior to said support.

The fact three putatively core features of effective consultation (School knowledge, EP explaining role, and Planning/implementing interventions) were not recorded 
once undermines the argument that they are important for effective consultations. This is also true for Empowering individuals as this was only recorded once. They do not appear to be necessary and perhaps are not sufficient for change to be judged as having occurred. Even though there were instances of the EP offering solutions in most consultation, there was no discussion of the specifics of how any suggestion was to be implemented (as there were no recorded instances of Planning/implementing interventions). There was also no review of any prior interventions. This raises questions as to how effective the suggestions are. If they are left to the consultees to establish and decide how often an intervention should be run for, will it be as effective as if it were decided with the person who is believed to have expert knowledge?

There was a lack of consistency regarding the discrepancy between the ratings given by parents and teachers: one consultation saw the teacher identifying change and the parent not, another saw the parent judging there to have been progress but the teacher not. This reflects the fact TME is based upon the perceptions of change by consultees and thus there may be different conceptions and criteria for judging change between consultees (Connor, 2010). However, the sample is too small to draw any patterns or conclusions from this data.

Change may not have been observed in some consultations because the goals were not specific enough or were poor quality, such as not being sufficiently related to the key area of need. If the goals were not sufficiently defined or relevant to the child's needs, then change was unlikely to have been judged to occur. This is most clearly seen for one of the goals for Child 1 , as the parent did 
not understand what the goal referred to and thus couldn't rate progress. This reveals a potentially large problem with TME and arguably consultation: consultees agreeing with goals or recommendations but not knowing what they are. This greatly undermines the efficacy of consultation, because if a key person expected to help the child or young person make progress does not understand what has been agreed to, they cannot support them to make positive changes.

\subsubsection{QCA}

QCA identified three combination of features which were sufficient for change after calibration and Boolean minimisation. The validity of QCA for this data set is undermined as three goals which saw change contained no features after calibration (goals for the parent consultation of child 2). Therefore, limited conclusions can be drawn from this analysis. The combinations which contain a mixture of present and absent features are subsequently explored. One such combination of conditions which led to change was: Setting out consultation plan, Understanding the presenting problem, Discussing what's already working, and Gathering information. The other combination was: Ideas for future EP work, Setting out consultation plan, EP using expert knowledge, Summarising, and Suggesting solutions. Only one feature is shared between these combinations (Setting out consultation plan). This gives tentative support for the importance of establishing the consultation plan as this feature was also observed during the other consultation which saw change and had recorded features post calibration. This feature is the first step in Monsen's streamlined version of the problemanalysis framework (Woolfson et al., 2003) and provides support for the utility of this model. 
There was also overlap between the two consultations as to the features that were absent. For both consultations with a mixture of present and absent features, the lack of empowering individuals, valuing contributions from those involved, and discussing CYP strengths did not prohibit change from being observed. This raises questions about the efficacy of certain popular models, such as Solutionfocused. This is because a core idea of this approach for EP consultation is that to be effective, EPs need to empower the consultees, value their contributions, and highlight the capabilities of the child or young person. This was a common sentiment among the interviewees and reveals a disparity between what EPs say are core features of consultation and what was sufficient for positive change.

\subsection{Limitations}

\subsubsection{Interviews}

Despite the large amount of interview data, there are limitations with the methods chosen and the data analysis. No measures were taken to ensure the reliability of the TA, such as using inter-rater reliability. It is therefore unknown to what extent the biases of the sole analyst of the transcripts biased the analysis. There are also limitations of the methodology employed (TA) as this provides only a surface level analysis of codes and themes. As such, the depth of the data was not plumbed, and latent themes were not examined.

For the features that were identified, many were broad, ill-defined concepts such as 'collaborative' rather than features which could be observed. This means that there were many features which were inductively coded which could not have been used as deductive codes or form part of the observation schedule. There is 
therefore the potential that the observation schedule missed some core features due to the fact many "features" of consultation are not operationalised.

There were also limitations of the tools used to conduct the interviews. Although Zoom underwent security improvements, there was still a risk of interference or data loss which are not present in face-to-face interviews. To mitigate this risk, the in-built recording function was not used. There were also connectivity issues present in a few consultations. Typically, only a few words were lost, but it is unknown how much of an impact this may have had on the contents of the interviews. There were also three interviews which interrupted by family members. Whilst this did not directly lead to a loss of data, it interrupted the flow of the interview and may have impacted on what the interviewee said. It is unknown how great an impact these factors had on the TA, although the risk of codes or themes being lost due to them is minimised because of the amount of data collected.

Another limitation related to the use of video technology, and one which speaks to the heart of tech consultations, relates to the level of engagement of consultees. Whilst tech consultations can increase accessibility for consultees, they can also result in consultees participating in other activities during the consultation. This reduces their ability to focus and thus potentially understand certain parts of the consultation. For example, during the establishing goals phase at the end of the joint home-school consultation for child 1, the parent was driving and thus could not engage as fully. This likely led to the parent being unable to give a rating for the second goal as they did not understand it. Therefore, tech consultations may undermine the efficacy of consultations because consultees may not have the 
mental space to fully give to the consultation, thus undermining engagement. This reduces the ability of the results to generalise to face-to-face consultation, as such distractions are less likely when everyone is in the same room together.

\subsubsection{Observations}

\subsubsection{Methodological}

There were a number of potential methodological limitations of the chosen methods for the quantitative arm of the research. One such concern related to the nature of the features. By limiting the features to what was explicitly said, features such as body language and more abstract features were necessarily excluded from the analysis. Therefore, potentially valuable features may have been missed. A related issue concerned the nature of recording the presence of features. As there was only one observer, there is a risk of subjective interpretation of features. The ICC of the observation checklist was under 0.5 and therefore, by the standards given by Koo \& Li (2016), is 'poor.' Thus, there is the potential for unreliability in the recording of the features.

One component of solution-focused approaches (exploring exceptions) was not included in the observation schedule due to a clerical error. Thus, instances of an observed feature which was mentioned by interviewees was missed. This undermines the validity of the observation results. Another issue relating to the features included in the observation schedule related to their potential thoroughness. The large disparity between the theoretically derived codes and the inductive codes suggests the current literature does not capture the breadth of features present in consultation. Whilst the features of consultation were supported in previous work, it was a small-scale project limited to a small number 
of EPs. Therefore, the observation schedule may be missing key features of an effective consultation. This undermines the validity of the quantitative results.

Another potential limitation related to the use of TME. This tool has not been demonstrated as being a suitable measure of the effectiveness of consultation. There is evidence to suggest it can be used to measure change for a child on a given goal, for example (Connor, 2010). However, as this same thesis identified, it is very difficult to attribute the observed change to the consultation itself due to the many other factors which may influence the rating of change. Without rigorous identification of interventions or means to support CYP and follow-up to confirm these happen, we cannot know how much of an impact the consultation had on the consultees and the consequent impact on the CYP.

There was another practical issue with the use of TME for this research. The majority of consultations (four of the six) took place prior to the Christmas holidays. This break was then followed by a second national lockdown. The children therefore spent a majority of the 6-8-week period out of school, where most of their support was expected to be delivered. This may have resulted in the children making less progress than predicted, given the extended time they were out of school.

\subsubsection{Sample}

The initial conception of the research limited observations to joint home-school consultations. However, due to the difficulty in arranging such observations, the scope was broadened to any consultation. Since the interviews occurred prior to the observations, when the research questions focused solely on joint home- 
school consultations, interviewees may have put the focus of their answers on joint home-school consultations. One interviewee made such a comment. It is therefore unknown whether the answers from the interviewees would be different if the scope of the questions had been broader from the beginning. However, most interviewees seemed to approach the questions with consultations in general in mind. Thus, one can be reasonably confident the qualitative data results are like what would have otherwise been seen. The number of interviews (30) also helped reduce the impact this narrower a focus some interviewees had towards the questions.

Issues with the generalisability of the findings were raised due to the fact the observations were almost exclusively from one EP. Both EPs observed worked in the same LA and all the observed consultations were remote. We therefore cannot be certain that the findings extend to other EPs in other LAs and to in-person consultations. The issue of generalisability is also raised by the fact one of the consultations (the parent consultation for child 4), the main body was dictated by the use of the Cognitive abilities profile. This highly structured tool therefore involved many questions exploring the presenting problem and other areas. As such, it may not be representative of a consultation which does not use that tool or is less structured.

\subsubsection{QCA}

QCA is a valuable tool for examining causal patterns in conditions for complex phenomena. However, it does not allow the valuation of the relative impact of different features for change. This is a problem as it is therefore difficult to know 
how important features are for change. For example, individual differences as a feature (specifically the stress levels of the consultees) appears to have a large impact on change, whereas setting out the consultation plan appears to have a much smaller impact. This qualitative analysis cannot be corroborated by QCA and therefore potentially important conclusions may be lost.

There are also concerns as to the appropriateness of QCA for this data set. Marx \& Dusa (2011) recommends eschewing QCA when there are more conditions than cases. This is because of the increased risk of each case forming a unique configuration, which invalidates the ability of QCA to find common combinations. There is also an increased chance of the data being random but still finding an explanatory model (Marx, 2010). This appears to be the case for the present data set. There were 10 cases (six of which had unique features) and 14 conditions. There was therefore an increased risk of being unable to find meaningful combinations of conditions to glean patterns. The results showed that each combination only corresponded to one consultation with very little overlap between combinations. This made drawing conclusions regarding the consistent combination of features to change very difficult.

Another issue related to the calibration thresholds. Using the mean as the threshold resulted in the consultation which saw the most change (parent consultation for child 2) recording no features present. This undermines the ability to draw conclusions regarding combinations of conditions. A more appropriate threshold would be one weighted by the total number of observations per case. 
This would overcome the problem of some cases containing a higher number of features and thus consigning other cases to record no features after calibration.

\subsection{Future directions}

Whilst this research contributes to our collective understanding of consultation, there are future directions in which this research can be taken to broaden its impact. Exploring the views of consultees with regards to the effective features of consultations would be highly valuable. This is because those who are involved but do not have the theoretical training can provide opinions not filtered through the biases of their training or desire for it to be seen as an effective way of working. They will also have greater first-hand experience of what the consequences of a consultation are and whether it was effective or not.

Despite the limitations put forward in section 5.2.2, the use of an observation schedule and QCA to explore combinations of causal conditions is valid. To increase the chance of meaningful conclusions being drawn, a greater number of consultations should be observed. There would thus be a more conducive case to condition ratio, for example at least 30 cases to the 14 conditions. TME could be used again as the measure of change, although this could be done in tandem with other more robust measures, as was done in Connor (2010).

Alternatively, another measure of consultation efficacy could be developed. This measure would focus on a mechanism by which consultation can have a direct impact on the consultees. For example, by changing the perspectives of the consultees. This could be in relation to feeling better able to support the child or young person or more hopeful for the future. A multi-item questionnaire exploring 
the construct(s) would be presented to the consultees before and after the consultation. This same questionnaire could be presented a few months later to see how long-term the change in perspectives for the consultee(s) is (if at all). How perspective change then impacts CYP could be explored through interviews or questionnaires, as potentially increased support may be given, or the consultees may have a more positive outlook for the CYP.

The present data presents opportunities for further work. Given the surface level analysis of the interview transcripts, there is large amount of data not yet examined. The use of Grounded theory (Strauss \& Corbin, 1994) or Interpretative Phenomenological Analysis (Smith \& Osborn, 2003) may allow a more detailed exploration of the latent themes within the data.

\subsection{Researcher reflections}

This section will explore my reflections on the research process and what I have learned from conducting this piece of research. Prior to developing this work, I did not value qualitative research methodologies. I did not understand them and consequently did not believe they could be used to explore complex phenomena in a meaningful. Learning about TA and utilising it in this research has thoroughly dissuaded me of that notion. I now clearly understand why qualitative research methods are used and their value. I will be integrating them into my future research as I believe mixed methods research is the most robust and comprehensive means of examining something like consultation.

Whilst the process of TA was laborious, the results were worth the time spent. I take satisfaction in the ease with which the themes revealed themselves after the 
rounds of coding the transcripts. This suggests that the methodology was robust and allowed for the detailing of what I sought to examine (the effective features of consultation). I am also grateful I sent out several calls for participants. The large number of interviews presented the opportunity to create very rich data about the views regarding effective consultations from a wide range of EPs.

This work has been greatly affected by the global pandemic. However, these difficulties presented the possibility to expand the scope of this work and it has been improved for it. I have also been presented with an opportunity to explore consultation as it will likely be performed in the future: as technologically mediated consultations. Whilst tech consultations are unlikely to replace face-to-face consultations entirely, they will undoubtedly form an integral part of the EP working landscape in the future. Thus, to have explored their use and what makes them effective is highly valuable and can help EPs ensure their consultations are effective.

The development and conducting of this research has been the most rewarding piece of work I have ever done. To deeply delve into the theoretical background of consultation and then explore it through qualitative and quantitative methods has given me valuable insight into this tool. I am very grateful for the opportunity to have done this work. Engaging in this exploration of consultation has solidified my desire to employ this as my primary model of working. I have been fully persuaded of its utility through the discussion with EPs and gaining a deeper understanding of what it is and what it can achieve. This has strengthened my resolve to continue researching it and make it as effective as possible. Not just for the children and 
young people it is used in service of, or the consultees who engage in it, but other EPs who use this methodology. We are in a privileged position to help those in very difficult situations. It is therefore imperative that the methods we use are evidence-based and have rigorously shown to be beneficial for those involved.

\subsection{Conclusions and recommendations}

This piece of work represents an attempt to systematically identify the features of consultation which lead to change for CYP. By employing a mixed methods approach, the beliefs of practicing EPs regarding the effective features of consultation were detailed, along with recorded instances of various features of consultation. These recordings were tabulated against measures of change for cooperatively agreed goals by the EP and consultees. The relative presence or absence of said features were then analysed to see if patterns of features could be identified. Whilst statistical analyses did not yield conclusive results, the breadth of qualitative data combined with the non-formal analysis of features and ratings of change present a picture of what is necessary for an effective consultation. Given this, the goal of this research is to provide guidance to EPs such that they are more confident in their ability lead an effective consultation and help create positive change for the CYP they work with. This is through ensuring they include in their consultations the features identified as being effective for eliciting change.

To lead an effective consultation, EPs need to have specialist knowledge to thoroughly explore an area of need for a child or young person. By creating a collaborative space in which consultees feel valued, through the development of 
rapport and encouraging the participation of consultees, EPs can hope to change the perspectives of those involved and identify potential solutions. By exploring the views of consultees and using various questions, a shared understanding of the child or young person and situation can be created. Through consultation, EPs can impact not only those involved in the consultation, by providing therapeutic support, but those outside the consultation through the ripple effects consultation can have on people and systems. By being collaborative, consultees can not only feel empowered to support CYP but to take ownership of the situation and actively work to improve the situation for all. To facilitate EPs in their pursuit of effective consultations, a checklist of effective features has been created (Appendix M). This will serve as a guide for EPs and TEPs in how to lead an effective consultation.

Given this research, an effective consultation can be defined as: 'a meeting (at least 30 minutes in a confidential space) of an EP and at least one knowledgeable person of the child or young person (preferably more) wherein the EP uses their expert knowledge to facilitate engagement of the consultees, through developing a rapport, to bring the consultees' expert knowledge to collaboratively gain a clearer understanding of the presenting problem and the context through questioning and exploring the views of CYP. It has a clear purpose and structure established at the beginning of or prior to the meeting which aims to create a path forward, through the EP empowering the consultees to realise their own and the child's strengths in which everyone comes away with a path forward and actively agrees to these next steps. After the consultation, the EP should reflect on the process and seek to 
gain feedback to improve future consultations and check progress on the agreed recommendations and goals.'

Consultation is fundamental to the work of EPs in the UK. However, there remain significant questions as to what constitutes consultation and how it can be effective in supporting CYP. This presents challenges to TEPs and EPs alike, resulting in many claiming to practice consultation when in fact they do not. It is therefore of vital importance for us as a profession to clarify what we mean by consultation and how we can engage in it effectively. My hope is that this work can go some way in shining a light on the core features of an effective consultation and thus empower EPs to lead consultations which improve the lives of those we seek to help. 


\section{References}

Ajmal, Y., \& Rees, I. (2001). Solutions in Schools: Creative Applications of Solution Focused Brief Thinking with Young People and Adults (Vol. 1).

Andrews, S., Ellis, D. A., Shaw, H., \& Piwek, L. (2015). Beyond Self-Report: Tools to Compare Estimated and Real-World Smartphone Use. PLOS ONE, 10(10), e0139004. https://doi.org/10.1371/journal.pone.0139004

Argyris, C., \& Schon, D. A. (1992). Theory in Practice: Increasing Professional Effectiveness (1 edition). Jossey-Bass.

Ashton, R., \& Roberts, E. (2006). What is Valuable and Unique about the Educational Psychologist? Educational Psychology in Practice, 22(2), 111-123. https://doi.org/10.1080/02667360600668204

Association for Educational Psychologists. (2020). Survey into the effects of covid19 on the provision of educational psychology services in england.

Atkinson, C., Bragg, J., Squires, G., Muscutt, J., \& Wasilewski, D. (2011). Educational psychologists and therapeutic interventions preliminary findings from a UK-wide survey. Debate, 140, 6-12.

https://www.research.manchester.ac.uk/portal/en/publications/educationalpsychologists-and-therapeutic-interventions--preliminary-findings-from-a-ukwidesurvey(e1cf0136-f743-4cee-97bf-c13642038a56)/export.html

Attride-Stirling, J. (2001). Thematic networks: an analytic tool for qualitative research. Qualitative Research, 1(3), 385-405. 
Babinski, L. M., \& Rogers, D. L. (1998). Supporting new teachers through consultee-centered group consultation. Journal of Educational and Psychological Consultation, 9(4), 285-308. https://doi.org/10.1207/s1532768xjepc0904_1

Balodi, K. C. (2016). Configurations and entrepreneurial orientation of young firms: Revisiting theoretical specification using crisp-set qualitative comparative analysis. Management Decision, 54(4), 1004-1019. https://doi.org/10.1108/MD-04-20150145

Bell, H. D., \& McKenzie, V. (2013). Perceptions and Realities: The Role of School Psychologists in Melbourne, Australia. The Educational and Developmental Psychologist, 30(1), 54-73. https://doi.org/10.1017/edp.2013.1

Benn, A. E., Jones, G. W., \& Rosenfield, S. (2008). Analysis of instructional consultants' questions and alternatives to questions during the problem identification interview. Journal of Educational and Psychological Consultation, 18(1), 54-80. https://doi.org/10.1080/10474410701864115

Bergan, J. R., \& Kratochwill, T. R. (1990). Behavioral Consultation and Therapy: An Individual Guide (1990 edition). Springer.

Bhardwaj, A., Byng, C., \& Morrice, Z. (2020). A rapid literature review of how to support the psychological well-being of school staff during and after Covid-19.

Boyatzis, R. E. (1998). Transforming qualitative information: Thematic analysis and code development. SAGE. 
Braun, V., \& Clarke, V. (2006). Using thematic analysis in psychology. Qualitative Research in Psychology, 3(2), 77-101.

https://doi.org/10.1191/1478088706qp063oa

British Psychological Society. (2015). Quality Standards for Educational Psychology Services - Good Practice Guidelines - Publication by Series Publications. https://shop.bps.org.uk/publications/publication-by-series/goodpractice-guidelines/quality-standards-for-educational-psychology-services.html.

British Psychological Society. (2019). Quality standards for educational psychology services.

https://www.bps.org.uk/sites/bps.org.uk/files/Member\%20Networks/Divisions/DEC P/ID3188\%20Quality\%20Standards\%20for\%20EPSs\%20INF318\%20WEB.pdf

Bronfenbrenner, U. (1995). Developmental ecology through space and time: A future perspective. In Examining lives in context: Perspectives on the ecology of human development (pp. 619-647). American Psychological Association. https://doi.org/10.1037/10176-018

Bruno, A., Galuppo, L., \& Gilardi, S. (2011). Evaluating the reflexive practices in a learning experience. European Journal of Psychology of Education, 26, 527-543. https://doi.org/10.1007/s10212-011-0061-x

Button, K. S., Ioannidis, J. P. A., Mokrysz, C., Nosek, B. A., Flint, J., Robinson, E. S. J., \& Munafò, M. R. (2013). Power failure: why small sample size undermines the reliability of neuroscience. Nature Reviews Neuroscience, 14(5), 365-376. 
Cabinet Office. (2020). Staying at home and away from others (social distancing). In GOV.UK. https://www.gov.uk/government/publications/full-guidance-on-stayingat-home-and-away-from-others/full-guidance-on-staying-at-home-and-away-fromothers.

Cardillo, J. E., \& Choate, R. O. (1994). Illustrations of goal setting. Lawrence Erlbaum Associates.

Cicchetti, D. (1994). Guidelines, Criteria, and Rules of Thumb for Evaluating Normed and Standardized Assessment Instrument in Psychology. Psychological Assessment, 6, 284-290. https://doi.org/10.1037/1040-3590.6.4.284

Cline, T. (1994). Quality Assurance in an Educational Psychology Service: What Can We Learn from Earlier Experience in Service Evaluation? School Psychology International. https://doi.org/10.1177/0143034394153002

Connor, T. (2010). Target monitoring and evaluation : Measuring the impact of educational psychology interventions [Ph. $\{\{\mathrm{D}\}\}$.]. Institute of Education, University of London.

Cording, J. (2011). A study of Educational Psychologists' use of consultation and users' views on what a service should deliver. 158.

Crabtree, B. F., \& Miller, W. F. (1992). A template approach to text analysis:

Developing and using codebooks. In Doing qualitative research (pp. 93-109). Sage Publications, Inc. 
Creswell, J. W., \& Creswell, J. D. (2003). Research Design: Qualitative, Quantitative, and Mixed Methods Approaches (5 edition). SAGE Publications, Inc. Croll, P. (1986). Systematic Classroom Observation. Routledge.

De Shazer, S. (1984). The Death of Resistance. Family Process, 23(1), 11-17. https://doi.org/10.1111/j.1545-5300.1984.00011.x

De Shazer, S. (1985). Keys to solution in brief therapy. Norton.

De Shazer, S. (1994). Words were originally magic. W W Norton \& Co.

Dennis, R. (2004). So far so good? A qualitative case study exploring the implementation of consultation in schools. Educational Psychology in Practice, 20(1), 17-29. https://doi.org/10.1080/0266736042000180384

Denscombe, M. (2008). Communities of Practice: A Research Paradigm for the Mixed Methods Approach. Journal of Mixed Methods Research.

https://doi.org/10.1177/1558689808316807

Department for Education. (2015). SEND code of practice: 0 to 25 years.

Deutsch, R. (2021). Cognitive abilities profile.

https://www.dynamicassessment.co.uk/cognitive-abilities-profile/

Deutsch, R. M., \& Mohammed, M. G. (2009). The cognitive abilities profile. Real Group.

Diamantopoulos, A., Sarstedt, M., Fuchs, M., Wilczynski, P., \& Kaiser, S. (2012). Guidelines for choosing between multi-item and single-item scales for construct 
measurement: A predictive validity perspective. Journal of the Academy of Marketing Science, 40, 434-449. https://doi.org/10.1007/s11747-011-0300-3

Dickinson, D. (2000). Consultation: Assuring the quality and outcomes.

Educational Psychology in Practice, 16(1), 19-23.

https://doi.org/10.1080/713666039

Dinkmeyer, D., \& Carlson, J. (2016). Consultation: Creating School-Based Interventions (4th edition). Routledge.

Dunsmuir, S., Brown, E., lyadurai, S., \& Monsen, J. (2009). Evidence-based practice and evaluation: From insight to impact. Educational Psychology in Practice, 25(1), 53-70. https://doi.org/10.1080/02667360802697605

Dușa, A. (2018). QCA with R. A Comprehensive Resource. https://doi.org/10.1007/978-3-319-75668-4

Eddleston, A. (2016). An action research study to select an effective model to evaluate consultation within two educational psychology services [PhD thesis].

Eddleston, A., \& Atkinson, C. (2018). Using professional practice frameworks to evaluate consultation. Educational Psychology in Practice, 34(4), 430-449. https://doi.org/10.1080/02667363.2018.1509542

Erchul, W. P. P., \& Martens, B. K. (2012). School consultation: Conceptual and empirical bases of practice (2010th edition). Springer. 
Fallon, K., Woods, K., \& Rooney, S. (2010). A discussion of the developing role of educational psychologists within children's services. Educational Psychology in Practice, 26(1), 1-23. https://doi.org/10.1080/02667360903522744

Farrell, P., \& Woods, K. (2015). Reflections on the role of consultation in the delivery of effective educational psychology services. Educational Psychology Research and Practice, 1(1), 2-9.

Fereday, J., \& Muir-Cochrane, E. (2006). Demonstrating Rigor Using Thematic Analysis: A Hybrid Approach of Inductive and Deductive Coding and Theme Development. International Journal of Qualitative Methods, 5(1), 80-92. https://doi.org/10.1177/160940690600500107

Feuerstein, R., Rand, Y., Haywood, C., Kyram, C., \& Hoffman, M. (1995). Learning potential assessment device manual. ICELP Press.

Flake, J. K., Pek, J., \& Hehman, E. (2017). Construct Validation in Social and Personality Research: Current Practice and Recommendations. Social Psychological and Personality Science, 8(4), 370-378.

\section{https://doi.org/10.1177/1948550617693063}

Gaasterland, C. M. W., Jansen-van der Weide, M. C., Weinreich, S. S., \& van der Lee, J. H. (2016). A systematic review to investigate the measurement properties of goal attainment scaling, towards use in drug trials. BMC medical research methodology, 16, 99. https://doi.org/10.1186/s12874-016-0205-4

Gamer, M., Lemon, J., \& Singh, I. F. P. (2019). Irr: Various Coefficients of Interrater Reliability and Agreement. 
Gutkin, T. B., \& Conoley, J. C. (1990). Reconceptualizing school psychology from a service delivery perspective: Implications for practice, training, and research. Journal of School Psychology, 28(3), 203-223. https://doi.org/10.1016/00224405(90)90012-V

Gutkin, T. B., \& Curtis, M. J. (1999). School based consultation theory and practice: The art and science of individual service delivery.

Hallgren, K. A. (2012). Computing Inter-Rater Reliability for Observational Data: An Overview and Tutorial. Tutorials in Quantitative Methods for Psychology, 8(1), 23-34. https://doi.org/10.20982/tqmp.08.1.p023

Hampshire EPS. (2010). How do educational psychology services currently evaluate themselves? NAPEP survey.

Hasselbusch, A., \& Penman, M. (2008). Working Together: An Occupational Therapy Perspective on Collaborative Consultation. Kairaranga, 9(1), 24-31. http://eprints.bournemouth.ac.uk/9861/

Hatzichristou, C., Lampropoulou, A., Georgouleas, G., \& Mihou, S. (2017). A Multilevel Approach to System-Level Consultation : Critical Components and Transnational Considerations (1st ed.). Routledge.

https://www.taylorfrancis.com/https://www.taylorfrancis.com/chapters/edit/10.4324/ 9781315795188-5/multilevel-approach-system-level-consultation-chrysehatzichristou-aikaterini-lampropoulou-georgios-georgouleas-spryridoula-mihou 
Health \& Care Professions Council. (2015). Standards of proficiency - Practitioner psychologists /. https://www.hcpc-uk.org/resources/standards/standards-ofproficiency-practitioner-psychologists/.

Henderson, A. (2013). An exploration of the impact of consultation on educational psychology service users, namely teachers, parents and pupils in a large rural local authority [Ed. $\{\{P s y c h\}\} .\{\{D\}\}$.$] . University of Birmingham (United Kingdom).$

Henning-Stout, M. (1994). Consultation and connected knowing: What we know is determine by the questions we ask. Journal of Educational and Psychological Consultation, 5(1), 5-21. https://doi.org/10.1207/s1532768xjepc0501_1

House, E. R. (1991). Realism in Research: Educational Researcher. https://doi.org/10.3102/0013189X020006002

Hughes, A. S. (2016). Mixed methods research. APS Observer, 29(5). https://www.psychologicalscience.org/observer/mixed-methods-research

Hylander, I. (2017). Establishing Psychological Consultation Services to Promote Student Well-Being in Schools and Preschools (1st ed.). Routledge.

https://www.taylorfrancis.com/https://www.taylorfrancis.com/chapters/edit/10.4324/ 9781315795188-2/establishing-psychological-consultation-services-promotestudent-well-being-schools-preschools-ingrid-hylander

Islam, S. N. (2013). An investigation into educational psychologists' perceptions of traded service delivery, using soft systems methodology [PhD thesis]. 
Johnson, R. B., \& Onwuegbuzie, A. J. (2004). Mixed Methods Research: A Research Paradigm Whose Time Has Come: Educational Researcher. https://doi.org/10.3102/0013189X033007014

Jones, N., \& Frederickson, N. (Eds.). (1990). Refocusing Education Psychology. Falmer Press Ltd.

Kaplan, J. M., \& Smith, W. G. (1977). The use of attainment scaling in the evaluation of a regional mental health program. Community Mental Health Journal, 13(2), 188-193. https://doi.org/10.1007/BF01410888

Kaye, S.-A., Lewis, I., \& Freeman, J. (2018). Comparison of self-report and objective measures of driving behavior and road safety: A systematic review. Journal of Safety Research, 65, 141-151. https://doi.org/10.1016/j.jsr.2018.02.012 Kelly, B. (2006). Exploring the usefulness of the monsen problem-solving framework for applied practitioners. Educational Psychology in Practice, 22(1), 117. https://doi.org/10.1080/02667360500512312

Kennedy, E. K., Cameron, R. J., \& Monsen, J. (2009). Effective Consultation in Educational and Child Psychology Practice: Professional Training for Both Competence and Capability. School Psychology International, 30(6), 603-625. https://doi.org/10.1177/0143034309107079

Kennedy, E. K., Frederickson, N., \& Monsen, J. (2008). Do educational psychologists "walk the talk" when consulting? Educational Psychology in Practice, 24(3), 169-187. https://doi.org/10.1080/02667360802256733 
Kimmelman, J., Mogil, J. S., \& Dirnagl, U. (2014). Distinguishing between Exploratory and Confirmatory Preclinical Research Will Improve Translation. PLoS Biology, 12(5). https://doi.org/10.1371/journal.pbio.1001863

Kiresuk, T. J., \& Sherman, R. E. (1968). Goal attainment scaling: A general method for evaluating comprehensive community mental health programs. Community Mental Health Journal, 4(6), 443-453.

https://doi.org/10.1007/BF01530764

Kissinger, A. (2019). TikZiT.

Knotek, S. (2012). Utilizing culturally responsive consultation to support innovation implementation in a rural school. Consulting Psychology Journal: Practice and Research, 64, 46-62. https://doi.org/10.1037/a0027993

Knotek, S. E., Babinski, L. M., \& Rogers, D. L. (2002). Consultation in New Teacher Groups: School Psychologists Facilitating Collaboration Among New Teachers. The California School Psychologist, 7(1), 39-50.

https://doi.org/10.1007/BF03340888

Koo, T. K., \& Li, M. Y. (2016). A guideline of selecting and reporting intraclass correlation coefficients for reliability research. Journal of Chiropractic Medicine, 15(2), 155-163. https://doi.org/10.1016/j.jcm.2016.02.012

Kratochwill, T., \& Stoiber, K. (2002). Evidence-Based Interventions in School Psychology: Conceptual Foundations of the Procedural and Coding Manual of Division 16 and the Society for the Study of School Psychology Task Force. 
School Psychology Quarterly, 17, 341-389.

https://doi.org/10.1521/scpq.17.4.341.20872

Larney, R. (2003). School-Based Consultation in the United Kingdom: Principles, Practice and Effectiveness. School Psychology International, 24(1), 5-19.

https://doi.org/10.1177/0143034303024001518

Leadbetter, D. J. (2004). The role of mediating artefacts in the work of educational psychologists during consultative conversations in schools. Educational Review, 56(2), 133-145. https://doi.org/10.1080/0031910410001693227

Leadbetter, J. (2006). Investigating and Conceptualising the Notion of Consultation to Facilitate Multi-agency Work. Educational Psychology in Practice, 22(1), 19-31. https://doi.org/10.1080/02667360500512387

Leadbetter, J. (2000). Patterns of Service Delivery in Educational Psychology Services: Some implications for practice. Educational Psychology in Practice, 16(4), 449-460. https://doi.org/10.1080/713666113

Lee, K., \& Woods, K. (2017). Exploration of the developing role of the educational psychologist within the context of "traded" psychological services. Educational Psychology in Practice, 33(2), 111-125.

https://doi.org/10.1080/02667363.2016.1258545

Lijphart, A. (1975). II. The Comparable-Cases Strategy in Comparative Research. Comparative Political Studies, 8(2), 158-177. 
Likert, R. (1932). A technique for the measurement of attitudes. Archives of Psychology, 22 140, 55-55.

Marx, A. (2010). Crisp-set qualitative comparative analysis (csQCA) and model specification: Benchmarks for future csQCA applications. International Journal of Multiple Research Approaches, 4(2), 138-158.

\section{https://doi.org/10.5172/mra.2010.4.2.138}

Marx, A., \& Dusa, A. (2011). Crisp-set qualitative comparative analysis (csQCA), contradictions and consistency benchmarks for model specification.

Methodological Innovations Online, 6(2), 103-148.

https://doi.org/10.4256/mio.2010.0037

Massé, L., Couture, C., Levesque, V., \& Bégin, J.-Y. (2013). Impact of a school consulting programme aimed at helping teachers integrate students with behavioural difficulties into secondary school: Actors' points of view. Emotional and Behavioural Difficulties, 18(3), 327-343.

https://doi.org/10.1080/13632752.2013.775719

Merton, R. K., Fiske, M., \& Kendall, P. L. (1990). The Focused Interview: A Manual of Problems and Procedures (2 edition). Free Press.

Meyers, B. (2002). The contract negotiation stage of a school-based, crosscultural organizational consultation: A case study. Journal of Educational and Psychological Consultation, 13(3), 151-183. 
Meyers, J., Truscott, S. D., Meyers, A. B., Varjas, K., \& Kim, S. Y. (2014).

Qualitative and Mixed Methods Designs in Consultation Research. Routledge Handbooks Online. https://doi.org/10.4324/9780203133170.ch5

Miles, M. B., \& Huberman, A. M. (1994). Qualitative Data Analysis: An Expanded Sourcebook. SAGE.

Monsen, Jeremy, Brown, E., Akthar, Z., \& Khan, S. (2009). An evaluation of a pretraining assistant educational psychologist programme. Educational Psychology in Practice, 25, 369-383. https://doi.org/10.1080/02667360903315180

Monsen, Jj, \& Frederickson, N. (2008). The Monsen et al. problem solving model ten years on. The problem analysis framework: A guide to decision making, problem solving and action within applied psychological practice. Undefined. https://www.semanticscholar.org/paper/The-Monsen-et-al.-problem-solving-modelten-years-A-Monsen-Frederickson/4bdf96345fba088df0f9ac9f157edf4fb619df35

Monsen, Jeremy, Graham, B., Frederickson, N., \& Cameron, R. J. (Seán). (1998). An accountable model of practice. Educational Psychology in Practice, 13(4), 234-249. https://doi.org/10.1080/0266736980130405

Munafò, M. R., \& Smith, G. D. (2018). Robust research needs many lines of evidence. Nature, 553(7689), 399-401. https://doi.org/10.1038/d41586-01801023-3

Munro, E. (2000). Angles on Developing Consultation: First steps to making consultation our own. Educational Psychology in Practice, 16(1), 53-58. 
Murphy, J. J. (1997). Solution-focused counseling in schools (1st ed.). American Counseling Association.

National College for Teaching and Leadership. (2014). Educational psychology workforce survey: Research report April 2014. Manchester, NH: NCTL.

Newell, M., \& Newman, D. (2014). Assessing the State of Evidence in Consultation Training. Routledge Handbooks Online.

https://doi.org/10.4324/9780203133170.ch17

Newman, D. S., McKenney, E. L. W., Silva, A. E., Clare, M., Salmon, D., \& Jackson, S. (2017). A qualitative metasynthesis of consultation process research: What we know and where to go. Journal of Educational and Psychological Consultation, 27(1), 13-51. https://doi.org/10.1080/10474412.2015.1127164

Noell, G. H., \& Gansle, K. A. (2014). Research Examining the Relationships Between Consultation Procedures, Treatment Integrity, and Outcomes. Routledge Handbooks Online. https://doi.org/10.4324/9780203133170.ch15

Nolan, A., \& Moreland, N. (2014). The process of psychological consultation. Educational Psychology in Practice, 30(1), 63-77. https://doi.org/10.1080/02667363.2013.873019

Nosek, B. A., Spies, J. R., \& Motyl, M. (2012). Scientific Utopia: II. Restructuring Incentives and Practices to Promote Truth Over Publishability. Perspectives on Psychological Science, 7(6), 615-631. https://doi.org/10.1177/1745691612459058 
O'Farrell, P., \& Kinsella, W. (2018). Research exploring parents', teachers' and educational psychologists' perceptions of consultation in a changing Irish context. Educational Psychology in Practice, 34(3), 315-328.

\section{https://doi.org/10.1080/02667363.2018.1461612}

Paez, A. (2017). Grey literature: An important resource in systematic reviews. Journal of Evidence-Based Medicine. https://doi.org/10.1111/jebm.12265

Patton, M. Q. (1990). Qualitative evaluation and research methods, 2nd ed. Sage Publications, Inc.

Paul, K. (2020). 'Zoom is malware': Why experts worry about the video conferencing platform. The Guardian.

Pipher, L. E. (2013). Consultation approach and teacher expectations: Implications for consultant effectiveness.

R Core Team. (2017). R: A language and environment for statistical computing.

Ragin, C. C. (1987). The Comparative Method: Moving Beyond Qualitative and Quantitative Strategies. University of California Press.

Reddy, L., Barboza, S., \& Files, T. (2000). Clinical Focus of Consultation Outcome Research with Children and Adolescents. Special Services in the Schools, 16. https://doi.org/10.1300/J008v16n01_01

Rhodes, J., \& Ajmal, Y. (2004). Solution focused thinking in schools: Behaviour, reading and organisation. BT Press. 
Rice, P. L., \& Ezzy, D. (1999). Qualitative Research Methods: A Health Focus (1st edition). Oxford University Press.

Rihoux, B., \& Lobe, B. (2009). The case for Qualitative Comparative Analysis (QCA): Adding Leverage for thick cross-case comparison. In The SAGE Handbook of Case-Based Methods (pp. 222-242).

https://doi.org/10.4135/9781446249413.n13

Rihoux, B., \& Ragin, C. (2009). Configurational Comparative Methods: Qualitative Comparative Analysis (QCA) and Related Techniques. SAGE Publications, Inc. https://doi.org/10.4135/9781452226569

Roach, A., \& Elliott, S. (2005). Goal Attainment Scaling: An Efficient and Effective Approach to Monitoring Student Progress. TEACHING Exceptional Children, 37, 8-17. https://doi.org/10.1177/004005990503700401

Robson, C., \& McCartan, K. (2015). Real World Research (4th edition). John Wiley \& Sons.

Roller, J. (1998). Facilitating Pupil Involvement in Assessment, Planning and Review Processes. Educational Psychology in Practice, 13(4), 266-273. https://doi.org/10.1080/0266736980130408

Royal Borough of Kensington \& Chelsea. (2019). Educational Psychology Service / Royal Borough of Kensington and Chelsea.

https://www.rbkc.gov.uk/kb5/rbkc/fis/service.page?id=_NhSwWLqgxM\&localofferc hannel $=0$. 
Sander, J. B., Finch, M. E. H., Pierson, E. E., Bishop, J. A., German, R. L., \& Wilmoth, C. E. (2016). School-based consultation: Training challenges, solutions and building cultural competence. Journal of Educational and Psychological Consultation, 26(3), 220-240. https://doi.org/10.1080/10474412.2015.1042976

Shannon, D., \& Posada, S. (2007). The Educational Psychologist in the Early Years: Current practice and future directions. Educational Psychology in Practice, 23(3), 257-272. https://doi.org/10.1080/02667360701507343

Sheridan, S. M., Bovaird, J. A., Glover, T. A., Garbacz, S. A., \& Witte, A. (2012). A Randomized Trial Examining the Effects of Conjoint Behavioral Consultation and the Mediating Role of the Parent-Teacher Relationship. School Psychology Review; Bethesda, 41(1), 23-46.

Sheridan, S. M., \& Kratochwill, T. R. (2007). Conjoint Behavioral Consultation: Promoting Family-School Connections and Interventions. Springer Science \& Business Media.

Sheridan, S. M., Witte, A. L., Holmes, S. R., Coutts, M. J., Dent, A. L., Kunz, G. M., \& Wu, C. (2017). A randomized trial examining the effects of Conjoint Behavioral Consultation in rural schools: Student outcomes and the mediating role of the teacher-parent relationship. Journal of School Psychology, 61, 33-53. https://doi.org/10.1016/j.jsp.2016.12.002

Sheridan, S., Richards, J. R., \& Smoot, T. Y. (2000). School Consultation. Educational Psychology Papers and Publications. 
Shrout, P. E., \& Fleiss, J. L. (1979). Intraclass correlations: Uses in assessing rater reliability. Psychological Bulletin, 86(2), 420-428.

\section{https://doi.org/10.1037//0033-2909.86.2.420}

Slonski-Fowler, K., \& Truscott, S. (2004). General education teachers' perceptions of the prereferral intervention team process. Journal of Educational and Psychological Consultation - J EDUC PSYCHOLOGICAL CONS, 15, 1-39. https://doi.org/10.1207/s1532768xjepc1501_1

Smillie, I., \& Newton, M. (2020). Educational psychologists' practice: Obtaining and representing young people's views. Educational Psychology in Practice, 36(3), 328-344. https://doi.org/10.1080/02667363.2020.1787955

Smith, J. A., \& Osborn, M. (2003). Interpretative phenomenological analysis. In Qualitative psychology: A practical guide to research methods (pp. 51-80). Sage Publications, Inc.

Smith, P. C., Budzeika, K. A., Edwards, N. A., Johnson, S. M., \& Bearse, L. N. (1986). Guidelines for clean data: Detection of common mistakes. Journal of Applied Psychology, 71(3), 457-460. https://doi.org/10.1037/0021-9010.71.3.457 Stallman, R. (2016). FLOSS and FOSS. In GNU. https://www.gnu.org/philosophy/floss-and-foss.en.html.

Strauss, A., \& Corbin, J. (1994). Grounded theory methodology: An overview (pp. 273-285). Sage Publications, Inc. 
Tashakkori, A., \& Teddlie, C. (2010). Overview of contemporary issues in mixed methods research (pp. 1-42). SAGE Publications, Inc.

https://doi.org/10.4135/9781506335193.n1

Thiem, A., \& Duşa, A. (2013). Crisp-Set QCA. In A. Thiem \& A. Duşa (Eds.), Qualitative Comparative Analysis with R: A User's Guide (pp. 27-50). Springer. https://doi.org/10.1007/978-1-4614-4584-5_3

Truscott, D. M., \& Truscott, S. D. (2004). A professional development model for the positive practice of school-based reading consultation. Psychology in the Schools, 41(1), 51-65. https://doi.org/https://doi.org/10.1002/pits.10138

Truscott, S., Kreskey, D., Bolling, M., Psimas, L., Graybill, E., Albritton, K., \& Schwartz, A. (2012). Creating consultee change: A theory-based approach to learning and behavioral change processes in school-based consultation. Consulting Psychology Journal: Practice and Research, 64, 63-82. https://doi.org/10.1037/a0027997

Tuckett, A. (2005). Applying Thematic Analysis Theory to Practice: A researcher's experience. Contemporary Nurse, 19, 75-87. https://doi.org/10.5172/conu.19.12.75

Vigliocco, G. (2001). Tip-of-the-tongue, Psychology of. In N. J. Smelser \& P. B. Baltes (Eds.), International Encyclopedia of the Social \& Behavioral Sciences (pp. 15759-15762). Pergamon. https://doi.org/10.1016/B0-08-043076-7/01525-4 
Wagner, P. (2000). Consultation: Developing a comprehensive approach to service delivery. Educational Psychology in Practice, 16(1), 9-18.

\section{https://doi.org/10.1080/026673600115229}

Wagner, P. (1995a). A consultation approach to the educational psychologist's work with schools. Educational and Child Psychology, 12(3), 22-28.

Wagner, P. (1995b). School Consultation: Frameworks for the practising Educational Psychologist A handbook. London: Kensington \& Chelsea Educational Psychology Service.

Wagner, P. (2008). Consultation as a framework for practice (pp. 139-161).

Webster, L., Knotek, S., Babinski, L., Rogers, D., \& Barnett, M. (2003). Mediation of consultee's conceptual development in new teacher groups: Using questions to improve coherency. Journal of Educational and Psychological Consultation - J EDUC PSYCHOLOGICAL CONS, 14, 281-301.

https://doi.org/10.1207/s1532768xjepc143\&4_5

Wickham, H. (2016). ggplot2: Elegant graphics for data analysis. Springer-Verlag. https://ggplot2.tidyverse.org

Wicks, A. (2013). Do frameworks enable educational psychologists to work effectively and efficiently in practice? A critical discussion of the development of executive frameworks. Educational Psychology in Practice, 29(2), 152-162. 
Willig, C. (2008). Introducing qualitative research in psychology (2nd edition). Open University Press.

Woods, K. (2014). The Preparation of Practitioner Educational Psychologists in England. International Journal of School \& Educational Psychology.

Woolfson, L., Whaling, R., Stewart, A., \& Monsen, J. (2003). An integrated framework to guide educational psychologist practice. Educational Psychology in Practice, 19, 283-304. https://doi.org/10.1080/0266736032000138535

Zeisel, J., \& Eberhard, J. P. (2006). Inquiry by Design:

Environment/Behavior/Neuroscience in Architecture, Interiors, Landscape, and Planning (Revised edition). W. W. Norton.

Zoom. (2020). Release notes for april 25, 2020. https://support.zoom.us/hc/enus/articles/360042279352-Release-notes-for-April-25-2020 


\section{Appendices}

Appendix A: Breakdown of consultation, child, EP, and consultees Consultation number Child EP Consultees

\begin{tabular}{llll}
\hline 1 & 1 & 1 & Mother and teacher \\
2 & 2 & 2 & Father \\
3 & 2 & 2 & Teacher \\
5 & 3 & 2 & Mother \\
6 & 4 & 2 & Teacher \\
6 & 4 & 2 & Father and father
\end{tabular}




\section{Appendix B: Interview schedule}

1) What is your role?

2) How do you define consultation? What does it mean to you?

3) What key words would you use?

4) How often have you engaged with consultation?

5) What history of consultation training do you have?

6) Does your current EPS value consultation/operate a consultation-based service?

7) Why do you use consultation?

8) What do you believe are the key features of a consultation? What needs to be present for it to be more than a conversation?

9) What features do you most frequently see (what is seen may be different what they believe is effective)?

10) What do you believe are the key features of an effective consultation (including examples)?

11) What makes them effective?

12) How could consultations be more effective?

13) What are the barriers to effective consultation?

14) If you could not use consultation, what work would you use instead?

15) What is the unique contribution of consultation? 


\section{Appendix C: Definitions of features of consultation}

Category Definition

School knowledge

A back-and-forth exchange where the EP made a comment or asked a question which increased understanding of how the school works.

Empowering individuals Any comments or questions which aimed to increase the skills of the consultees (teachers, parents, SENCOs, etc.)/upskilled consultees so they can solve their problems (Nolan \& Moreland, 2014).

Ideas for future EP work Discussion of potential work an EP could do in the future, such as consultation, assessment, observation, etc.

Setting out plan for Discussion of what would happen over the course consultation of the consultation.

EP explaining role EP explicitly talked about the work of an EP and their purpose.

EP using expert EP discussed topics which they have knowledge knowledge of (from both professional experience and academic reading) within school psychology theory and practice.

Planning/implementing Discussion and agreement between | the interventions consultant and consultee(s) on any support that 
would be implemented to support the CYP (Sheridan et al., 2000).

Summarising

Understanding

presenting problem
The EP said back what has previously been stated by consultee(s) in the consultation (not necessarily building on it)

A back-and-forth exchange where the EP made a comment or asked a question which explored the main presenting concern(s) including scope, environmental factors, exceptions, etc. and why a problem may be present (Sheridan et al., 2000)

Everyone's contributions Consultees gave their view on something valued e.g. presented hypotheses, suggested solutions, or the EP explicitly acknowledged someone for their contribution. Not just when the consultee(s) spoke/gave an answer to a factual question.

Discussing what's A back-and-forth exchange where the EP made a already working comment or asked a question which explored an intervention/change which had improved the current situation for the CYP. This included evaluation of said intervention/change.

CYP strengths Any discussion of the CYP's positive qualities: attributes, personality, actions, etc. 
Suggesting solutions The EP volunteered a solution to the presenting concern.

Information gathering A back-and-forth exchange where the EP made a comment or asked a question which sought to gather more information about a non-key concern(s). 


\section{Appendix D: TME form}

After the consultation

This form is to help measure the progress of the child or young person towards the targets agreed in the consultation. For each target area, please describe how the child or young person is performing currently. Decide how close they are to achieving their goal. Please place a letter ' $B$ ' by the number you think corresponds to how they are currently performing (with 10 being achieving the goal completely). Place a letter 'E' by the number where you expect the child or young person to be in 8 weeks' time.

\section{8 weeks after the consultation}

Please describe how the child or young person is performing currently. Please also decide how far they have actually progressed towards achieving their goal and put a letter ' $A$ ' on the same scale by the corresponding number.

\begin{tabular}{|l|l|}
\hline Pupil & School \\
\hline Consultee & Date of consultation: \\
\hline Educational Psychologist & Date of follow-up: \\
\hline
\end{tabular}

Target 1:

\begin{tabular}{|l|l|l|l|l|l|l|l|l|l|l|}
\hline Rating & 1 & 2 & 3 & 4 & 5 & 6 & 7 & 8 & 9 & 10 \\
\hline Descriptor of baseline level & \\
\hline
\end{tabular}

Target 2:

\begin{tabular}{|l|l|l|l|l|l|l|l|l|l|l|}
\hline Rating & 1 & 2 & 3 & 4 & 5 & 6 & 7 & 8 & 9 & 10 \\
\hline \multicolumn{1}{|l|}{ Descriptor of baseline level } \\
\hline
\end{tabular}


Descriptor of level achieved

Target 3:

\begin{tabular}{|l|l|l|l|l|l|l|l|l|l|l|}
\hline Rating & 1 & 2 & 3 & 4 & 5 & 6 & 7 & 8 & 9 & 10 \\
\hline
\end{tabular}


Appendix E: Consent form

CONSENT FORM FOR EPS, TEACHERS, AND PARENTS WHO PARTICIPATE IN THE CONSULTATION AND COMPLETE THE QUESTIONNAIRE AND/OR ARE INTERVIEWED

Please complete this form after you have read the Information Sheet and/or listened to an explanation about the research.

Title of Study: What makes joint home-school consultations effective?

Department: Psychology and Human Development

Name and Contact Details of the Researcher(s): Patrick Langford

Name and Contact Details of the Principal Researcher: Professor Andy Tolmie Dr Tom Connor

Name and Contact Details of the UCL Data Protection Officer:

This study has been approved by the UCL Research Ethics Committee

Thank you for considering taking part in this research. The person organising the research must explain the project to you before you agree to take part. If you have any questions arising from the Information Sheet or explanation already given to you, please ask the researcher before you decide whether to join in. You will be given a copy of this Consent Form to keep and refer to at any time.

I confirm that I understand that by ticking/initialling each box below I am consenting to this element of the study. I understand that it will be assumed that unticked/initialled boxes means that I DO NOT consent to that part of the study. I understand that by not giving consent for any one element that I may be deemed ineligible for the study.

\begin{tabular}{|l|l|l|}
\hline & & $\begin{array}{l}\text { Yes/ } \\
\text { No }\end{array}$ \\
\hline 1. & $\begin{array}{l}\text { *I confirm that I have read and understood the Information Sheet for the above } \\
\text { study. I have had an opportunity to consider the information and what will be } \\
\text { expected of me. I have also had the opportunity to ask questions which have } \\
\text { been answered to my satisfaction }\end{array}$ & \\
\hline
\end{tabular}




\begin{tabular}{|c|c|}
\hline 2. & $\begin{array}{l}\text { *I consent to the processing of my personal information (number of years } \\
\text { working as a professional, views on consultation) for the purposes explained to } \\
\text { me. I understand that such information will be handled in accordance with all } \\
\text { applicable data protection legislation. }\end{array}$ \\
\hline \multirow[t]{3}{*}{3.} & $\begin{array}{l}\text { All of the data will be stored on a password protected laptop, computer, and in a } \\
\text { secure online repository on the Open Science Framework (OSF). }\end{array}$ \\
\hline & $\begin{array}{l}\text { *I understand that all personal information will remain confidential and that all } \\
\text { efforts will be made to ensure I cannot be identified. }\end{array}$ \\
\hline & $\begin{array}{l}\text { I understand that my data gathered in this study will be given a unique numerical } \\
\text { identifier It will not be possible to identify me in any publications or databases my } \\
\text { data appears in. }\end{array}$ \\
\hline 4. & $\begin{array}{l}\text { *I understand that my information may be subject to review by responsible } \\
\text { individuals from the University for monitoring and audit purposes. }\end{array}$ \\
\hline \multirow[t]{2}{*}{5.} & $\begin{array}{l}{ }^{*} \text { I understand that my participation is voluntary and that I am free to withdraw at } \\
\text { any time without giving a reason, without the care I receive, or my legal rights } \\
\text { being affected. }\end{array}$ \\
\hline & $\begin{array}{l}\text { I understand that if I decide to withdraw, any personal data I have provided up to } \\
\text { that point will be deleted unless I agree otherwise. }\end{array}$ \\
\hline 6. & $\begin{array}{l}\text { I understand the potential risks of participating and the support that will be } \\
\text { available to me should I become distressed during the course of the research. }\end{array}$ \\
\hline 7. & $\begin{array}{l}\text { I understand that the data will not be made available to any commercial } \\
\text { organisations but is solely the responsibility of the researcher(s) undertaking this } \\
\text { study. }\end{array}$ \\
\hline 8. & $\begin{array}{l}\text { I understand that I will not benefit financially from this study or from any possible } \\
\text { outcome it may result in in the future. }\end{array}$ \\
\hline 9. & $\begin{array}{l}\text { I agree that my anonymised research data may be used by others for future } \\
\text { research. No one will be able to identify you when this data is shared. }\end{array}$ \\
\hline 10. & $\begin{array}{l}\text { I understand that the information I have submitted will be published as a report } \\
\text { and I wish to receive a copy of it. Yes/No }\end{array}$ \\
\hline 11. & I am aware of who I should contact if I wish to lodge a complaint. \\
\hline 12. & Use of information for this project and beyond \\
\hline
\end{tabular}




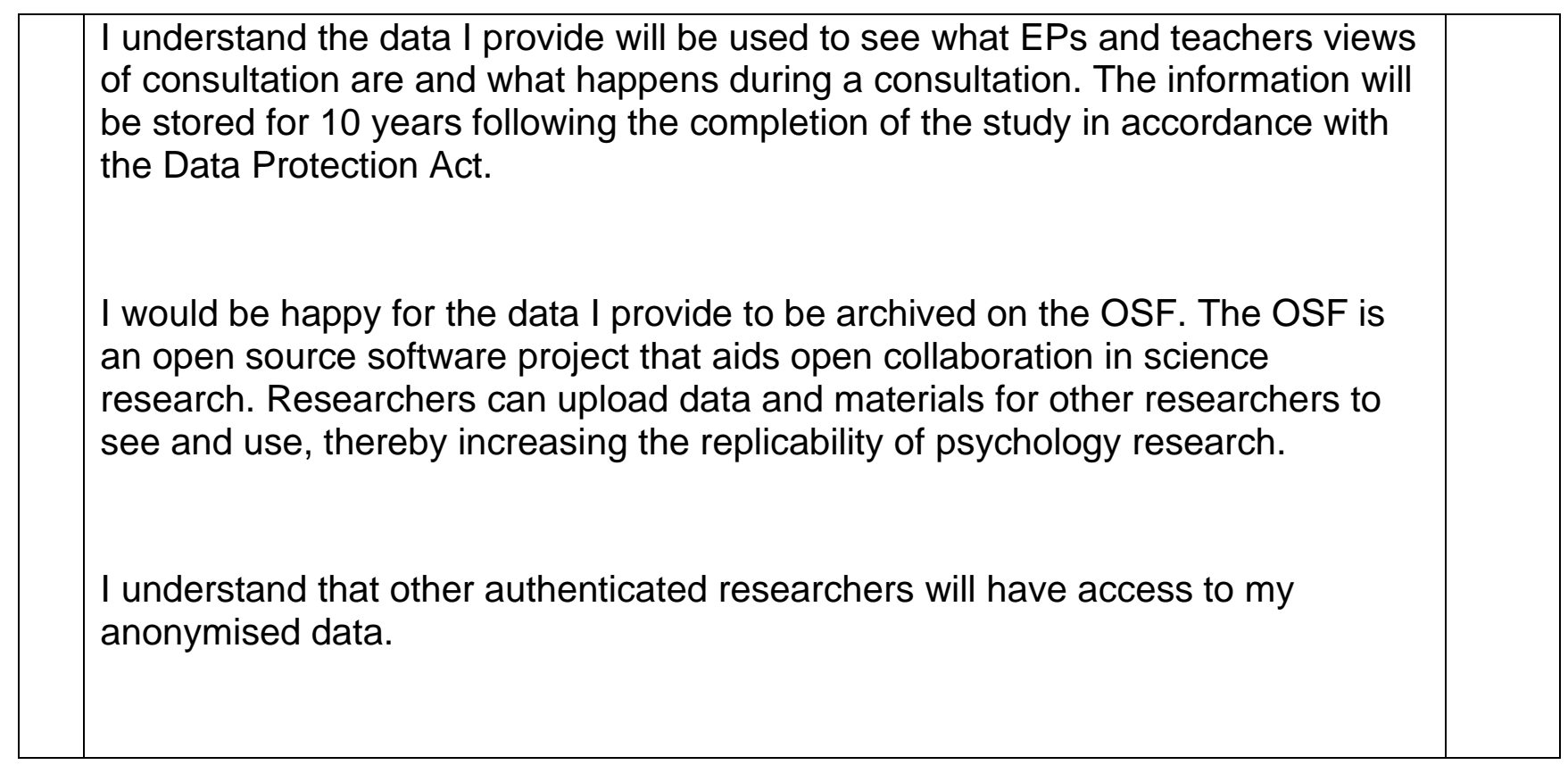

If you would like your contact details to be retained so that you can be contacted in the future by UCL researchers who would like to invite you to participate in follow up studies to this project, or in future studies of a similar nature, please tick the appropriate box below.

\begin{tabular}{|l|l|l|}
\hline Yes, I would be happy to be contacted in this way & \\
\hline No, I would not like to be contacted & \\
\hline
\end{tabular}

Once you have completed and signed the consent form, please send it via email to the researcher (Patrick Langford) at:

Name of participant

Date

Signature

Email address 


\section{Appendix F: Definitions of inductive codes for features of consultation Code Definition}

Assessment

Changing

perspectives

Clarity

Collaborative

Confidential

Consultee view of

consultation

Consultee views of EPs

Different views

Documentation

Education systems
How consultation can be a form of assessment.

Any discussion of the EP changing the perspectives of consultees during consultation or the understanding of consultation by consultees.

Gaining clarity regarding the issues through formulation etc.

Any discussion of a joint or collaborative aspect of consultation.

Confidentiality and privacy

How the consultees view consultation and understand it, as well as discussion of increasing understanding through training.

How the consultee views the role of the EP, including as the expert.

Gaining the views of a variety of different people, including the young person, to explore narratives and triangulate evidence.

Writing of notes or reports which detail what happened. How the school systems and bureaucratic processes of the British education system impact consultation. 
EP encouraging The EP being engaged in the consultation through active engagement listening to challenge narratives and facilitate discussion.

EP view of The EPs understanding of consultation.

consultation

EP view of EPs The EPs understanding of their role, including as the expert.

EP workload How the high workload EPs experience impacts consultation.

Goal setting Explicit discussion of outcomes and goal setting.

Individual How the personalities and histories of the consultees differences and consultors impacts consultation.

Key people Having the people who are most concerned present.

Language Using language that can be understood by all as well as issues regarding English as an Additional Language.

Preparation Time for the consultees and consultors to prepare.

Preventative How consultation can help prevent issues arising or exacerbating.

Questioning Use of a wide range of questions within consultation for a multitude of purposes, including to explore and challenge.

Rapport The importance of relationships with those involved and how it can be developed. 
Reflective

Reflexive

Resources

Space

Supporting

consultees

Time

Understanding of

SEN

Use of aids

Way forward
Reflecting on an individual consultation, receiving feedback, or having a review consultation to explore how the situation has progressed.

In consultation checking, by the EP, of how they and others might be affected by the discussion as well as what they are saying and why.

How a lack of resources from the school can impact on consultation, including not giving teachers enough time for them.

Having both the physical and mental space to engage with consultation.

EPs providing therapeutic support for consultees during a consultation.

Having enough time within the consultation to maximise its use.

How consultees and schools see special educational needs in children and how it impacts consultation.

Using aids such as Planning Alternative Tomorrows with Hope etc.

General statements about how consultation can provide a way forward. 
Willing to engage Consultees being willing to engage with the process of consultation. 


\section{Appendix G: Definitions of inductive codes for what makes the features effective}

Code Definition

Consultee Consultees having a sense of responsibility for what will

ownership happen next to support the CYP.

Consultees as Viewing consultees as experts in the lives of the child or as

experts teachers of the child who have valuable knowledge to share.

Efficient Being able to impact at multiple levels, over time, and have wide ranging impacts.

Outside system EPs being outside the school system giving them a meta perspective, a new way of seeing things, which allows them to challenge and explore.

Realistic The recommendations made are realistic to the setting and capabilities of those involved, including regarding resources, and are time bound.

Varied space for Consultation being a highly flexible vehicle to support CYP. approach 
Appendix H: Breakdown of the number of interviews the features were recorded in and how many total times across all interviews

\begin{tabular}{lll} 
Code & File $\mathrm{n}$ & Total code $\mathrm{n}$ \\
\hline Everyone's contributions valued & 14 & 33 \\
CYP strengths & 7 & 9 \\
Empowering individuals & 19 & 68 \\
Exception seeking & 5 & 8 \\
EP explaining role & 5 & 5 \\
Ideas for future EP work & 4 & 4 \\
Information gathering & 18 & 48 \\
EP using expert knowledge & 30 & 223 \\
Understanding presenting problem & 16 & 35 \\
School knowledge & 3 & 4 \\
Setting out plan for consultation & 16 & 31 \\
Suggesting solutions & 11 & 14 \\
Summarising & 6 & 7 \\
Planning/ implementing interventions & 8 & 15 \\
Discussing what's already working & 11 & 21 \\
Assessment & 5 & 14 \\
Changing perspectives & 29 & 212 \\
Clarity & 118 \\
Collaborative & 37 \\
\hline
\end{tabular}


Confidential

Consultee view of consultation

Consultee views of EPs

Different views

Documentation

Education systems

EP encouraging engagement

EP view of consultation

EP view of EPs

EP workload

Goal setting

Individual differences

Key people

Language

Preparation

Preventative

Questioning

Rapport

Reflective

Reflexive

Resources
$10 \quad 13$

$28 \quad 155$

$26 \quad 84$

$27 \quad 150$

810

$27 \quad 134$

$29 \quad 119$

$22 \quad 77$

$14 \quad 28$

$7 \quad 16$

$13 \quad 21$

$24 \quad 47$

$27 \quad 81$

813

$10 \quad 22$

$5 \quad 5$

$19 \quad 43$

$26 \quad 91$

$26 \quad 110$

$9 \quad 21$

$15 \quad 22$ 
Space

Supporting consultees

Time

Understanding of SEN

Use of aids

Way forward

Willing to engage

Consultee ownership

Consultees as experts

Efficient

Outside system

Realistic

Varied space for approach
$15 \quad 20$

$12 \quad 27$

$22 \quad 61$

$\begin{array}{ll}3 & 7\end{array}$

$10 \quad 22$

$13 \quad 22$

$19 \quad 41$

$15 \quad 27$

56

$18 \quad 43$

$8 \quad 12$

$7 \quad 11$

$10 \quad 15$ 
Appendix I: Correspondence between the deductive and inductive codes for the effective features of consultation and what makes them effective

What makes the

feature effective Feature of consultation

Consultee Changing perspectives, Collaborative, Consultee view of

ownership EPs, Contributions valued, Empowering individuals, EP

encouraging engagement, EP view of EPs, Individual

differences, Key people, Rapport, Supporting consultees,

Way forward, Willing to engage

Consultees as Collaborative, Contributions valued, Different views, EP

experts encouraging engagement, EP view of consultation, Goal

setting, Individual differences, Language, Rapport, What's

already working

Efficient Empowering individuals, Knowledge, Preventative,

Suggesting solutions, interventions

Outside system Education systems, Understanding of SEN

Realistic Collaborative, Different views, Reflective

Varied space for Assessment, Changing perspectives, Exception seeking,

approach Individual differences, Knowledge, Questioning, Reflexive,

Suggesting solutions, Supporting consultees, interventions,

Understanding the presenting problem 
Appendix J: Baseline, expected, and actual TME ratings for each goal Change for each goal for each child with which consultees

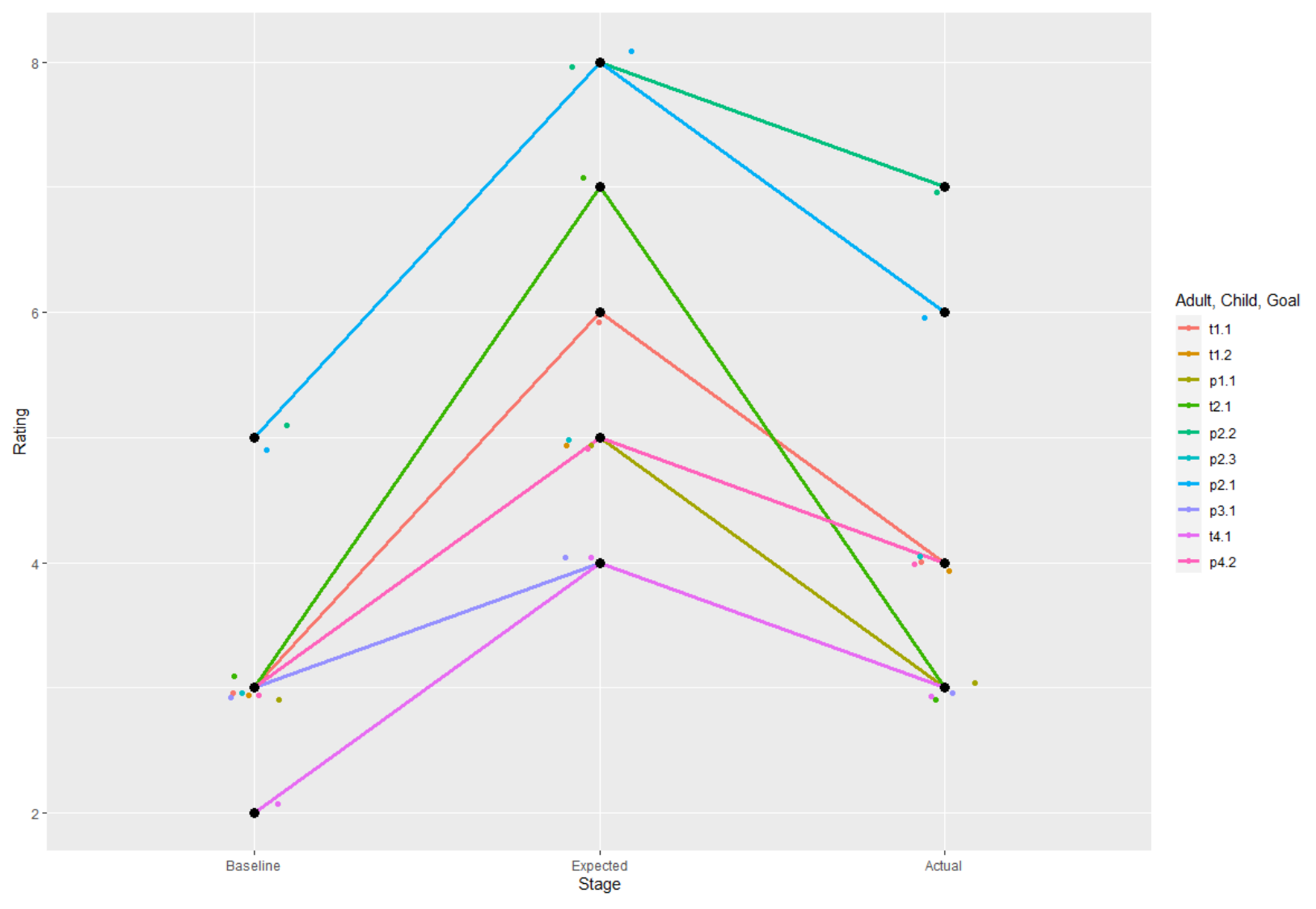

Note. Points are jittered around the rating to increase clarity when points overlap. 
Appendix K: Combination of features after Boolean minimisation (and which cases they correspond to)

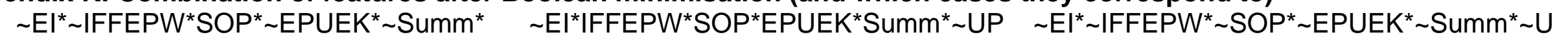
rn $\mathrm{UPP}^{*} \sim \mathrm{ECV}^{*} \mathrm{DWAW}^{*} \sim \mathrm{CYPS}^{*} \sim \mathrm{SS} \mathrm{IG}^{*}$

$\mathrm{P}^{*} \sim \mathrm{ECV}^{*} \sim \mathrm{DWAW}^{*} \sim \mathrm{CYPS}^{*} \mathrm{SS}^{*} \sim 1 \mathrm{G}$ $\mathrm{PP}^{*} \sim \mathrm{ECV}^{*} \sim \mathrm{DWAW}^{*} \sim \mathrm{CYPS}^{*} \sim \mathrm{SS}^{*} \sim 1 \mathrm{G}$

t1 0

0

0

.1

0

0

p 0

0

1. 


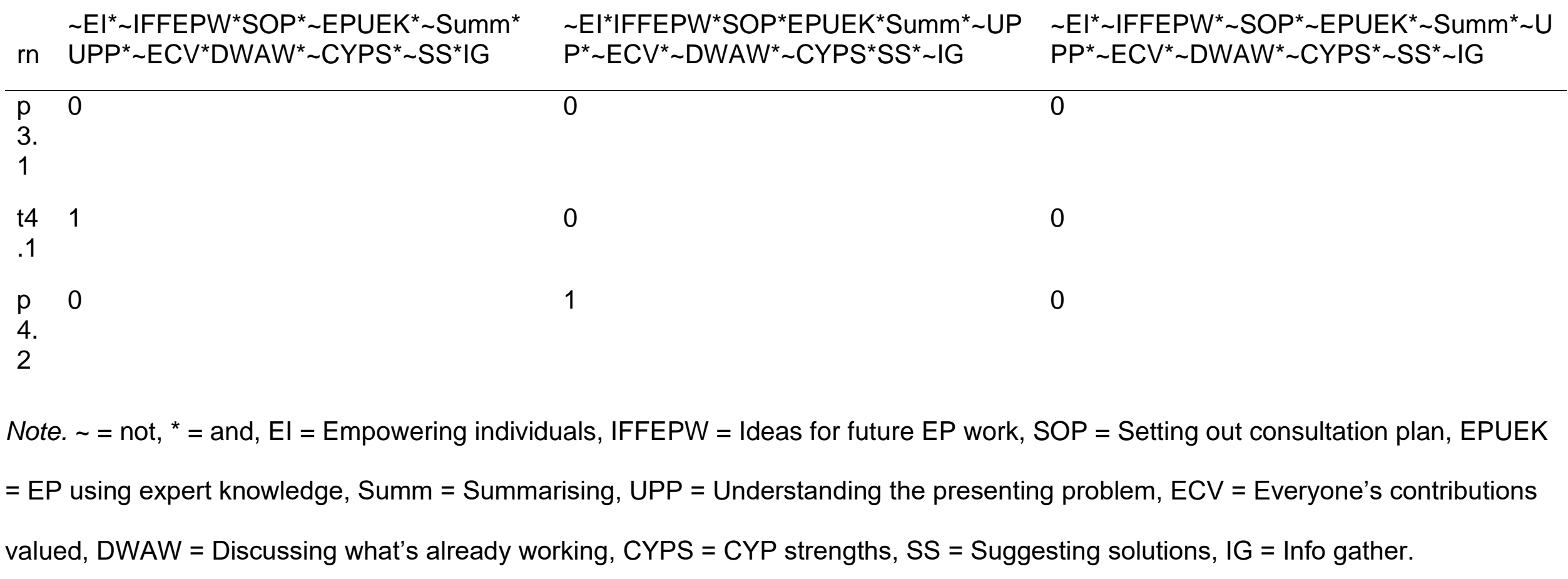


Appendix L: Features of consultation and recorded change for each goal

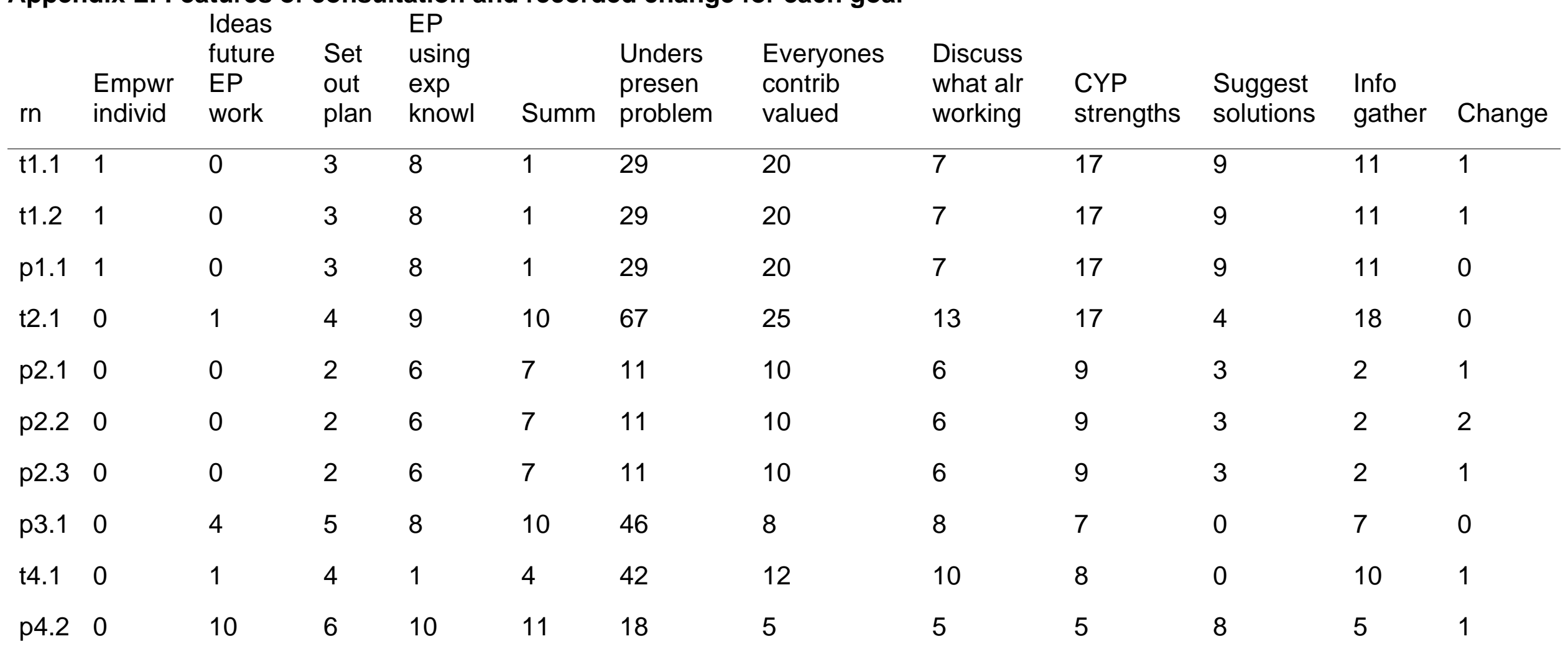




\section{Appendix M: Checklist for effective features of consultation}

Feature of consultation

Present/Absent/Na

Educating consultees on consultation prior to the

consultation

Setting out the plan for the consultation

Using expert knowledge

Understanding the presenting problem

Collaborating with the consultees

Developing rapport

Changing the consultees' perspective(s)

Gaining the views of the CYP

Using a wide range of questions

Empowering consultees

Discussion of CYP strengths

Suggesting solutions

Gaining the views of the consultees

Providing therapeutic support to the consultees

Gathering information on a wide range of areas

Being reflective on your practice

Having a confidential space

Having enough time (at least 30 minutes) 
Everyone understanding the goals/recommendations 